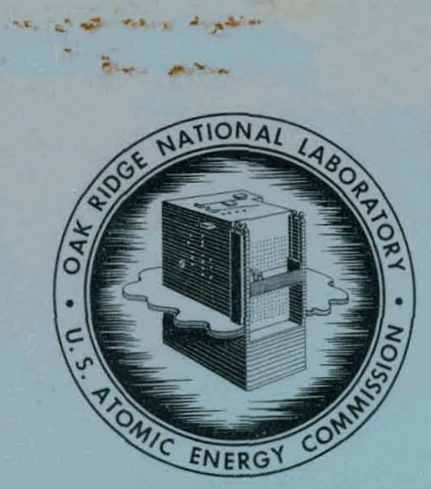

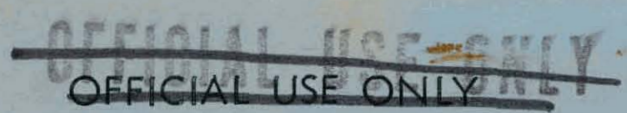

OAK RIDGE NATIONAL LABORATORY operated by

UNION CARBIDE CORPORATION

NUCLEAR DIVISION

for the

U.S. ATOMIC ENERGY COMMISSION

ORNL - TM- 1825

12357

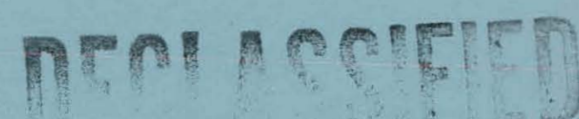

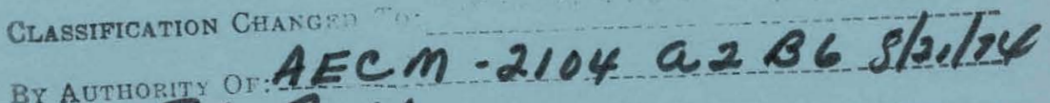
BY: BL Rudd

FUELS AND MATERIALS DEVELOPMENT PROGRAM QUARTERLY PROGRESS

REPORT FOR PERIOD ENDING MARCH 31, 1967

P. Patriarca

\title{
LIBRARY REFERENCE COPY
}

NOTICE This document contains information of a preliminary nature and wns prepared primarily for internal use at the Oak Ridge National Laboratory. It is subject to revision or correction and therefure does not represent a final report. 


\section{DISCLAIMER}

This report was prepared as an account of work sponsored by an agency of the United States Government. Neither the United States Government nor any agency Thereof, nor any of their employees, makes any warranty, express or implied, or assumes any legal liability or responsibility for the accuracy, completeness, or usefulness of any information, apparatus, product, or process disclosed, or represents that its use would not infringe privately owned rights. Reference herein to any specific commercial product, process, or service by trade name, trademark, manufacturer, or otherwise does not necessarily constitute or imply its endorsement, recommendation, or favoring by the United States Government or any agency thereof. The views and opinions of authors expressed herein do not necessarily state or reflect those of the United States Government or any agency thereof. 


\section{DISCLAIMER}

Portions of this document may be illegible in electronic image products. Images are produced from the best available original document. 


\section{LEGAL NOTICE}

This report was prepared as an account of Government sponsored work. Neither the United States, nor the Commission, nor any person acting on behalf of the Commission:

A. Makes any warranty or representation, expressed or implied, with respect to the accuracy, completeness, or usefulness of the information contained in this report, or that the use of any information, apparatus, method, or process disclosed in this report may not infringe privately owned rights; or

B. Assumes any liabilities with respect to the use of, or for damages resulting from the use of any information, apparatus, method, or process disclosed in this report.

As used in the above, "person acting on behalf of the Commission" includes any emplayee or curitractor of the Commission, or employee of such contractor, to the extent that such employee or contractor of the Commission, or employee of such contractor prepares, disseminates, or provides access to, any information pursuant to his employment or contract with the Commission, or his employment with such contractor. 
Contract No. W-7405-eng-26

FUELS AND MATERIALS DEVELOPMENT PROGRAM QUARTERLY PROGRESS REPORT FOR PERIOD ENDING MARCH 31, 1967

Compiled by

P. Patriarca

\begin{abstract}
This report was prepared as an account of work sponsored by the United States Government. Neither the United States nor the United States Energy Research and Development Administration, nor any of their employees, nor any of their contractors, subcontractors, or their employees, makes any warranty, express or implied, or assumes any legal Warranty, express or implied, or assumes any responsibility for the accuracy, completeness or usefulness of any information, apparatus, product or process disclosed, or represents that its use would not infringe privately owned rights.
\end{abstract}

MAY 1967

OAK RIDGE NATIONAL LABORATORY

Oak Ridge, Tennessee

operated by

UNION CARBIDE CORPORATION

for the

U.S. ATOMIC ENERGY COMMISSION 


\section{THIS PAGE}

WAS INTENTIONALLY

LEFT BLANK 
FOREWORD

This is the twelfth quarterly progress report describing work performed at the Oak Ridge National Laboratory for the Fuels and Materials Branch, Division of Reactor Development and Technology, U.S. Atomic Energy Commission. The specific programs covered are as follows:

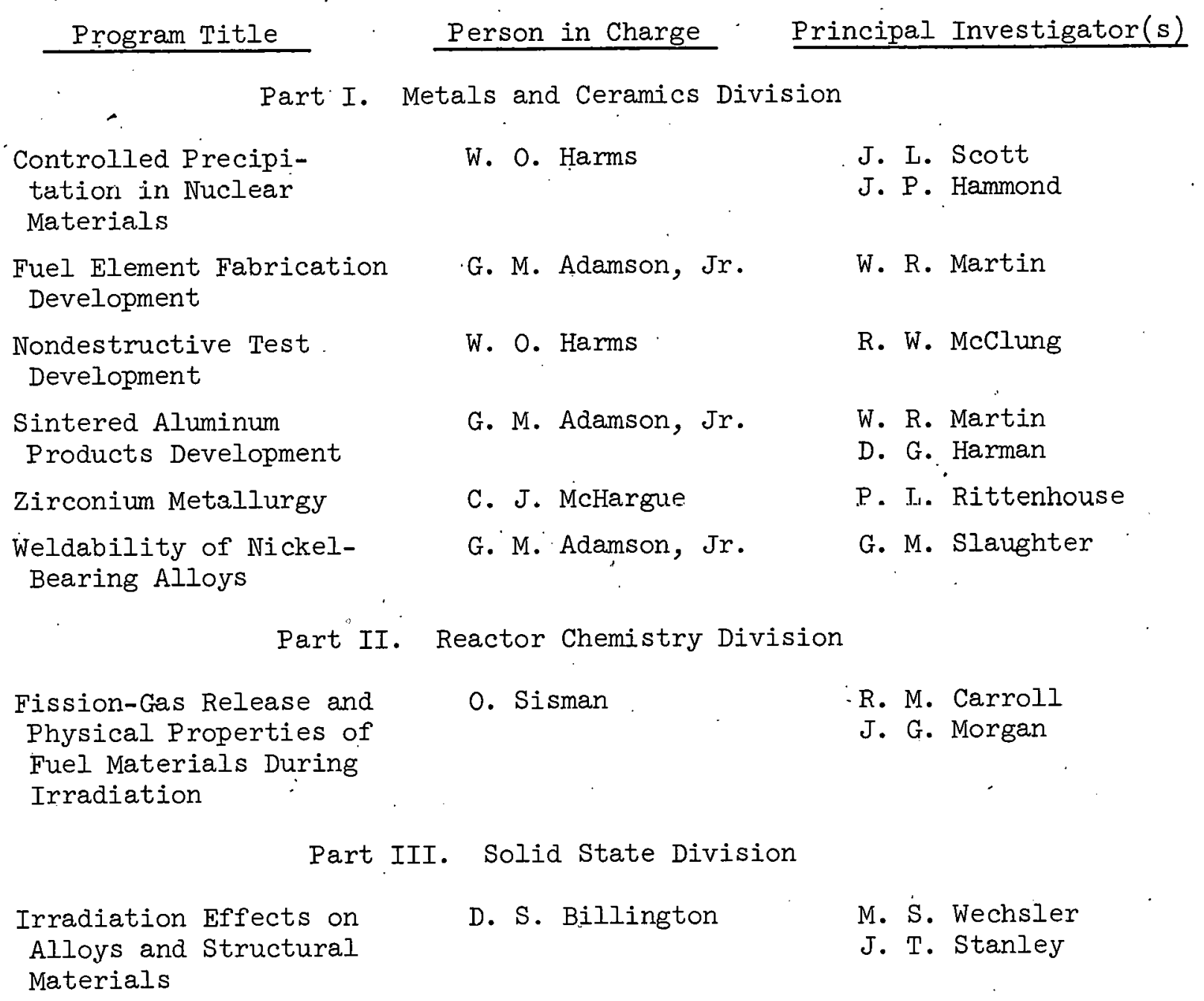




\section{THIS PAGE}

\section{WAS INTENTIONALLY \\ LEFT BLANK}


Summary . . . . . . . . . . . . . . . . . . . . . . . ix

Part I. Metals and Ceramics Division

Controlled Precipitation in Nuclear Materials . . . . . . . . . 3

Controlled Precipitation in Aluminum Alloys . . . . . . . . . . 3

Production of Fine Precipitates in Uranium Nitride . . . . . . . 7

Molybdenum Additions . . . . . . . . . . . . . . 7

Thorium and Oxygen Additions . . . . . . . . . . . . 8

Synthesis and Fabrication Equipment . . . . . . . . . . 8

2. Fuel Element Fabrication Development . . . . . . . . . . . . 9

Conversion of $\mathrm{UF}_{6}$ to $\mathrm{UO}_{2}$ with a Flame Reactor . . . . . . . . . 9

Preparation of $\mathrm{PuO}_{2}$ Powder from $\mathrm{PuF}_{6}$ by Chemical

Vapor Deposition. . . . . . . . . . . . . . . . . . . 11

Deposition of Tungsten-Rhenium Alloys . . . . . . . . . . . . 13

3. Nondestructive Test Development . . . . . . . . . . . . . . 19

Electromagnetic Test Methods . . . . . . . . . . . . . . 19

Analytical Studies... . . . . . . . . . . . 19

Phase-Sensitive Eddy-Current Instrument . . . . . . . . . 19

Ultrasonic Test Methods . . . . . . . . . . . . . 20

Fabrication of Reference Notches . . . . . . . . . . 20

Reference Standards ................ 20

Penetrating Radiation Methods . . . . . . . . . . . . . 21

4. Sintered Aluminum Products Development . . . . . . . . . . . 22

Dispersion Preparation . . . . . . . . . . . . . . . . . 22

Fowder Consolidation . . . . . . . . . . . . . . . 26

Evaluation of Product . . . . . . . . . . . . . . . 33

Commercial Alloys . . . . . . . . . . . . . . 33 .

Fracture Studies . . . . . . . . . . . . . 35

Nondestructive Test Development . . . . . . . . . . . 40

Development of Advanced SAP Materials . . . . . . . . . . 42

5. Zirconium Metallurgy ................... 43

Anisotropy in Zircaloy .. . . . . . . . . . . . . . . 43

Testing of Tubing . . . . . . . . . . . . . . 43

Yield Strength-Texture Correlations . . . . . . . . . 44 
Stress Orientation of Hydrides in Zircaloy . . . . . . . . . . . 45

Tempcrature Cycling Under Load . . . . . . . . . . . 45

Hydrides in Zircaloy Tubing . . . . . . . . . . . . 45

Zirconium and Zirconium Alloy Deformation : . . . . . . . . . . 47

Equipment . . . . . . . . . . . . . . . . . 47

Single-Crystal Tests ... . . . . . . . . . . . . 47

Inhibition of Oxidation by Anodic Films . . . . . . . . . . . . 49

6. Weldability of Nickel-Bearing Alloys . . . . . . . . . . . . 52

Special Alloy Fabrication . . . . . . . . . . . . . 52

Hot-Ductility Testing . . . . . . . . . . . . . . . 54

VARFESTRATINT Testing pertormed Undèr subcontract at Rennoclacr Polyteohnic Institute

Part. TT. Reactor Chemistry Division

7. Fission-Gas Release and Physical Properties of Fuel Material

During Irradiation . . . . . . . . . . . . . . . . . . 59

Fission-Gas Release . . . . . . . . . . . . . . 59

Electrical Measurements . . . . . . . . . . . . 63

Thermal Diffusivity. of $\mathrm{UO}_{2}$ During Irradiation . . . . . . . . 65

Part III. Solid State Division

8. Irradiation Effects on Alloys and Structural Materials . . . . 69

Radiation Effects on Pressure-Vessel Steels . . . . . . . . 69

Tensile Tests on Irradiated Iron . . . . . . . . . . . . . . 75

On tlie Temperature and Etrain Ratc Dependence of Radiation

Hardening in Iron . . . . . . . . . . . . . . . . . . . 81

Niobium: Purification and Perfection . . . . . . . . . . 88

A. Purification . . . . . . . . . . . . 88

Experimental Procedure.. . . . . . . . . . . . . 88

Discussion .................. . . 90

B. Perfection . . . . . . . . . . . . . . . . 9i

kxpèrimental Frocedure . . . . . . . . . . . . . . . 91

Discussion ................ . . 92

Conclusions . . . . . . . . . . . . . 92

Còncerning the Etching of Dislocations in Niobium . . . . . . . 94

'l'he Interaction of Radiation Produced Delecls and Interstitial

Impurity Atoms in Niobium . . . . . . . . . . . . . . 98 
vii

Specimen Preparation . . . . . . . . . . . . . 100

Measurement Techniques . . . . . . . . . . . . 102

Pre-Irradiation Measurements . . . .......... 102

Irradiation and Annealing Procedures . . . . . . . . . 105

Internal Friction Results .. . . . . . . . . . . 106

Resistivity.Results . . . . ............ . 106

Discussion . . . . . . . . . . . . . . . . 108 
THIS PAGE

WAS INTENTIONALLY

LEFT BLANK 


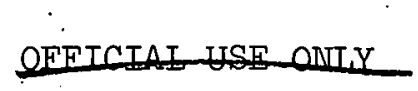

ix

\section{SUMMARY}

\section{PART I. METALS AND CERAMICS DIVISION}

\section{Controlled Precipitation in Nuclear Materials}

The feasibility of a new method for processing dispersion-hardened aluminum-base alloys with improved microstructures waș demonstrated. one experimental alloy was dispersion hardened by reacting ultrafine $\mathrm{SiO}_{2}$ in finely ground $\mathrm{Al}-2.3$ at. \% Ce powder. This alloy contained approximately $4 \%$ oxide but its strength at $450^{\circ} \mathrm{C}$ was equivalent to that of a conventional SAP alloy containing $15 \% \mathrm{Al}_{2} \mathrm{O}_{3}$.

Dispersion-hardened aluminum prepared by reacting ultrafine fibrillar boehmite $(\mathrm{AlOOH})$ in finely ground $\mathrm{Al}-5.5 \% \mathrm{Mg}$ powder showed improved lowstrain-rate fracture ductility with good strength.

A new uranium nitride synthesis rig that produces a powder with less than $500 \mathrm{ppm} 0$ and $100 \mathrm{ppm} \mathrm{C}$ was developed. This material is used for controlled precipitation studies.

\section{Fuel Element Fabrication Development}

Urania powders are being made using a new high-temperature flame reactor that involves a one-step deposition process of heating $\mathrm{UF}_{6}, \mathrm{H}_{2}$, and $\mathrm{O}_{2}$ at low pressures in a hydrogen-fluorine flame. Initial experiments using this device are encouraging.

The preparation of $\mathrm{PuO}_{2}$ from $\mathrm{PuF}_{6}$ using chemical vapor deposition is an attractive method for making $\mathrm{PuO}_{2}$ by means that could eventually allow the codeposition of $\mathrm{PuO}_{2}-\mathrm{UO}_{2}$ powders. The device for the deposition of $\mathrm{PuO}_{2}$ has been built and proof checked. We are now awaiting approval of the operation Safeguards Committee to begin the plutonia experiments.

Chemlcal vapor doposition of the tungsten-rhenium binary alloys is being examined. Scale-up studies from small to larger sections are being performed. Initjal experiments on making 4-ft lengths of tungsten-rhenium tubing have shown a rhenium variation related to temperature gradients 
along the length of the rod. A tentative phase diagram for the tungstenrhenium system has been established for the temperature region of 1000 to $1300^{\circ} \mathrm{C}$.

\section{Nondestructive Test Development}

We are developing new tochniques usl equipment for the nondestructive evaluation of materials and components. Major emphasis has been on eddy-current, ultrasonic, and penetrating-radiation methods.

Our analytical work on electromagnetic phenomena has included development of a closed-form solution for the case ul a rectingular croassection coil encircling a slad rod. Circull diagrams for the portable phase-sensitive instrument have been prepared and released to the ORIL office of Industrial Cooperation.

Our work on electrical-discharge machining of reference discontinuities emphasized development of techniques for making transverse discontinuities in tubing as small as 0.187-in. inside diameter. We continued work to correlate the ultrasonic response from various reference discontinuities in aluminum and stainless steel sheets.

We made quantitative low-voltage radiographis studieo on graphlte with both helium and air atmospheres.

\section{Sintered Aluminum Products Development.}

Aluminum oxide-strengthened alloys are made by powder-metallurgy techniques. These alloys have high strength-to-weight, ratios and low neulpon ćross sections but exhibit. pur billet faurlcability and low ductility at elevated temperatures. Tn esislul, itis uelleved that the lack of consistent and uniform strength in the alloys is a consequence of poor process control during billet fabrination. Wo are sludying the blilet processing variables that we believe influence the properties of the product extruded from this billet.

The aluminum oxide dispersion is prepared by ball milling atomized aluminum powder into flake that is consolidated into a billet by vacuum hot pressing. Ball-milling studies have progressed from small laboratory 
size mills to larger pilot-plant-type mills. Increased milling action has been noted in the larger mill, and the milling process parameters having been determined on the small laboratory mills are being adjusted. Previously, we have shown that contaminants in the billet can be removed to what we believe are tolerable levels. Hydrogen contents are reduced by vacuum annealing, but rehydration after annealing can occur if the billets are not stored in sealed containers. This hydrogen is believed to seriously affect the mechanical properties of sintered aluminum products.

Fracture studies into the cause of the low ductility at elevated temperatures are in progress. Voids in the SAP start at oxide-rich sites at very low strains, grow, and link together during further straining. It has been observed that the entire oxide-matrix interface fractures during deformation. Improvement in the strength of this interface could increase the ductility of SAP alloys.

\section{Zirconiun Metallurgy}

Compression tests have been performed on six additional lots of Zircaloy tubing. Tension and torsion tests are in progress on nine lots of tubing.

A correlation between yield strength (both tension and compression) and texture coefficients has been derived for Zircaloy-2:

Zircaloy-2 specimens temperature cycled under stress for as many as 88 cycles showed no increase in sensitivity to stress orientation of the hydrides relative to that observed after 20 cycles.

The orientation of hydrides precipitated in Zircaloy tubing under zero stress, is related to the preferred orientation of the tubing. The frequency of hydride poles at any given orientation increases as the texture coefficient for the basal plane at that orientation increases.

Hydrides precipitated in Zircaloy tubing under an elastic hoop stress show a tendency to reorient only if there is an appreciable concentration of basal poles parallel to the tangential direction and if this concentration is equal to or greater than the concentration of vasal poles in the radial direction. 
The electrical discharge machine, essential in the preparation of strain-free zirconium single crystals for deformation studies; has been modified to allow more precise and deeper cuts. The circuitry has also been modified to eliminate the problem created by shorting between the tool and the specimen. This greatly increases, the cutting speed.

Single-crystal specimens of Zircaloy-2 have been tested in tension to determine yield strength as a function of crystallographic orientation and to find the critical resolved shear stress for $\{10 \overline{1} 0\}\langle 11 \overline{2} 0\rangle$ slip.

The weight gain for annealed zirconium specimens preanodized to incorporate phosphorus into the oxide film is less than half that for unahodized specimens after $64 \mathrm{hr}$ in $500^{\circ} \mathrm{C}$ steam. Preanodizing inhibits to some extent all of the various modes of oxide growth that we had observed for zirconium oxidizing in $500^{\circ} \mathrm{C}$ steam. Anodic films with incorporated sulfur also inhibit oxidation, but to a much lesser extent.

\section{Weldability of Nickel-Bearing Alloys}

The melting and fabrication of several heats of Incoloy 800 and Inconel 600 of controlled chemical composition are under way. These heats will be used for weldability evaluations using the hot-ductility and VARESTRAINT tests. Hot-ductility tests are under way on Incolny $80 n$ alloys. 'lo date, a high-purity ternary alloy has been compared to a. commercial heat of material. Both materials show excellent recovery and, consequently, are categorized as weldable. However, the pure ternary retains its ductility to a higher tempcrature and is superior trom that slandpoint.

Prellminary results have been obtained from Rensselaer on the effect of heat input on the weldability of a commercial heat of Inçoncl 600 . Although there was considerable data scatter, therc wcre significant differences in cracking propensity for the three sets of welding conditions. A heat input of 30,000 joules/in. was more unfavorable than was either 60,000 or 20,000 joules/in. 
OFF-IEIAE USE ONY

xiii

PART II. REACTOR CHEMISTRY DIVISION

7. Fission-Gas Release and Physical Properties of Fuel Materials During Irradiation

The defect-trap.model for fission-gas release has been placed in mathematical form for use with the oscillating experiments. The first solution was obtained for the case where the neutron flux was oscillated at constant temperature. This was the easiest case to handle mathematically, but experimentally it was found very difficult to maintain a constant temperature while the neutron flux was oscillated.

The more difficult mathematical solution of the case where both the neutron flux and temperature are allowed to oscillate has now also been solved. The algebraic equations have been placed in a computer program designed to make an empirical fit of the experimental data to obtain values for the parameters in the equations. A test run of the computer program has been made, and so far revealed only a few errors which we think can be easily corrected.

Some electrical measurements have been attempted that revealed several anomalous effects. We have attempted to determine the cause of these effects and have not yet been able to explain them with complete satisfaction. We think they must be associated with the fact that a thin film of $\mathrm{UO}_{2}$ has evaporated from the specimen by surface fission and deposited on the lead wires and thermocouples.

We have completed the installation of equipment to make transient tests for thermal diffusivity.

PART III. SOLID STATE-DIVISION

8. Irradiation Effecț on Alloys and structural Materials

Studies of the radiation embrittlement of weld heat-affected-zone samples and base plate of ASTM A-212B pressure-vessel steel are continuing. In this report we show the effect of irradiation temperature on the shift of ductile-brittle transition temperature of base plate and 


\section{xiv}

HAZ specimens of three different heats of A-212B steel. Heat-to-heat variations of sensitivity to radiation embrittlement are quite striking.

Studies of the increase of yield stress of Ferrovac-E iron samples irradiated to the same'dose but at different rates have now been completed. No effect of dose rate on yield stress increase was observed for dose rates ranging from about $1.7 \times 10^{11}$ to $2.3 \times 10^{13}$ neutrors $/ \mathrm{cm}^{2} \cdot \mathrm{sec}$ $(E>1 \mathrm{Mev})$. Studies of annealing of radiation hardening were carried out in the temperature range from 300 to $400^{\circ} \mathrm{C}$. It was observed that the radiation damage became more stable with increasing dose in the interval $4 \times 10^{17}$ to $5 \times 10^{18}$ neutrons $/ \mathrm{cm}^{2}$ ( $E>1 \mathrm{Mev}$ ). Also the annealing did not take place with a constant activation energy. Studies were also carried out which indicate an effect of interstitial impurities in producing radiation hardening. In these studies samples were irradiated at low temperature and tested at $0^{\circ} \mathrm{C}$ with no apparent increase in yield stress. Similar samples given identical treatment, but annealed in the temperature interval from 0 to $100^{\circ} \mathrm{C}$ before testing at $0^{\circ} \mathrm{C}$, showed an increase in yield stress about equal to that observed in specimens irradiated at $90^{\circ} \mathrm{C}$.

The temperature and strain-rate dependence of the flow stress of irradiated polycrystalline iron specimens were tested. The results were analyzed to give activation energies and activation volumes for flow. The activation volume was not changed by irradiation while the activation energy was increased by irradiation.

A niobium single crystal with a total impurity content of $<75 \mathrm{ppm}$ and a resistivity ratio $R \cdot 300 / R \quad 4.2=1420$ was produced. An annealing procedure for improving the perfection of niobium single crystals was determined and $x$-ray topographs of the resulting crystals were made.

Studies of dislocation motion in niobium single crystals using etch pits were continued and procedures for decoraling dislucations in very high-purity niobium were determined.

Stage III annealing in irradiated niobium was studied using internal friction measurements and resistivity measurements. The results showed that Stage III annealing is due to migration of oxygen atoms to radiation produced defects. This result has important implications for theories of radiation hardening since it is known that a large hardness increase occurs during this annealing stage. 
QFFICIAI-USE-OAIY

PART I.

METALS AND CERAMICS DIVISION 


\section{THIS PAGE}

WAS INTENTIONALLY

LEFT BLANK 


\section{CONTROLLED PRECIPITATION IN - NUCLEAR MATERIALS}

$$
\text { J. L. Scott J. P. Hammond }
$$

The purpose of this program is to develop improved structures in both fissionable and nonfissionable materials through controlled precipitation. In our recent work we have placed emphasis on improving aluminum alloys by dispersion hardening. These alloys would be used instead of SAP for heavy-water-moderated, organic-cooled reactors. We have also continued work on controlled precipitation in uranium nitride. Here the effort during the current reporting period was limited to developing improved techniques for synthesizing high-purity uranium nitride powder.

Controlled Precipitation in Aluminum Alloys

\section{J. P. Hammond}

Efforts were continued to improve high-temperature mechanical properties in SAP-type materials for potential use in heavy-water-moderated, organic-cooled reactors. For this application, greater uniformity of mecharical properties and, especially, improved fracture ductility under elevated-temperature, low-strain-rate loading are needed. We have sought a solution to these problems by examining alloys containing rare-earth intermetallics and seeking to better control the size and distribution of the dispersant component by using the SLIS technique of preparing powders. ${ }^{1}$ However, the quenching of cerium and yttrium aluminides into the aluminum lattice by splat cooling (for subsequent controlled precipitation) proved difficult; ${ }^{2}$ moreover, recent results suggest that fine dispersions of these intermetallics may not exhibit sufficient thermal

${ }^{1}$ J. P. Hammond, Fuels and Materials Development Program Quart. Progr. Rept. Sept. 30, 1965, ORNL-TM-1270, pp. 5-6.

${ }^{2}$ J. P. Hammond, Fuels and Materials Development Program Quart. Progr. -Rept. Dec. 31, 1965, ORNL-TM-1400, pp. 5-8. 
stability. Our current approach is to concentrate on oxides as the dispersant material, emphasizing improved means for introducing or forming them within the matrix phase.

A promising method recently devised uses high-energy ball milling in argon under hermetically sealed conditions. The oxide is added in the mill.charge, as opposed to allowing it to form during milling in air, as is done in the conventional SAP procedure. The oxide may be introduced in its final form or as an unstable oxygen cárrier, such as $\mathrm{SiO}_{2}$, for reacting with a constituent of the matrix to form the desired dispersant $\frac{i n n}{n i t u . ~}$

Table 1.1 compares hot-hardness results of two experimental alloys with that of a conventional SAF-type material containing $6 \% \mathrm{Al}_{2} \mathrm{O}_{3}$. One of the experimental alloys was fabricated directly from an $\mathrm{Al}-2.3$ at. \% $\mathrm{Ce}$ splat; the other contained an oxide formed by reacting $4 \% \mathrm{SiO}_{2}$ with the same $\mathrm{Al}-2.3$ at. $\% \mathrm{Ce}$ splat. While the alloy prepared directly from the splat compares unfavorably with the SAP material, the second alloy exhibited a hardness at $600^{\circ} \mathrm{C}$ over three times greater than for the SAP material.

Table 1.1. Comparison of Hot Hardnesses of Experimental Alloys. with a Representative SAP Material

\begin{tabular}{|c|c|c|c|}
\hline \multirow{2}{*}{$\begin{array}{c}\text { Tempera- } \\
\text { ture } \\
\left({ }^{\circ} \mathrm{C}\right)\end{array}$} & \multicolumn{3}{|c|}{ Hot Hardness (DFN, l-kg load) } \\
\hline & $X A P-0 O 1^{a}$ & $\begin{array}{l}\text { Splat-Cooled } \\
\mathrm{Al}-2.3 \text { at. } \% \mathrm{Ce}^{\mathrm{b}}\end{array}$ & $\begin{array}{l}\mathrm{Al-2.3} \text { at. } \% \mathrm{Ce} \text { Splat } \\
\text { reacted with } 4 \% \mathrm{SiO}_{2}\end{array}$ \\
\hline $25-29$ & 77 & 40 & 126 \\
\hline 300 & 38 & 28.5 & 79 \\
\hline 400 & 25 & 14.5 & 56 \\
\hline 500 & 14 & 6 & 40 \\
\hline 550 & 8 & 3.5 & · \\
\hline 600 & 2.3 & & 8 \\
\hline
\end{tabular}

${ }_{A}$ SAP-type alloy containing $6 \% \mathrm{Al}_{2} \mathrm{O}_{3}$ furnished by ALCOA.

${ }^{b}$ Prepared from Al-2.3 at. \% Ce splat by cold pressing and extrusion at $500^{\circ} \mathrm{C}$.

CPrepared by reacting an Al-2.3 a.t. \% Ce snlat with $4 \%$ ultrafine $\mathrm{SiO}_{2}$ additive. Powders were first ball milled together, then reacted under argon at $450^{\circ} \mathrm{C}$, cold pressed, and extruded at $500^{\circ} \mathrm{C}$. 
Preliminary low-strain-rate, hot tensile tests conducted on a variety of oxide-hardened experimental alloys also gave promising results. Room- and elevated-temperature, low-strain-rate tensile properties are given in Table 1.2 for two such alloys along with those for SAP materials of increasing oxide loading for comparison.

Table 1.2. Comparison of Low-Strain Rate Mechanical Properties of Two Experimental Aluminum Alloys with Conventional SAP-Type Materialsa

\begin{tabular}{|c|c|c|c|c|c|c|c|}
\hline \multirow{2}{*}{$\begin{array}{l}\text { Alloy } \\
\text { Number }\end{array}$} & \multirow{2}{*}{ Material } & \multirow{2}{*}{$\begin{array}{l}\text { Strain } \\
\text { Rate } \\
\left(\min ^{-1}\right)\end{array}$} & \multirow{2}{*}{$\begin{array}{l}\text { Test } \\
\text { Temper- } \\
\text { ature } \\
\left({ }^{\circ} \mathrm{C}\right)\end{array}$} & \multirow{2}{*}{$\begin{array}{l}\text { Yield } \\
\text { Strength, } \\
0.2 \% \\
\text { (psi) }\end{array}$} & \multirow{2}{*}{$\begin{array}{l}\text { Ultimate } \\
\text { Tensile } \\
\text { Strength } \\
\text { (psi) }\end{array}$} & \multicolumn{2}{|c|}{ Elongation, \% } \\
\hline & & & & & & Uniform & Total \\
\hline 1 & $\begin{array}{l}\text { SAP, ALCOA } \\
552 \text { flake } \\
\text { with } \\
6 \% \mathrm{Al}_{2} \mathrm{O}_{3}(\mathrm{~b})\end{array}$ & $\begin{array}{l}0.02 \\
0.02 \\
0.002 \\
0.0002\end{array}$ & $\begin{array}{l}25-29 \\
450 \\
450 \\
450\end{array}$ & $\begin{array}{r}29,960 \\
13,300 \\
11,410 \\
8,480\end{array}$ & $\begin{array}{r}41,530 \\
13,710 \\
11,830 \\
9,470\end{array}$ & $\begin{array}{l}7.3 \\
0.7 \\
0.55 \\
0.65\end{array}$ & $\begin{array}{l}8.1 \\
1.3 \\
0.55 \\
0.70\end{array}$ \\
\hline 2 & $\begin{array}{l}\mathrm{SAP}, \mathrm{VMP} \\
\mathrm{H}-10 \text { powder } \\
\text { with } 9.5 \% \\
\mathrm{Al}_{2} \mathrm{O}_{3}(\mathrm{~b})\end{array}$ & $\begin{array}{l}0.02 \\
0.02 \\
0.002 \\
0.0002\end{array}$ & $\begin{array}{l}25-29 \\
450 \\
450 \\
450\end{array}$ & $\begin{array}{l}33,640 \\
14,180 \\
13,030 \\
11,680\end{array}$ & $\begin{array}{l}44,680 \\
15,250 \\
13,930 \\
12,750\end{array}$ & $\begin{array}{l}7.0 \\
0.77 \\
0.80 \\
0.70\end{array}$ & $\begin{array}{l}9.5 \\
2.05 \\
1.44 \\
1.0\end{array}$ \\
\hline 3 & $\begin{array}{l}\text { Experimental } \\
\text { Al-5.5\% Mg } \\
\text { filings } \\
\text { with } \\
4 \% \mathrm{AlOOH}(\mathrm{c})\end{array}$ & $\begin{array}{l}0.02 \\
0.02 \\
0.002 \\
0.0002\end{array}$ & $\begin{array}{l}25-29 \\
450 \\
450 \\
450\end{array}$ & $\begin{array}{r}53,640 \\
11,440 \\
9,810 \\
8,800\end{array}$ & $\begin{array}{r}61,830 \\
11,770 \\
10,300 \\
9,290\end{array}$ & $\begin{array}{l}5.48 \\
1.02 \\
0.91 \\
1.01\end{array}$ & $\begin{array}{l}6.12 \\
5.45 \\
3.60 \\
2.26\end{array}$ \\
\hline 4 & $\begin{array}{l}\text { Experimental } \\
\mathrm{Al} 2.3 \text { at. } \% \\
\text { Ce splat } \\
\text { with } \\
4 \% \mathrm{SiO}_{2} \text { (d) }\end{array}$ & $\begin{array}{l}0.02 \\
0.02 \\
0.002 \\
0.0002\end{array}$ & $\begin{array}{l}25-29 \\
450 \\
450 \\
450\end{array}$ & $\begin{array}{l}14,71+0 \\
12,305 \\
12,490\end{array}$ & $\begin{array}{l}19,411 \\
16,818 \\
15,120\end{array}$ & $\begin{array}{l}0.52 \\
0.37 \\
0.93\end{array}$ & $\begin{array}{l}0.59 \\
0.37 \\
0.93\end{array}$ \\
\hline
\end{tabular}

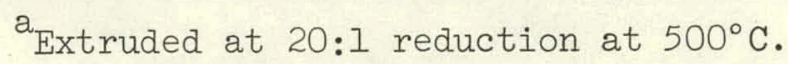

${ }^{b}$ oxide formed by reaction with air during open ball milling with Varsol containing 3\% stearic acid. Powder was vacuum hot pressed at $600^{\circ} \mathrm{C}$ and extruded.

${ }^{C}$ oxide dispersant ( $\mathrm{AlOOH}$ ) introduced as additive to $\mathrm{Al}-5.5 \% \mathrm{Mg}$ powder and ball milled with petroleum ether containing $0.5 \%$ stearic acid as grinding fluid in a hermetically sealed drum. Powder was heated in vacuum at $500^{\circ} \mathrm{C}$, cold pressed, and extruded.

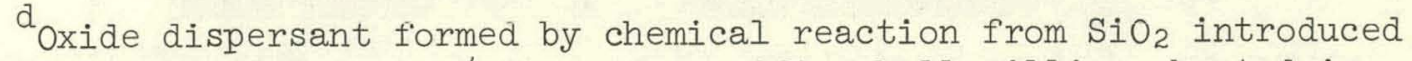
as additive to $\mathrm{Al}-2.3 \mathrm{at}$ \% Ce powder. After ball milling, heated in argon at $450^{\circ} \mathrm{C}$, cold pressed, and extruded. 
The oxide dispersant in alloy 3 in Table 1.2 was formed by reacting $4 \%$ ultrafine fibrillar boehmite (AlOOH) with finely milled $\mathrm{Al}-5.5 \% \mathrm{Mg}$ powder and gave both good strength and low-strain-rate ductility when compared with alloy 1, a SAP alloy of comparable dispersant content. The good ductility displayed by the new alloy is believed to be associated with magnesium held in solid solution in the aluminum matrix.

An electron micrograph of alloy 3 is shown in Fig. 1.I, illustrating the exceptionally good dispersion structure achievable by this means of fabrication. The average grain size is only about $1 / 3 \mu$ and the oxide dispersant is very fine (approximatel.y 200 to $300 \mathrm{~A}$ ) and well distributed. The globular shape of the dispersant suggests that it formed from the fibrillar boehmite by chemical reaction with the matrix.

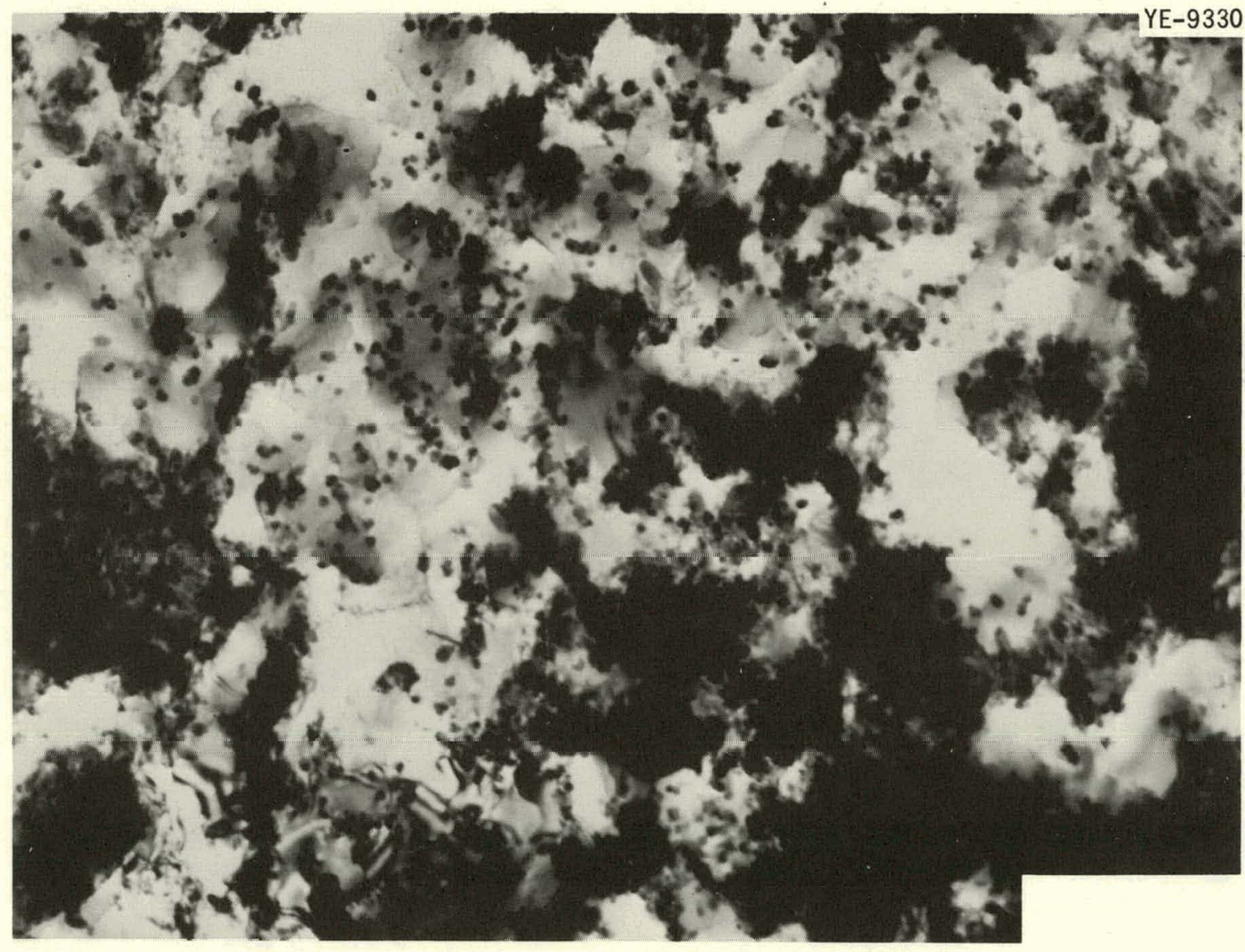

Fig. 1.1. Transmission Electron Micrograph of Aluminum Alloy Formed from Al-5.5\% Mg Powder Strengthened with 4\% Fibrillar Boehmite (AlOOH), Longitudinal Section. 56,000x. Reduced 15\%. 
It is to be noted that alloy 4 of Table 1.2, the material with high hot hardness mentioned earlier, gave tensile strengths at $450^{\circ} \mathrm{C}$ superior to those obtained for SAP with $9.5 \% \mathrm{Al}_{2} \mathrm{O}_{3}$ (compare alloy 4 with alloy 2 ). Ultimate tensile strengths achieved for this alloy are equivalent to a SAP material ${ }^{3}$ containing $15 \% \mathrm{Al}_{2} \mathrm{O}_{3}$, yet the amount of oxide in the present alloy is only approximately $4 \%$.

Examination of alloy 4 by electron metallography was not satisfactory because corrosion products formed during specimen preparation. Analysis of the dispersant in this alloy by $x$-ray diffraction revealed a new but unidentifiable phase as the sole secondary constituent. This observation supports the premise that $\mathrm{SiO}_{2}$ fully reacted with the cerium-bearing splat powder.

Production of Fine Precipitates in Uranium Nitride

$$
\text { T. G. Godfrey R. A. Potter }
$$

J. M. Leitnaker

Finely divided precipitate particles offer the prospect of reducing fuel swelling during irradiation through provision of nucleation and pinning sites for fission-gas bubbles. We are trying to incorporate such particles in uranium nitride through precipitation from a saturated solution of molybdenum in UN and through formation of second-phase particles by internal oxidation of a thorium-uranium nitride solid solution. We have recently been concerned with the installation and testing of a new synthesis and fabrication facility.

Molybdenum Additions

Experiments involving additions of molybdenum to UN are awaiting the preparation of the uranium-molybdenum alloys.

${ }^{3}$ Euratom's ORGEL Program, Part II, EUR 1830.e (1964). 
Thorium and Oxygen Additions

One set of samples was prepared to conclude the series described in the previous report. ${ }^{4}$ The experiment was designed to assess the effect of carbon on the internal oxidation process, but the results were inconclusive because of gross oxygen contamination that apparently occurred prior to the sintering step.

Synthesis and Fabrication Equipment

The synthesis equipment that we have used in all UN work to date has not been of the desired quality, but has sul'ticed f'or our initial experiments. Because of the increasingly stringent requirements of purity and reproducibility in our precipitate studies, the formerly used equipment has been abandoned.

A new facility for synthesis and fabrication of nitrides has recently been put into service. All operations, from cleaning the uranium or alloy to pressing the nitride pellet, are carried out in vacuum glove boxes. Nitride synthesis is performed in an Inconel retort that is loaded and sealed in the dry box, transferred to a synthesis furnace rig, and returned to the dry box for unloading. Weighing, grinding, mixing, blending, and pressing operations are done in the glove boxes. The pressed pellets, protected by the cumphor dry-pressing lubricant, are transferred to the sintering furnace, which is quickly evacuated.

Proof tests, although incomplete, have demonstrated that the new equipment is capable of producing powder and pellets having less than $500 \mathrm{ppm} O$ and less than 100 ppm C. Microstructural and x-ray diffraction examinations indicate that the nitride powder is of good quality and should meet the needs of our precipitate program.

\footnotetext{
${ }^{4}$ T. G. Godfrey, J. M. Leitnaker, and R. A. Potter, Fuels and Materials Development Program Quart. Progr. Rept. Dec. 31, 1966, ORNL-TM-1720, pp. 4-10.
} 


\title{
2. FUEL ELEMENT FABRICATION DEVELOPMENT
}

\author{
W. R. Martin
}

The direct conversion of fissionable halides to refractory fuel compounds by chemical vapor deposition (CVD) is being investigated for uranium and plutonium oxide fuels. We have studied techniques with application to the heavy-metal fluorides and chlorides. Our method of conversion has involved hydroreduction, reduction with hydrogen and alkali vapors of the halide, followed by oxidation of the heavy metal. Our CVD work is presently concentrating on the preparation of $\mathrm{PuO}_{2}$ powder from $\mathrm{PuF}_{6}$ and conversion of $\mathrm{UF}_{6}$ to $\mathrm{UO}_{2}$ using a high-temperature flame reactor.

We are continuing our work on the direct deposition of binary refractory-metal alloys with our current effort on the tungsten-rhenium system. Alloys in the form of tubing and plate having a uniform composition are being investigated, and the phase diagram of this binary alloy is being established for temperatures below $1500^{\circ} \mathrm{C}$.

\section{Conversion of $\mathrm{UF}_{6}$ to $\mathrm{UO}_{2}$ with a Flame Reactor}

\section{W. C. Robinson, Jr.}

An apparatus for the conversion of $\mathrm{UF}_{6}$ to $\mathrm{UO}_{2}$ utilizing the heat of reaction of hydrogen and fluorine gas has been constructed. A photograph of the device is given in Fig. 2.1. The "flame reactor" concept is utilized at K-25 for conversion of $\mathrm{UF}_{6}$ to $\mathrm{UF}_{4}$ and for the production of refractory-metal powder. ${ }^{1}$ We had previously demonstrated at ORNL that the hydrogen-fluorine flame could be stabilized at very low pressures. We have also demonstrated ${ }^{2}$ that $\mathrm{UF}_{6}$ could be converted to $\mathrm{UO}_{2}$ in a onestep deposition process involving the mixing of $\mathrm{UF}_{6}, \mathrm{H}_{2}$, and $\mathrm{O}_{2}$ in a

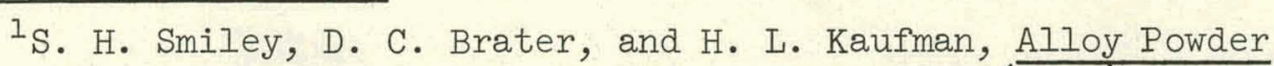
Preparation by Flame Reduction Techniques, K-L-6076 (1966).

${ }^{2}$ R. L. Heestand and C. F. Leitten, Jr., "Thermochemical Reduction of Uranium Hexafluoride for the Direct Fabrication of Uranium Dioxide Ceramic Fuels," Nucl. Appl. I (6), 584-588 (1965). 


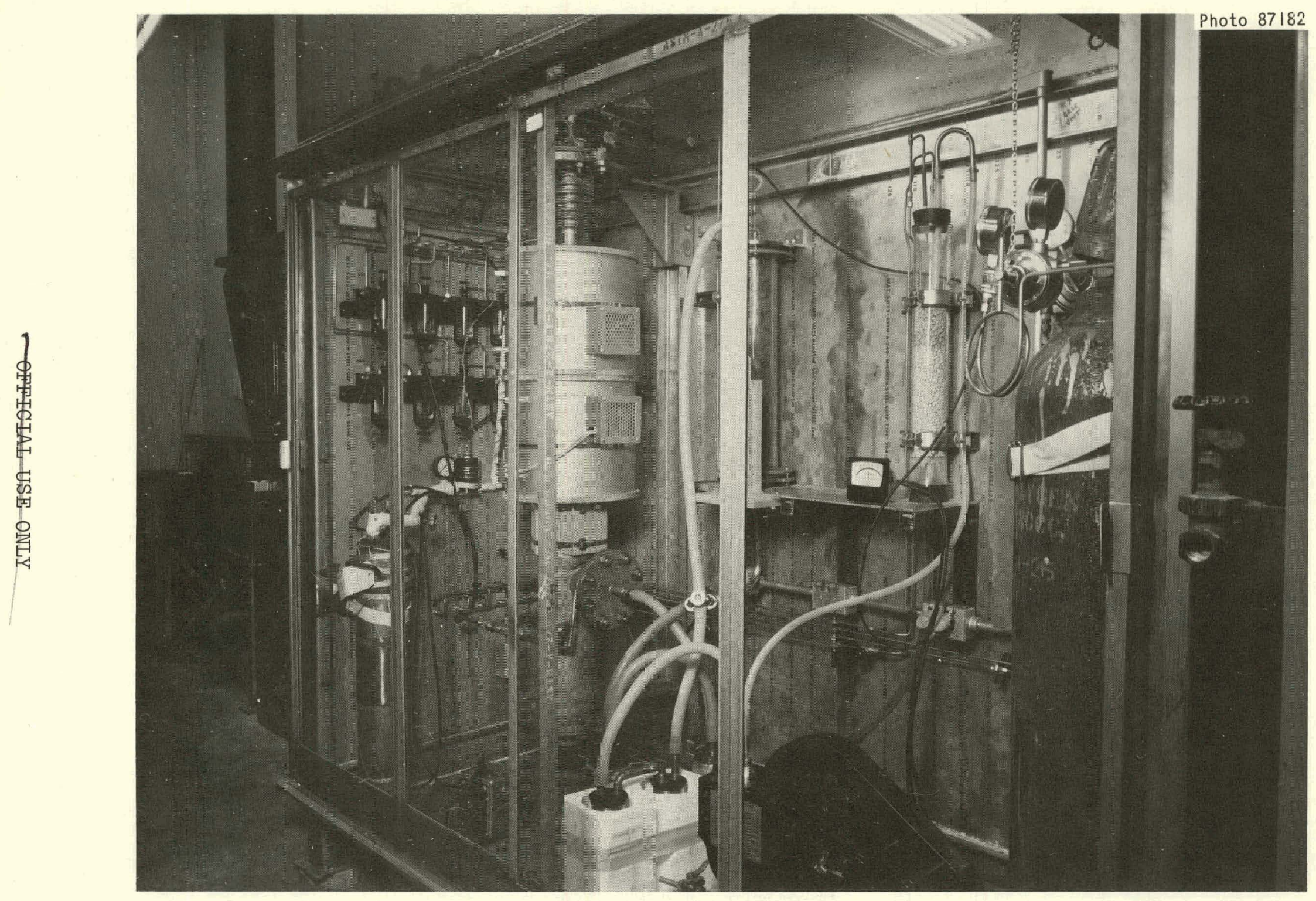

Fig. 2.1. A.pparatus for the Ccmversion of Uranium Hexafluoride to Uranium Dioxide. 
heated chamber at low pressures. The combination of these ideas led to the present apparatus, which may be an economical route for reprocessing uranium fuels to fine uranium oxide powder at rates approaching $5 \mathrm{~kg} /$ day.

The performance of the apparatus was good in the initial experiment. A stable flame of $\mathrm{UF}_{6}, \mathrm{H}_{2}, \mathrm{O}_{2}$, and $\mathrm{F}_{2}$ was established, and no deterioration of the injector was observed. A near 100\% conversion of the $\mathrm{UF}_{6}$ to oxide powder was achieved. The powder consisted of 60 wt $\% \mathrm{UO}_{2}$, 37 wt $\% \mathrm{U}_{3} \mathrm{O}_{8}$, and an as-yet unidentified contaminant of approximately 3 wt \%. The method of powder collection was inadequate and will have to be modified. Modifications are also necessary in the cold trap and cooling systems. When these difficulties are solved, the design will be finalized and the effect of processing parameters on the product will be evaluated.

Preparation of $\mathrm{PuO}_{2}$ Powder from $\mathrm{PuF}_{6}$ by Chemical Vapor Deposition

$$
\text { W. C. Robinson, Jr. }
$$

The conversion apparatus for the eventual preparation of $\mathrm{PuO}_{2}$ powder from $\mathrm{PuF}_{6}$ was operated in $\mathrm{Bldg}$. 4508. The device was operated using $\mathrm{UF}_{6}$ in lieu of $\mathrm{PuF}_{6}$ in order to evaluate NaF-KF traps for the removal of HF gas and hydrogen absorbers. Both of these absorbers performed adequately as no gas at all passed the hydrogen absorber and the gas flowing into the hydrogen absorber did not contain enough HF to change the $\mathrm{pH}$ of a small beaker of water. After this successful checkout period, the conversion apparatus has been moved to Bldg. 3019 where the apparatus will be evaluated using $\mathrm{PuF}_{6}$. An additional glove box has been attached that will contain a fluorination assembly designed to allow us to fluorinate the $\mathrm{PuF}_{4}$ to $\mathrm{PuF}_{6}$. The flow diagram of the complete assembly is shown in Fig. 2.2. The necessary services are presently being connected to the glove boxes.

An operating procedure for the equipment in the Metallurgy Section of Bldg. 3019 has been written and submitted to the Operations Safeguards Committee. After the services have been connected to the glove boxes, the apparatus will be assembled inside the boxes. Experiments can then begin immediately upon receiving permission from the Committee. 


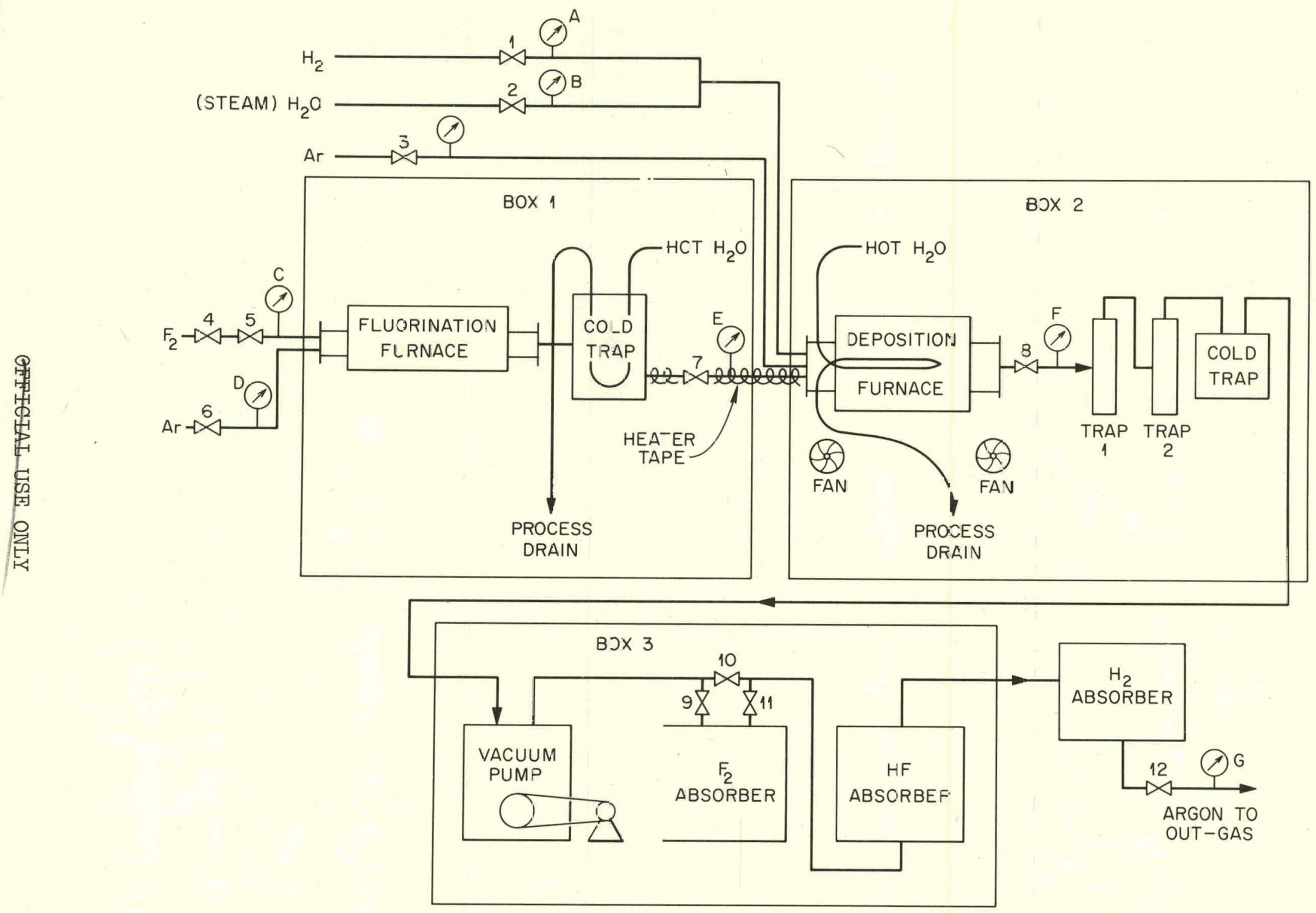

Fig. 2.2. Gas Flow Diagram of the Apjaratus for the Preparation of $\mathrm{PuO}_{2}$ from $\mathrm{PuF}_{6}$. 
Deposition of Tungsten-Rhenium Alloys

$$
\text { J. I. Federer W. R. Martin }
$$

A chemical vapor-deposition process for preparation of tungstenrhenium alloys having uniformity of composition in both the axial and radial directions of tubular deposits has been reported previously. ${ }^{3}$ The deposition reaction was the hydrogen reduction of $\mathrm{WF}_{6}$ and $\mathrm{ReF}_{6}$, the fluorides being injected directly into the deposition zone in order to minimize deposition in a temperature gradient and associated compositional variations. Efforts have continued to scale up the process by a factor of about 6 for preparation of flat stock for mechanical properties evaluation. Scale-up studies have consisted of studying the effects of total gas flow rate and $\mathrm{H}_{2}-$ to $-\mathrm{WF}_{6}+\mathrm{ReF} 6$ ratio on reduction efficiency, deposition rate, and surface morphology of the deposits. The conditions and some results of these experiments are presented in Table 2.1. The temperatures and pressures of these experiments were established during process development; the flow rates were increased approximately in proportion to the surface area of deposition.

${ }^{3}$ J. I. Federer and W. R. Martin, Fuels and Materials Development Program Quart. Progr. Rept. Dec. 31, 1966, ORNL-TM-1720, pp. 16-19.

Table 2.1. Conditions and Results of Scale-Up Experiments for Deposition of Tungsten-Rhenium Alloys

\begin{tabular}{|c|c|c|c|c|c|c|c|}
\hline \multirow{2}{*}{$\begin{array}{l}\text { Nominal } \\
\text { Rhenium } \\
\text { Content } \\
\text { (wt \%) }\end{array}$} & \multirow{2}{*}{$\begin{array}{l}\text { Temperature }{ }^{a} \\
\left({ }^{\circ} \mathrm{C}\right)\end{array}$} & \multirow{2}{*}{$\begin{array}{l}\text { Pressure } \\
\text { (torr) }\end{array}$} & \multicolumn{3}{|c|}{$\begin{array}{l}\text { Flow Rates } \\
\left(\mathrm{cm}^{3} / \mathrm{min}\right)\end{array}$} & \multirow{2}{*}{$\begin{array}{l}\text { Reduction } \\
\text { Efficiency } \\
\qquad(\%)\end{array}$} & \multirow{2}{*}{$\begin{array}{l}\text { Maximum } \\
\text { Deposition } \\
\text { Rate } \\
\text { (mils/hr) }\end{array}$} \\
\hline & & & $\overline{\mathrm{H}_{2}}$ & $\mathrm{WF}_{6}$ & $\mathrm{ReF}_{6}$ & & \\
\hline 3 & 750 & 5 & 1500 & 95 & 5 & 60 & 3 \\
\hline 5 & 850 & 50 & 1500 & 35 & 5 & 10 & \\
\hline 5 & 750 & 5 & 3000 & 190 & 10 & 60 & 3 \\
\hline 5 & 750 & 5 & 3000 & 95 & 5 & 80 & 4.5 \\
\hline 5 & 750 & 5 & 4200 & 190 & 10 & 60 & 5 \\
\hline 25 & 950 & 5 & 1500 & 75 & 25 & 90 & 3 \\
\hline 25 & 950 & 5 & 3000 & 75 & 25 & 90 & 4 \\
\hline
\end{tabular}

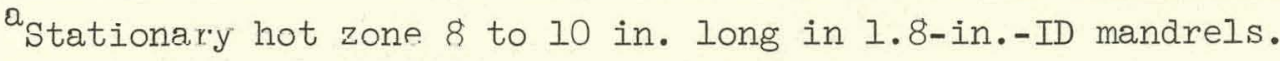

betermined in the region of maximum thickness for a deposition time of ahout $4 \mathrm{hr}$. 
All the deposits formed over a 10- to 12-in. length of the mandrel, or slightly longer than the uniform hot zone. An attempt to confine the deposit to the uniform hot zone by increasing the pressure from 5 to 50 torrs and the temperature from 750 to $850^{\circ} \mathrm{C}$ resulted in powder formation, deposition of a loosely adherent coating on the injector, and only a thin alloy coating on the mandrel. In the case of the deposits containing nominally 5\% Re, a hydrogen-to $-\mathrm{WF}_{6}+\mathrm{ReF} 6$ ratio of $30: 1$ resulted in a higher reduction efficiency (80\%) than ratios of $15: 1$ and 21:1. Reduction efficiencies of $90 \%$ were nhtaincd fur hydrogen-to- $\mathrm{WF}_{6}+\mathrm{ReF}_{6}$ ratios of 15:1 and 30:1 for the nominal 25\% Re alloys. The Low depusition rates wcre consistent wilh flow rates, reduction efficiency, and the surface area of deposition. Distinctly nodular regions were observed in all but the fourth and seventh experiments shown in Table 2.1; therefore, the conditions of the latter experiments were used in the first attempts to deposit flat stock.

Steel mandrels of octagonal cross section having 3/4-in.-wide flat sections were used for deposition of flat stock. The mandrels passed through the furnace hot zone at the rate of $0.25 \mathrm{in.} / \mathrm{hr}$ in order to extend the length of the deposits and to obtain thickness uniformity. Howcrer, both 5 and 25\% Re deposits contained numerous nodulcs and were not suitable for prepuration of specimens. Nodular growths have been obscrved previously in vapor deposits of both unalloyed tungsten and tungsten-rhenium alloys. ${ }^{4}$ The usual columnar grain structure is disrupted in nodules, and frequently the grain structure contains voids. Typical examples of nualuar growths in the alloys denositcd in the present study are sllown in Fig. 2.3. The nodules, as shown in Fig. 2.3, nucleated in the deposit all not on the steel substrate. If nucleation on the substrate can be discounted, then the wause for nodules may he associated with conditions on the deposition surface as affected by the composition of reacting gases. The present approach to eliminating nodules consists of varying deposition conditions within the framework of those conditions that thermodynamis calculalions indicate are most favurable for deposition of homogeneous alloys.

${ }^{4} \mathrm{~J}$. I. Federer and C. F. Leitten, Jr., Fuels and Materials Development Program Quart. Progr. Rept. Sept. 30, 1965, ORNL-TM-1270, p. 12. 


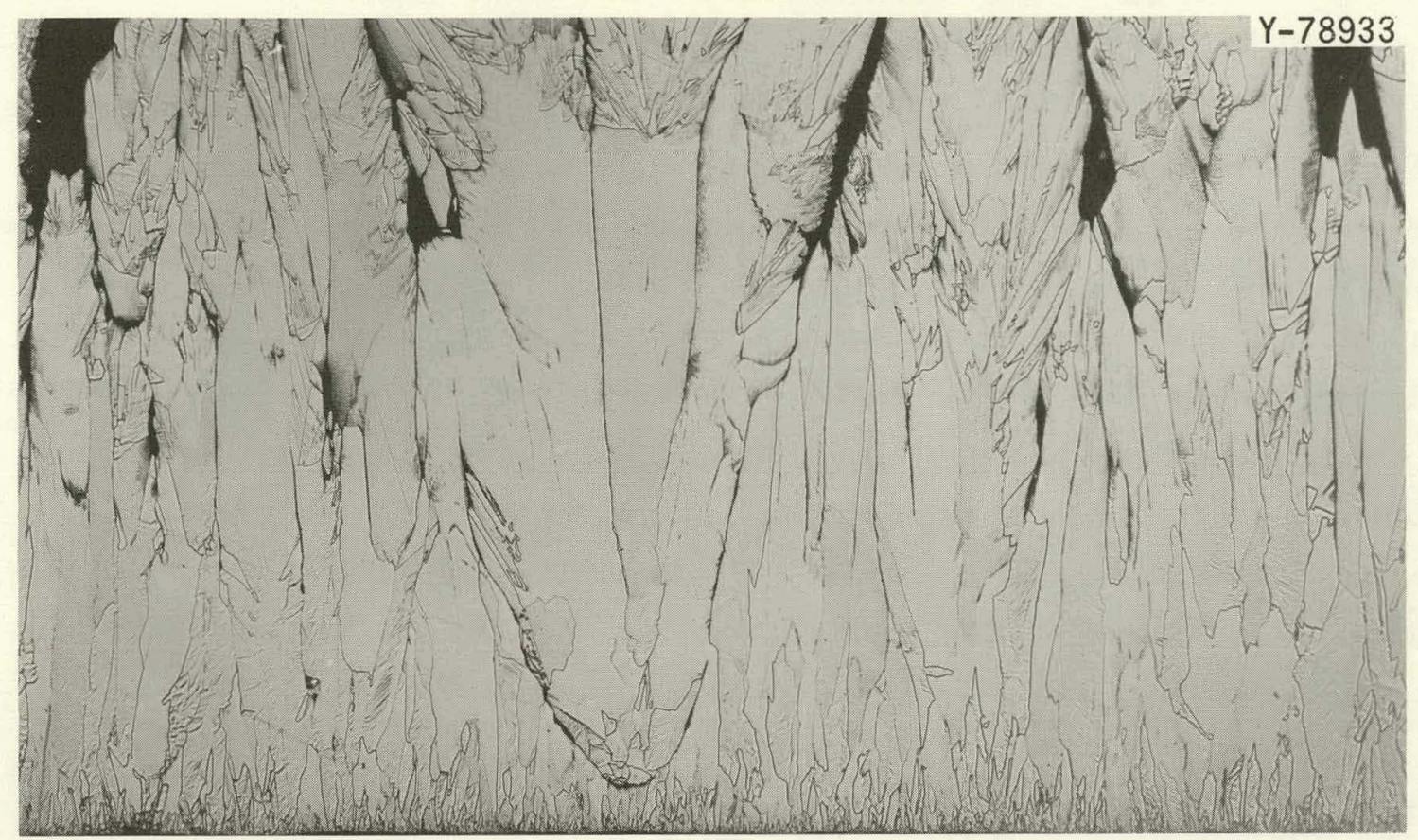

Fig. 2.3. Nodular Growth in Tungsten-Rhenium Deposit. Etchant: $1 \mathrm{NH}_{4} \mathrm{OH}$ (conc) and $1 \mathrm{H}_{2} \mathrm{O}_{2}(30 \%)$. I00X.

Alloys were also deposited in the external coating apparatuses used for depositing 4-ft lengths of unalloyed tungsten tubing. In this apparatus the mandrel, which is directly heated by passage of an electrical current, is located within a relatively large chamber that allows more complete mixing of gases than is possible during deposition inside long, narrow tubes. Nominal 5\% Re alloys were deposited under the same conditions used for depositing in the octagonal mandrels mentioned previously; however, a temperature gradient along the length of the mandrels resulted in a composition gradient. A 1/4-in.-ID tubular deposit varied in composition from $7.8 \%$ Re at the cooler end (gas inlet) to less than $0.01 \% \mathrm{Re}$ at the other end over a 38-in. length. A similar variation occurred in a specimen deposited on a 5/8-in.-wide, 0.032-in.-thick strip mandrel. These deposits, however, had a smooth surface texture with only a few isolated nodules. The elimination of the temperature gradient in the mandrel will be the object of future experiments.

A study of the phases present in as-deposited and annealed alloys has continued. Alloys were deposited at 1000,1200 , and $1500^{\circ} \mathrm{C}$, after which the phases present were determined by $x$-ray diffraction. The 
temperature and composition at which the $\beta$-tungsten, solid solution, and sigma phases formed, along with similar data determined previously, ${ }^{3}$ are shown in the tentative phase diagram portion in Fig. 2.4. The term $\beta$-tungsten refers to the phase having the $\beta$-tungsten or Al5-type structure. Hereafter, the phase will be referred to as the Al5 phase to avoid confusion with the tungsten-rich terminal solid solution which is designated as $\beta$ in the presently accepted binary phase diagram. Neither the maximum temperature of formation nor the upper solubility limit of the Al5 phase has been determined. The Al5 phase was not present in alloys containing about 20 to $42 \%$ Re annealed $1000 \mathrm{hr}$ at $1500^{\circ} \mathrm{C}$ but was present in alloys containing about 28 to $37 \%$ Re deposited at $1500^{\circ} \mathrm{C}$. This discrepancy may be due to temperature measurement error or a condition of metastability in the as-deposited Al5 phase. The latter possibility is being investigated by comparing the intensities of $x$-ray diffraction peaks for the Al5 phase in alloys deposited at several temperatures, then after annealing at $1300^{\circ} \mathrm{C}$. The proposed crystal structure of the A15 phase has six tungsten atoms in the positions $1 / 4,0,1 / 2 ; 1 / 2,1 / 4,0 ; 0,1 / 2,1 / 4 ; 3 / 4,0,1 / 2 ; 1 / 2,3 / 4,0 ; 0,1 / 2,3 / 4 ;$ and two rhenium atoms in the positions $0,0,0$ and $1 / 2,1 / 2,1 / 2$ of the unit cell. Calculated $x$-ray intensities based upon these positions agreed closely with experimental intensities determined from diffractometer traces as shown in Table 2.2, thus confirming the crystal structure. Since the x-ray scattering factors for tungsten and rhenium are almost identical, neutron diffraction is being used to investigate order in the unit cell. The first attempt, however, was unsuccessful due to overlapping peaks of the Al5 and solid solution phases. The experiment is being repeated using a pure Al5 alloy. 
OFPIEIAI URE-OATY

17

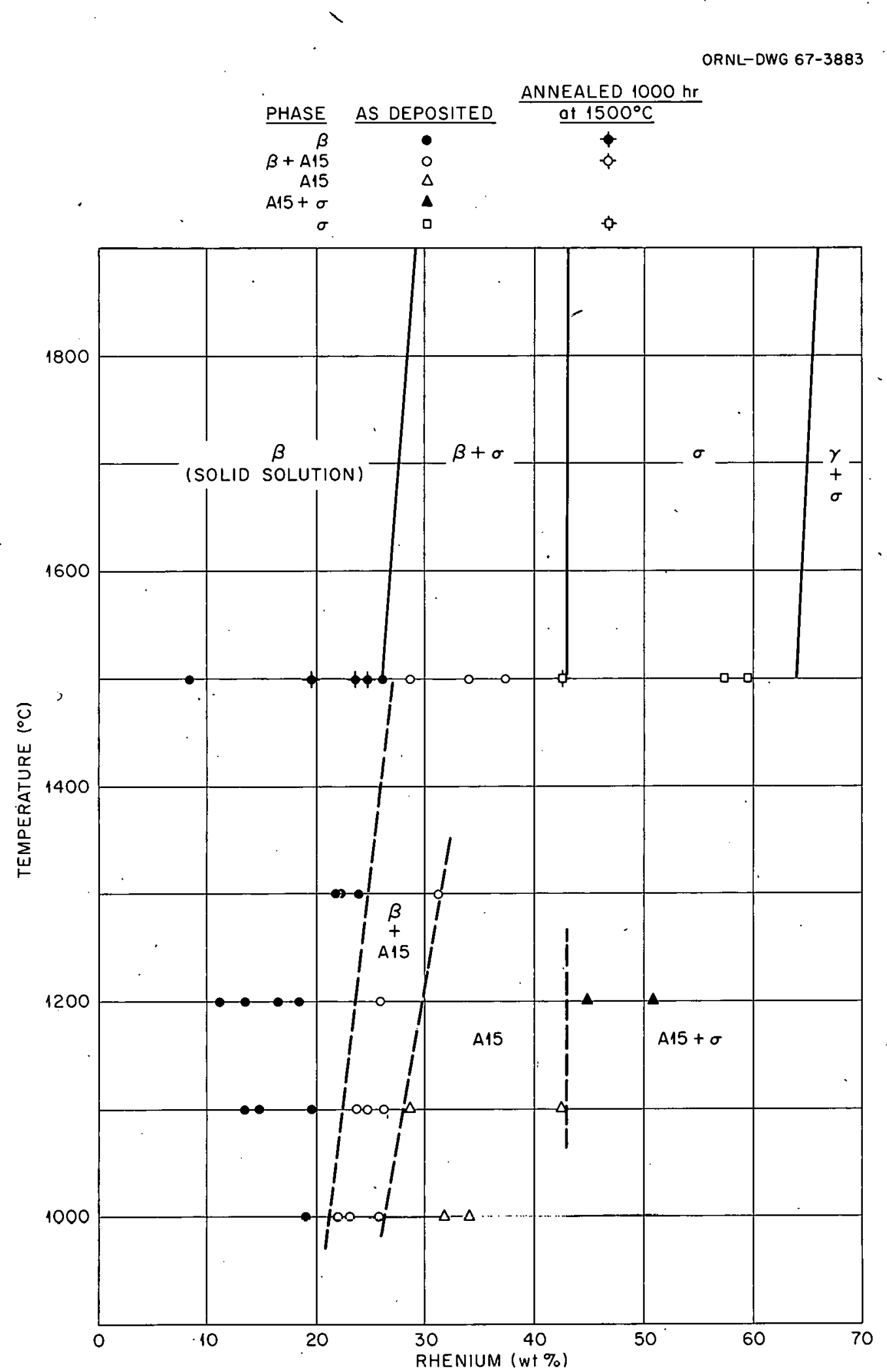

Fig. 2.4. Portion of the Tentative Tungster-Rhenium Phase Diagram. 
Table 2.2. Comparison of Calculated and Experimental $\mathrm{X}$-Ray Diffraction Intensities for the Al5-Type Phase

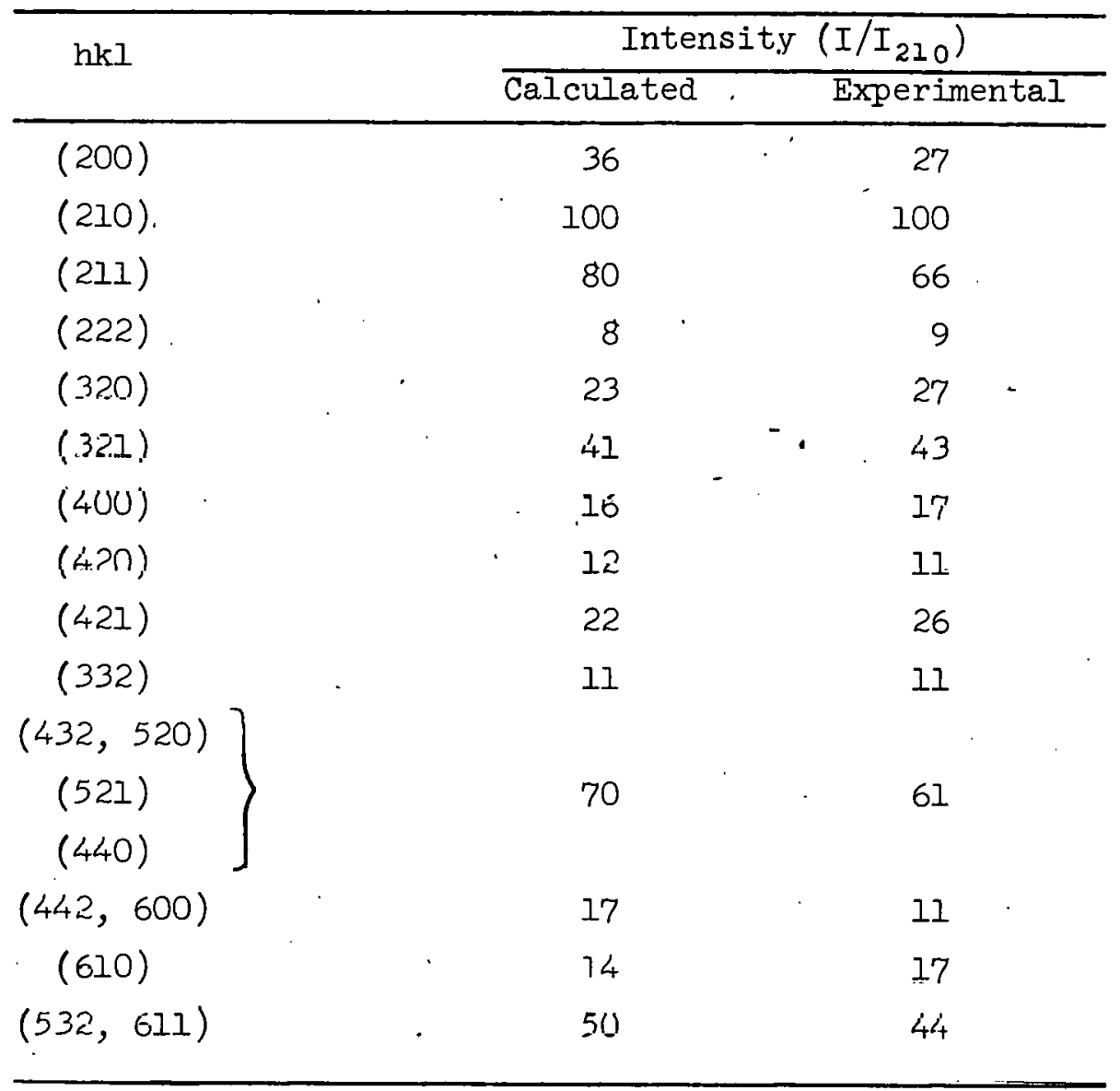




\section{NONDESTRUCTIVE TEST DEVELOPMENT}

\section{R. W. McClung}

This program is intended to develop new and improved methods of nondestructively evaluating reactor materials and components. To achieve this we are studying various physical phenomena, developing instrumentation and other equipment, devising application techniques, and designing and fabricating reference standards. Among the methods being actively pursued are electromagnetics (with major emphasis on eddy currents), ultrasonics, and penetrating radiation. These and other methods are being evaluated for both normal and remote inspection.

\section{Electromagnetic Test-Methods}

\section{V: Dodd}

\section{Analytical Studies}

We have continued research and development on electromagnetic phenomena on both analytical and empirical bases. We obtained a "closedform" solution of the vector potential for the case of a rectangular cross-section coil encircling a rod with one conductor clad on another. The solutions apply for any values of fill factor, coil length and. thickness, conductivity of the two metals, and thickness of the cladding metal. The solution is in terms of an integral equation. This solution will be very valuable in analyzing eddy-current tests for such configuration if an accurate approximation can be found for the integral equations.

\section{Phase-Sensitive Eddy-Current Instrument}

We completed the circuit diagrams for the portable phase-sensitive eddy-current instrument and they were released to the office of Industrial Cooperation at ORNL for external distribution. We wound two 0.055-in.-diam coils for use at 50 and $500 \mathrm{kilohertz.} \mathrm{These} \mathrm{coils} \mathrm{will}$ have greater sensitivity to small defects and allow us to inspect. 'small parts with less effect due to curvature and proximity of the specimen edge. 
Ultrasonic Test Methods

\section{K. V. Cook}

\section{Fabrication of Reference Notches}

We are continuing to work on the problems encountered in tubing inspection. A major problcm is the establishment of realistic ultrasonic notch standards for calibration. Since electrical-discharge machining (EDM) appears to be a reliable method for making both innerand outer-surface notches, we are contiruing our fabricaliui studico. Althnugh our development ol capullllies and tcchniques for marhining longitudinal reference notches is not necessarily completed, we have established reliable techniques thul dluw the machining of gond rewuducible longitudinal reference notches. For instance, we can machine longitudinal notches withir \pm 0.0001 in. of nominal depths and can place them inside tube bores as small as 0.065 in.

Our prèsent limitations on transverse or circumferential notches are $\pm 10 \%$ of nominal depths and placement inside bores of $0.380 \mathrm{in}$. or larger. Since we have a need for transverse reference notches in smaller tubing, we have designed and fabricated electrode arms that wi.1.7. allow transverse notches with $1 / 8$ - and 1/16-in. lengths to be placed inslde tules with bores approximating $1 / 4$ and $3 / 16$ in., respectively. Calibration curves are being generated for each of these arms.

\section{Reference Standards}

We have initiated a study that will attempt to correlate ultrasonic response from EDM notches, drilled holes, and flat-bottomed holes of various sizes machined in thin materials. At the present time we are working, with sheet material; however, we plan, to make a similar study with small-diameter tubing.

The previous report ${ }^{1}$ briefly described the four sheets of aluminum and the reference discontinuities. Similar sheets of stainless steel

\footnotetext{
${ }^{I_{K}}$. V. Cook, Fuels and Materials Development Program Quart. Progr. Rept. Dec. 31, 1966, ORNL-TM-1720, pp. 30-31.
} 
have been prepared with identical discontinuities and are being used to generate data relating incident angle to the amplitude of the ultrasonic beam reflected from the reference discontinuities. A standard 1/4-in.-diam cone collimator was employed for the preliminary data. In addition, we are now generating the same type of data, using a collimator that we normally use for tubing inspection.

\section{Penetrating Radiation Methods}

\section{R. W. MCClung}

In a continuation of development of low-voltage radiographic techniques, we are making quantitative studies for the radiography of thin sections of graphite. A step wedge with thicknesses from 0.100 to 1.650 in. was radiographed.with energies from 10 to $45 \mathrm{kvp}$ at exposures to achieve a wide range of film densities for each step thickness. The exposures were made with intervening atmospheres of both helium and air. We are now evaluating the data to allow generation of comprehensive. exposure charts. From these and subsequent calculations with the data, we will determine the attainable sensitivity under various conditions, the absorption equivalence of graphite compared to other materials, and the relative benefits of the helium atmosphere at various specimen thicknesses and $\mathrm{x}$-ray energies. 


\section{OFEICIAL USE ONLY \\ 22 \\ 4. SINTERED ALUMINUM PRODUCTS DEVELOPMENT}

W. R. Martin

Sintered aluminum products are high-strength aluminum alloys that have possible application in several reactor systems. These alloys with high strength-to-weight ratios could be used throughout reactor cores as both cladding and structural materials.

our program was initiated to investigate the problems and parameters related to primaxy billet fabrication of SAP for HWOCR fuel rods and pressure tubes. General process steps involve feed-powder characterization, dispersion preparation, and consolidation. We are endcavoring to optimize conditions of each operation to arrive at a more reliable and consistent product.

The bulk of work during this reporting period is related to dispersion preparation under conditions expected in production runs, consolidation of billets, and evaluation of the end product. our progress is summarized in the following section.

\section{Dispersion Preparation}

G. I. Copeland

The 36-in.-diam ball mill has bccn devigned and inst.a.t.led, and several runs have been made at ORNL. A photograph of the mill is shown in Fig. 4.I. This mill is being used to evaluate our milling parameters that were previously determined using 300-g size batches in a 10-in.-diam mill. We are also evaluating our milling specification using a pilot plant mill at Alcan Metal Powders, Inc. Four runs have been performed at Alcan, with parameters identical to the first four ORNL runs. The chemistry results of these runs are given in Table 4.1. The Alcan ruri: were milled in a 36-in.-diam, 6-in.-long mill, filtered, and then aried in a rotary vacuum dryer at approximately $250^{\circ} \mathrm{F}$. The ORNL runs were milled in a 36-in.-diam, 16-1n.-lony mill, filtcred, and then rinfied. twice with acetone. The chemistry samples were placed in a vacuum 


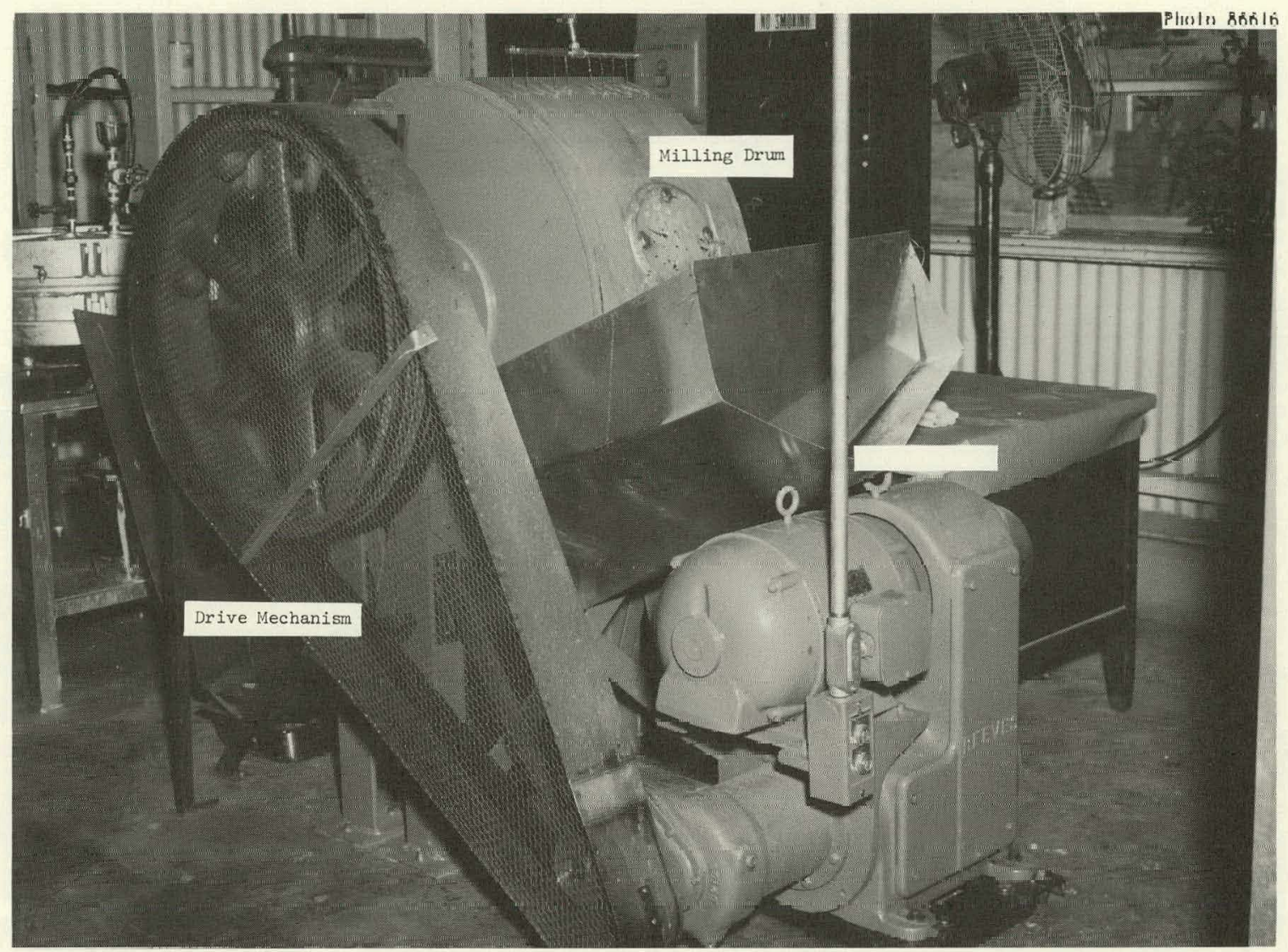

Fig. 4.l. ORNL Ball Mill Used to Evaluate Milling Parameters.

desiccator at room temperature overnight. The oxide analyses as a function of milling time are shown in Fig. 4.2. The decrease in slope of the line for the ORNL runs as compared with the Alcan runs may be explained by run OR 15. This run was made with forced-air circulation, whereas the other runs were simply vented to the atmosphere through a hole in the supporting shaft. The increase in oxide content for this run indicates that the other ORNL runs may have had an oxygen-lean atmosphere after the initial start of the milling. Future runs will have forced circulation of air to assure a normal air atmosphere in the mill. As shown in Fig. 4.3, there is an increase in the milling action of the 36-in.-diam mill, as compared with the 10-in.-diam mill, although the increase is not as great as had been anticipated. In an attempt to further evaluate the effect of mill diameter, Reynolds Metals Company is running a series of runs comparable to the first four ORNL runs in a 48-in.-diam, 6-in.-long mill for another comparison. 
Table 4.1. Chemistry of Ball-Milled Powdera

\begin{tabular}{|c|c|c|c|c|c|c|}
\hline \multirow{3}{*}{$\begin{array}{l}\text { Run } \\
\text { Number }\end{array}$} & \multirow{3}{*}{$\begin{array}{l}\text { Milling } \\
\text { Time } \\
(\mathrm{hr})\end{array}$} & \multirow{3}{*}{$\begin{array}{l}\text { Powder } \\
\text { Charge } \\
\text { Percent } \\
\text { of Ball } \\
\text { Weight }\end{array}$} & \multicolumn{4}{|c|}{ Chemical Composition (wt \%) } \\
\hline & & & \multicolumn{2}{|c|}{$\mathrm{Al}_{2} \mathrm{O}_{3}$ Content } & \multirow[b]{2}{*}{ IroII } & \multirow[b]{2}{*}{ Cartuon } \\
\hline & & & $\begin{array}{c}\text { Fast Neutron } \\
\text { Activation } \\
\text { Analysis }\end{array}$ & $\begin{array}{c}\text { Gaseous } \\
\text { HCl }\end{array}$ & & \\
\hline OR 1 & 6 & 6 & 3.72 & 2.95 & $N_{A}^{c}$ & 0.81 \\
\hline $\mathrm{OR} 2$ & 8 & 6 & 2.59 & 2.74 & 0.49 & 0.65 \\
\hline OR 3 & 10 & 6 & 3.14 & 2.90 & 0.28 & 0.69 \\
\hline OR 4 & 12 & 6 & 3.31 & 3.35 & 0.27 & 0.74 \\
\hline OR 5 & 12 & 6 & 3.07 & 3.52 & NA & NA \\
\hline $\mathrm{OR} 6$ & 12 & 4 & 4.72 & 5.18 & NA & NA \\
\hline OR 7 & 12 & 8 & 2.76 & NA & NA & NA \\
\hline $\mathrm{OR} 8$ & 12 & 10 & 2.00 & NA & NA & NA \\
\hline OR 9 & 16 & 4 & 5.38 & NA & NA & NA \\
\hline OR 10 & 18 & 4 & 6.48 & NA & NA & NA \\
\hline OR II & 20 & 4 & 6.20 & NA & NA & NA \\
\hline OR 12 & 26 & 4 & 9.74 & 10.0 & 0.56 & 1.46 \\
\hline OR 13 & $24^{\prime}$ & 4 & $\% .86$ & INA & INA & NA \\
\hline OR 14 & 22 & 4 & 7.84 & NA & NA & NA \\
\hline OR $1 b^{b}$ & 24 & 4 & 10.62 & NA & INA & NA \\
\hline MD 1 & 6 & 6 & 2.55 & 2.66 & 0.22 & 0.57 \\
\hline $\mathrm{MD} 2$ & 8 & 6 & 2.98 & 2.99 & 0.21 & 0.62 \\
\hline MD 3 & 10 & 6 & 4.34 & 4.08 & 0.22 & 0.81 \\
\hline$M D \quad 4$ & 12 & 6 & 4.38 & 4.37 & 0.21 & 0.85 \\
\hline
\end{tabular}

$a_{\text {Runs }}$ were milled in a 36-in.-diam mill under the following conditions: starting powder - MD 101 ( 0.57 wt $\% \mathrm{Al}_{2} \mathrm{O}_{3}, 0.24$ wt $\% \mathrm{Fe}, 0.008 \% \mathrm{C}$ ); mineral spirits - twicc wcight of powder (except run OR 5 was equal the weight of powder); stearic acid lubricant - $3 \%$ of powder weight; mill speed - critical speed, $44 \mathrm{rpm}$; OR runs were made at ORNL and the MD runs at Alcan Metal Powders, Inc.

$\mathrm{b}_{\text {Forced-air circulation. }}$

$\mathrm{c}_{\mathrm{NA}}$ - not analyzed. 


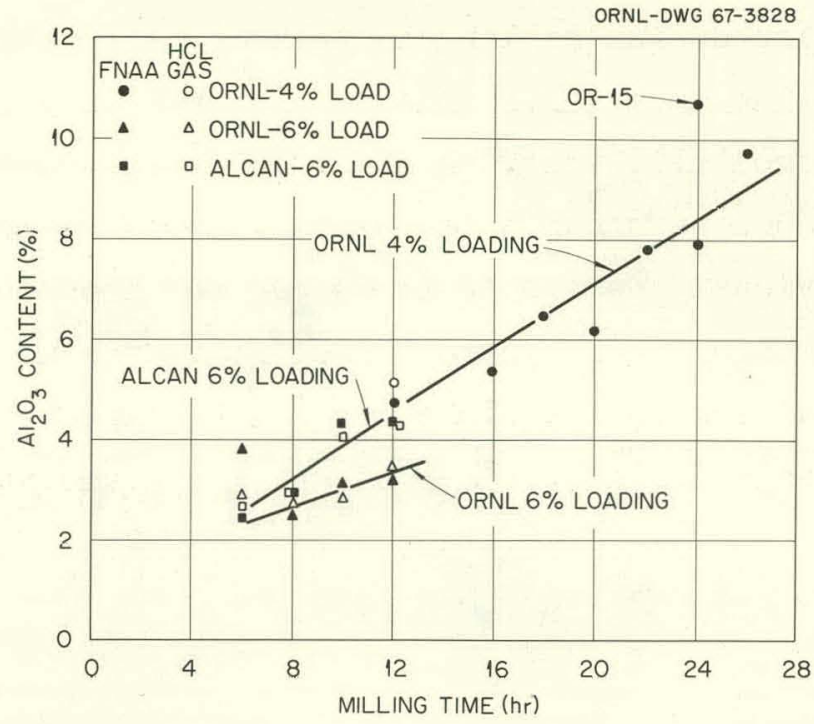

Fig. 4.2. Oxide Analyses as a Function of Milling Time $-\mathrm{Al}_{2} \mathrm{O}_{3}$ Content Versus Milling Time for 36-in.-diam Mill.

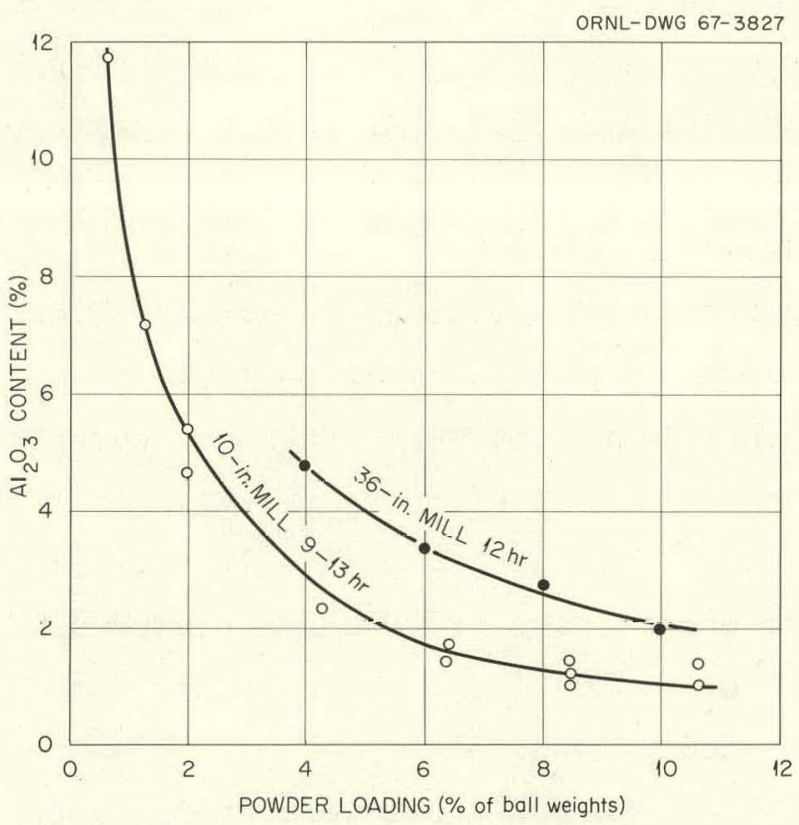

Fig. 4.3. Oxide Analyses as a Function of Powder Loading $-\mathrm{Al}_{2} \mathrm{O}_{3}$ Content Versus Powder Loading. 
The iron pickup during milling is seen to be approximately 0.3 wt $\%$ for the 10 wt $\%$ oxide material. This iron is probably in the form of small inclusions from mill wear. A small magnetic separator has been ordered, which should be capable of removing the free iron from the ball mill slurry. Previously, attempts to remove the iron introduced during milling were successful. I The carbon content is due to mineral spirits and lubricant remaining on the flake and can be expected to decrease to the 0.2 to $0.3 \%$ range during further high-temperature vacuum processing.

Powder Consolidation
M. M. Martin
D. H. Turner

The reference SAP consolidation process entails vacuum annealing flake powder, followed by vacuum hot pressing to form $80 \%$ dense billets. The product from hot extrusion of these consolidated compacts exhibits mechanical properties at $450^{\circ} \mathrm{C}$ with $0.0002 \mathrm{~min}^{-1}$ strain rate that are equivalent to commercial SAP 895. Our current work emphasizes optimization of the reference process and tooling scale-up from 2.0-in.-diam to 4.0- and 5.6-in.-diam billets.

The primary purposes of vacuum annealing the flake is to convert the aluminum oxide hydrate to a stable form of aluminum oxide and to remove contaminants. In optimizing the heat-treatment parameters, a thermogravimetric study on MD 3100 SAP powder revealed that the material rehydrates rapidly upon exposure to moist air at room temperature. The problem of handling and storage of vacuum annealed powder and $80 \%$ dense billets is of concern in that occulted water may increase the hydrogen content of the extruded product.

Rods of SAP 171 and SAP 172 that were produced by the reference process exhibited excellent mechanical properties. ${ }^{1}$ A vacuum anneal of 40-hr duration, however, caused severe degradation of both ultimate tensile and $0.2 \%$ offset yield strengths. A similar heat treatment performed on commercial SAP 895 resulted only in some degradation of

\footnotetext{
${ }^{I}$ D. H. Turner, Fuels and Materials Development Program Quart. Progr. Rept. Dec. 31, 1966, ORNL-TM-1720, p. 33 .
} 
ultimate tensile strength. Table 4.2 tabulates the results for both materials. It is interesting to note that ductility remained constant throughout the test. This reduction in properties is not understood. There is no evidence of cold working in the as-extruded rod; therefore the reduction in properties may be associated with the hydrogen.

Table 4.2. Effect of Vacuum Annealing on the Mechanical Properties of ORNL Reference Product and Commercial SAP 895

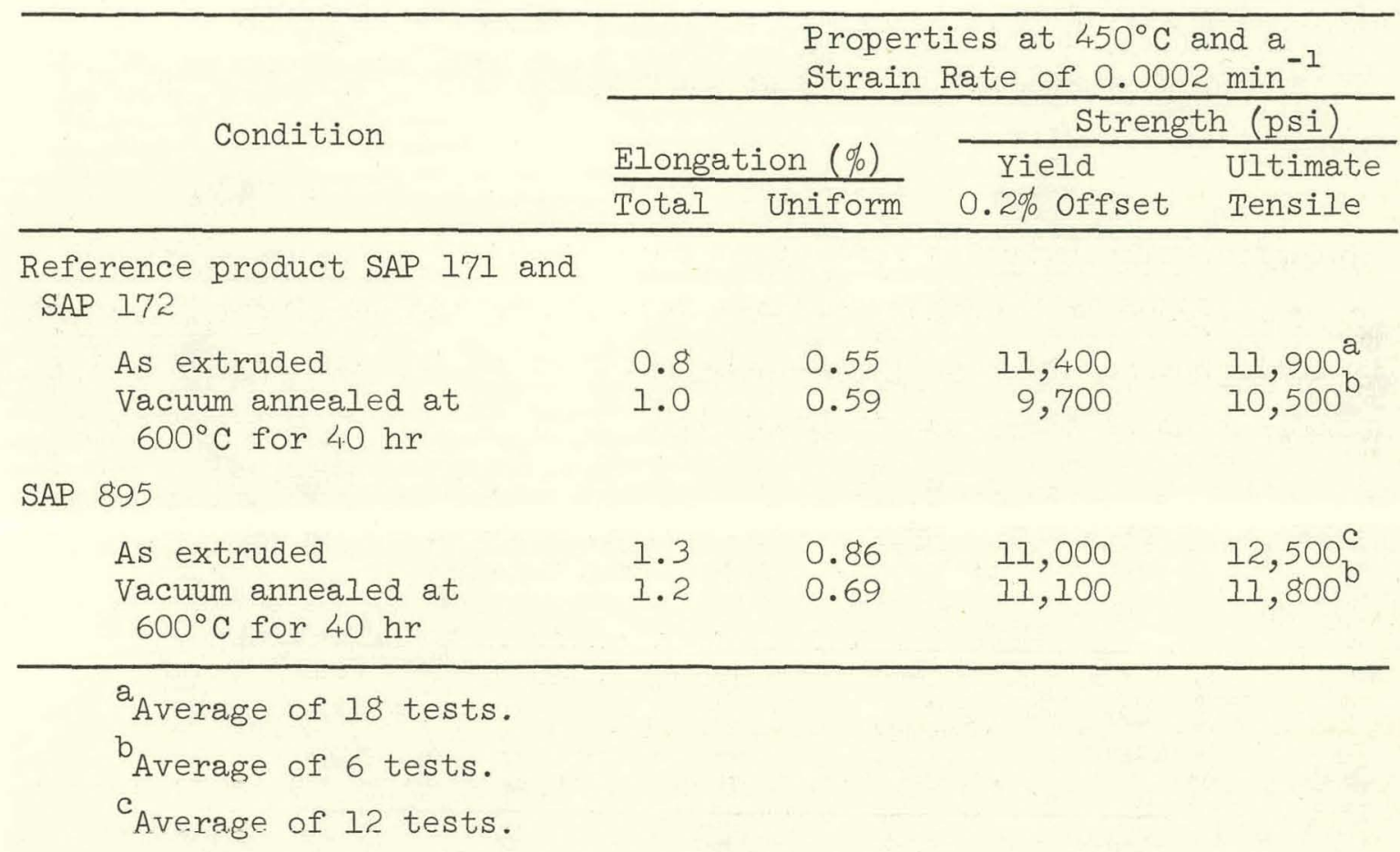

Previously, based upon a total gas analysis of $7.4 \mathrm{~cm}^{3} / 100 \mathrm{~g}$, we reported the hydrogen content of SAP 172 to be a maximum of $6.6 \mathrm{ppm}$. More recent determinations reveal hydrogen contents of 39 ppm for SAP 171 and 22 ppm for SAP 172; both values exceed the current maximum specification of $20 \mathrm{ppm} \mathrm{H}_{2}$ in SAP. In contrast, SAP 895 consistently contains less than $5 \mathrm{ppm}$. This difference in hydrogen content may account for the severe deterioration of tensile strength of the reference process product. Void formation is observed in SAP annealed for $100 \mathrm{hr}$ at $600^{\circ} \mathrm{C}$, when the hydrogen content exceeds $15 \mathrm{ppm}$. Currently, we have set the upper limit for hydrogen content at $10 \mathrm{ppm}$. 
We designed a series of eight 2-in.-diam and six 4-in.-diam consolidations to ( 1 ) establish the reproducibility of the reference process and (2) evaluate the effect of initial billet density upon the extruded product. Three density levels of 80 , 89, and $96 \%$ of theoretical characterize the billets. A single lot of MD 3100 flake was used for these experiments instead of a higher oxide content ORNL milled flake because of the quantity required.

The 2-in.-diam billets were produced from vacuum annealed MD 3100 prior to the time that rehydration was recognized as a serious problem. After various durations of storage in ambient air, the billets were extruded at $430^{\circ} \mathrm{C}$ at a reduction ratio of $30: 1$. Table 4.3 presents the hydrogen results trom five sumples cul fluil along the longth of euch extrusion. The hydrogen content is independent of sampling location; the difference in hydrogen values between high- and low-density billets is small but may be significant. Preparation of tensile specimens for this portion of the study is under way.

Table 4.3. Hydrogen Content of Reference Process SAP of Various Billet Densities

\begin{tabular}{|c|c|c|c|c|}
\hline \multirow[t]{2}{*}{$\begin{array}{c}\mathrm{S} \Lambda \mathrm{P} \\
\text { Number }\end{array}$} & \multirow[t]{2}{*}{ Density } & \multicolumn{2}{|c|}{$\begin{array}{l}\text { Hydrogen Range } \\
\text { (ppm) }\end{array}$} & \multirow[t]{2}{*}{$\begin{array}{l}\text { Mean }^{\text {A. }} \\
\text { Hydrogen } \\
\text { (ppm) }\end{array}$} \\
\hline & & High & Low & \\
\hline 230 & 95.5 & 17 & 9 & 12 \\
\hline 231 & 95.7 & 22 & 15 & $\perp^{\prime \prime}$ \\
\hline 232 & 89.5 & 24 & 16 & 19 \\
\hline 233 & 88.5 & $2 y$ & 23 & 25 \\
\hline 234 & 79.8 & 26 & 12 & 19 \\
\hline 235 & 80.7 & 25 & 6 & 17 \\
\hline 236 & 79.0 & 28 & 8 & 14 \\
\hline 237 & 80.7 & 26 & 19 & 22 \\
\hline
\end{tabular}

$\mathrm{a}_{\text {Five determinations. }}$ 
For the 4-in.-diam billets, two large batches of MD 3100 were annealed at approximately $620^{\circ} \mathrm{C}$ instead of at the prescribed $600^{\circ} \mathrm{C}$. As shown in Fig. 4.4, the powder agglomerated, which may be an advantage from the standpoint of handling for subsequent consolidation. This material, as well as the consolidated compacts, was stored in sealed plastic bags to minimize rehydration. Density levels of 80,92 , and $98 \%$ of theoretical again characterize the vacuum hot pressed billets; Fig. 4.5 shows two of the $80 \%$ dense products, which weigh approximately 5 Ib each.

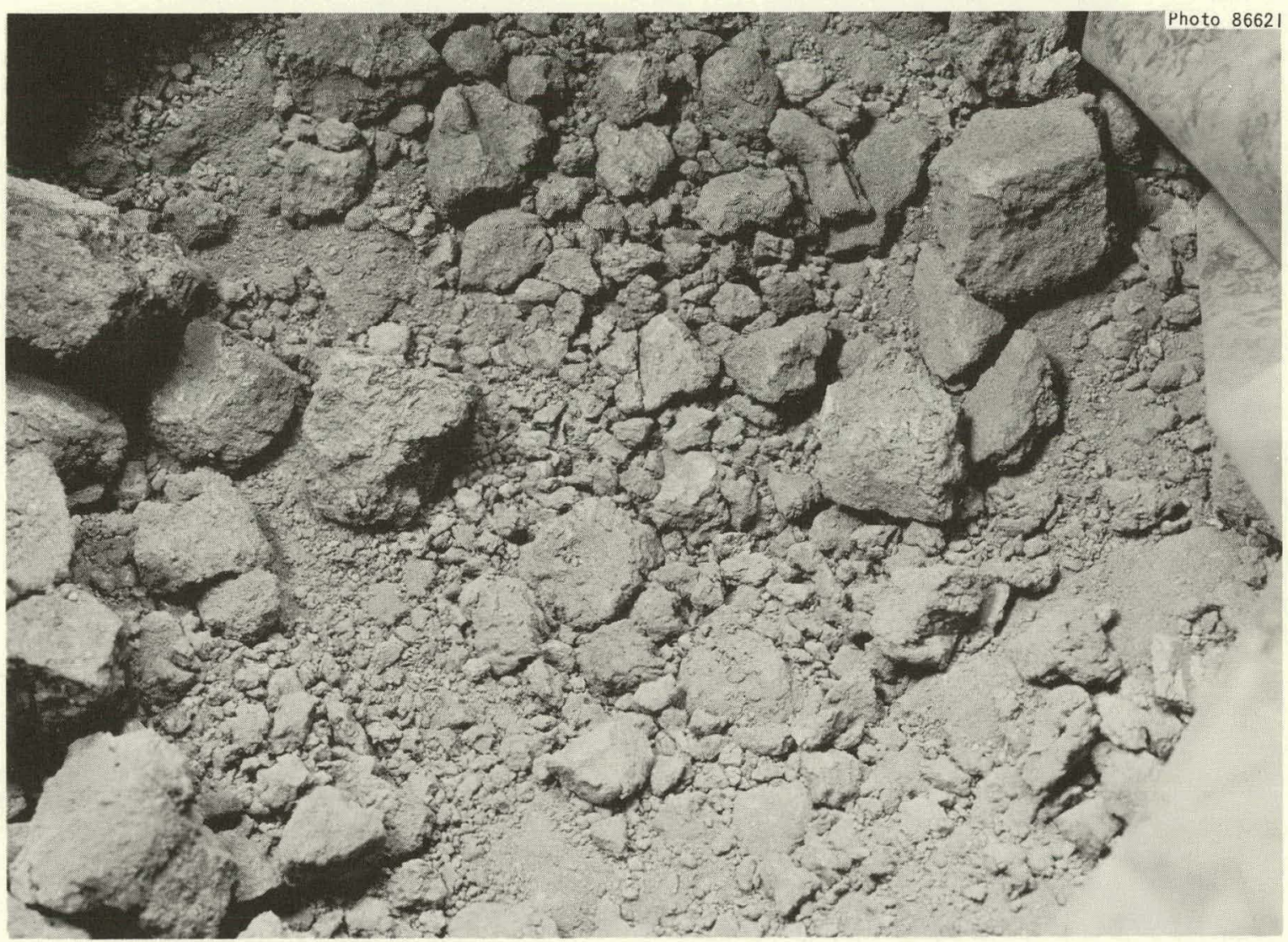

Fig. 4.4. MD 3100 Vacuum Annealed at Approximately $620^{\circ} \mathrm{C}$ for $20 \mathrm{hr}$. $7 \times$. Redideed $41 \%$.

The 4-in.-diam billets were extruded without difficulty through a shear die with a reduction ratio of $5.4: 1$, a billet temperature of $500^{\circ} \mathrm{C}$, and a tooling temperature of $200^{\circ} \mathrm{C}$. The resulting rounds have been cut into six extrusion blanks with wafers removed between each blank for 


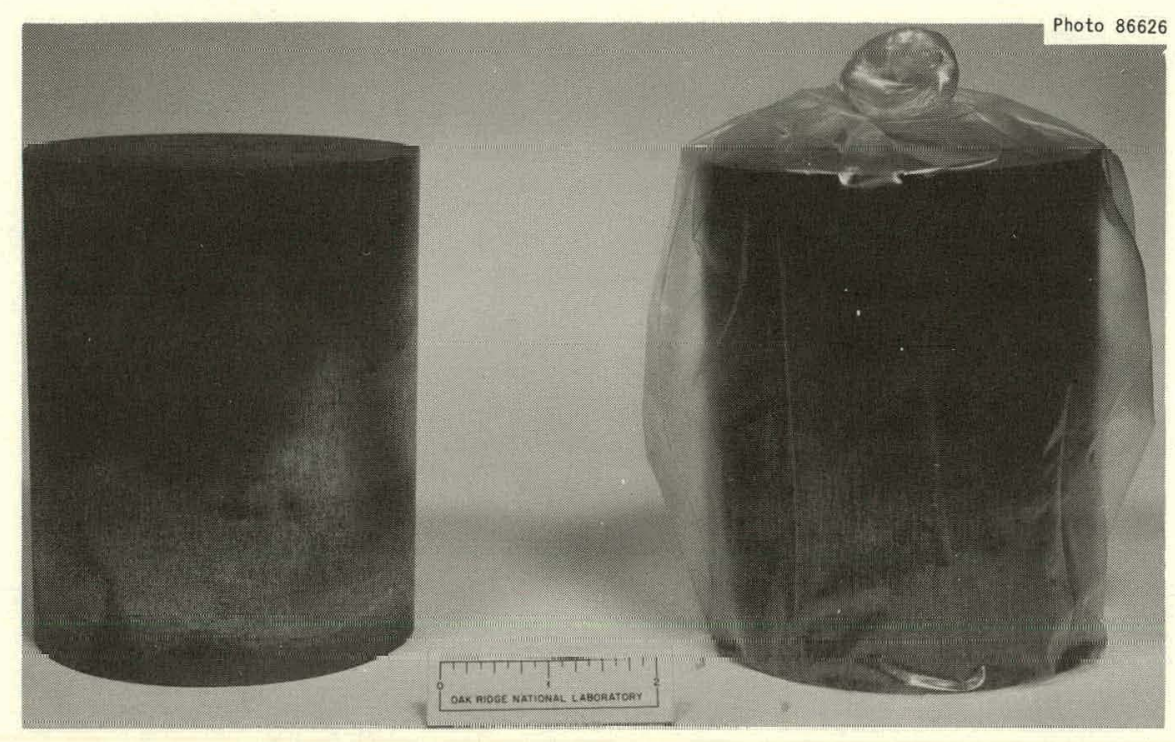

Fig. 4.5. Two 4-in.-diam Billets Annealed at $620^{\circ} \mathrm{C}$ with a Density of $80 \%$ of Theoretical.

chemical analyses. Three blanks from each round will be extruded again through a conical die at a reduction of 30:1 to provide material for mechanical property determinations. The chemical analyses of the primary extrusions are summarized in Table 4.4. The hydrogen analyses suggest that rehydration of $80 \%$ dense billets occurs even under caretul storage conditions but that higher density billets can be produced by the reference process with hydrogen contents equivalent to commercial products.

Six additional 4-in.-diam billets were consolidated from as-received MD 3100 flake primarily to provide some SAP extrusion experience on the 1250 -ton press. The billets were vacuum annealed $17.5 \mathrm{hr}$ at $600^{\circ} \mathrm{C}$ and transferred while still at temperature to the extrusion press preheat furnace. The pressure at the end of the vacuum annealing cycle reached $8 \times 10^{-6}$ torr. The primary extrusions were made immediately at a reduction ratio of $5.4: 1$, a billet temperature of $600^{\circ} \mathrm{C}$, and a tooling temperature of $200^{\circ} \mathrm{C}$. The primary extrusions were sampled similarly to that outlined above for the reference process study. The results of chemical analysis, shown in Table 4.4 for the primary extrusions, indicate hydrogen contents equivalent to commercial SAP 895. Previously, this consolidation technique yielded an extruded product whose ultimate tensile strength varied along the length of the rod. Since the hydrogen content 
Table 4.4. Analyses of Primary Extrusions from MD 3100 Flake Material ${ }^{a}$

\begin{tabular}{|c|c|c|c|c|}
\hline \multirow{2}{*}{$\begin{array}{c}\text { SAP } \\
\text { Number }\end{array}$} & \multirow{2}{*}{$\begin{array}{l}\text { Density } \\
\text { (percent of } \\
\text { theoretical) }\end{array}$} & \multicolumn{3}{|c|}{ Chemical Content (wt \%) } \\
\hline & & $\mathrm{Al}_{2} \mathrm{O}_{3}$ & $\overline{\mathrm{H}}$ & $\bar{C}$ \\
\hline \multicolumn{5}{|c|}{ Reference Process } \\
\hline $\begin{array}{l}245^{b} \\
246_{b}^{b} \\
247^{b} \\
248^{b} \\
249^{b} \\
250^{b}\end{array}$ & $\begin{array}{l}79.8 \\
81.6 \\
91.8 \\
92.8 \\
98.2 \\
97.3\end{array}$ & $\begin{array}{l}5.35 \\
5.45 \\
5.29 \\
5.34 \\
5.92 \\
5.38\end{array}$ & $\begin{array}{l}0.0011 \\
0.0010 \\
0.0005 \\
0.0005 \\
0.0004 \\
0.0005\end{array}$ & $\begin{array}{l}0.277 \\
0.276 \\
0.309 \\
0.302 \\
0.268 \\
0.276\end{array}$ \\
\hline \multicolumn{5}{|c|}{ As-Received Material } \\
\hline $\begin{array}{l}239^{c} \\
240^{b} \\
241^{b} \\
242^{b} \\
243^{b} \\
244^{b}\end{array}$ & $\begin{array}{l}71.5 \\
70.6 \\
80.6 \\
80.4 \\
86.7 \\
86.8\end{array}$ & $\begin{array}{l}8.01 \\
8.15 \\
6.54 \\
6.68 \\
6.51 \\
6.46\end{array}$ & $\begin{array}{l}0.0010 \\
0.0005 \\
0.0003 \\
0.0003 \\
0.0003 \\
0.0003\end{array}$ & $\begin{array}{l}0.202 \\
0.232 \\
0.356 \\
0.345 \\
0.302 \\
0.306\end{array}$ \\
\hline
\end{tabular}

is low, however, secondary extrusion is planned to provide material for further evaluation of mechanical properties.

Two 2-in.-diam billets produced from MD 3100 by the reference process were hydrostatically extruded at Battelle Memorial Institute. The extrusions were made at reduction ratios of 10:1 and 20:1. A third extrusion at a reduction ratio of 40:1 stalled in the die. Chemical analyses of the extruded rods, shown in Table 4.5, revealed exceptionally high hydrogen contents and low $\mathrm{Al}_{2} \mathrm{O}_{3}$ residues from aqueous $\mathrm{HCl}$ digestion. $\mathrm{X}$-ray diffraction identified the residues to be a mixture of eta and chi aluminas. The soluble oxide is probably a trihydrate, if hydrogen is assumed to be present as $\mathrm{H}_{2} \mathrm{O}$.

The stalled billet was sectioned to study material movement in the hydrostatic extrusion process. Figure 4.6 shows that the flow pattern is typical of streamline motion in a conventional extrusion process. 


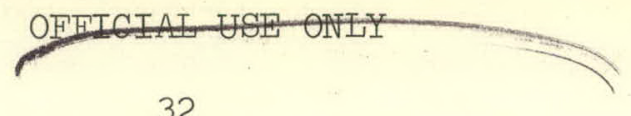

Table 4.5. Chemical Analyses of Hydrostatically Extruded SAP

\begin{tabular}{ccccc}
\hline & \multicolumn{4}{c}{ Chemical Content (wt \%) } \\
\cline { 2 - 5 } $\begin{array}{c}\mathrm{Al}_{2} \mathrm{O}_{3} \\
\text { Reduction }\end{array}$ & $\begin{array}{c}\text { (Fast Neutron } \\
\text { Activation } \\
\text { Analysis) }\end{array}$ & $\begin{array}{c}\mathrm{Al}_{2} \mathrm{O}_{3} \\
\text { (Aqueous } \\
\mathrm{HCl} \text { ) }\end{array}$ & $\mathrm{H}$ & $\mathrm{C}$ \\
\hline $10: 1$ & 8.58 & 4.13 & 0.15 & 0.29 \\
$20: 1$ & 7.99 & 3.85 & 0.17 & 0.27 \\
\hline
\end{tabular}

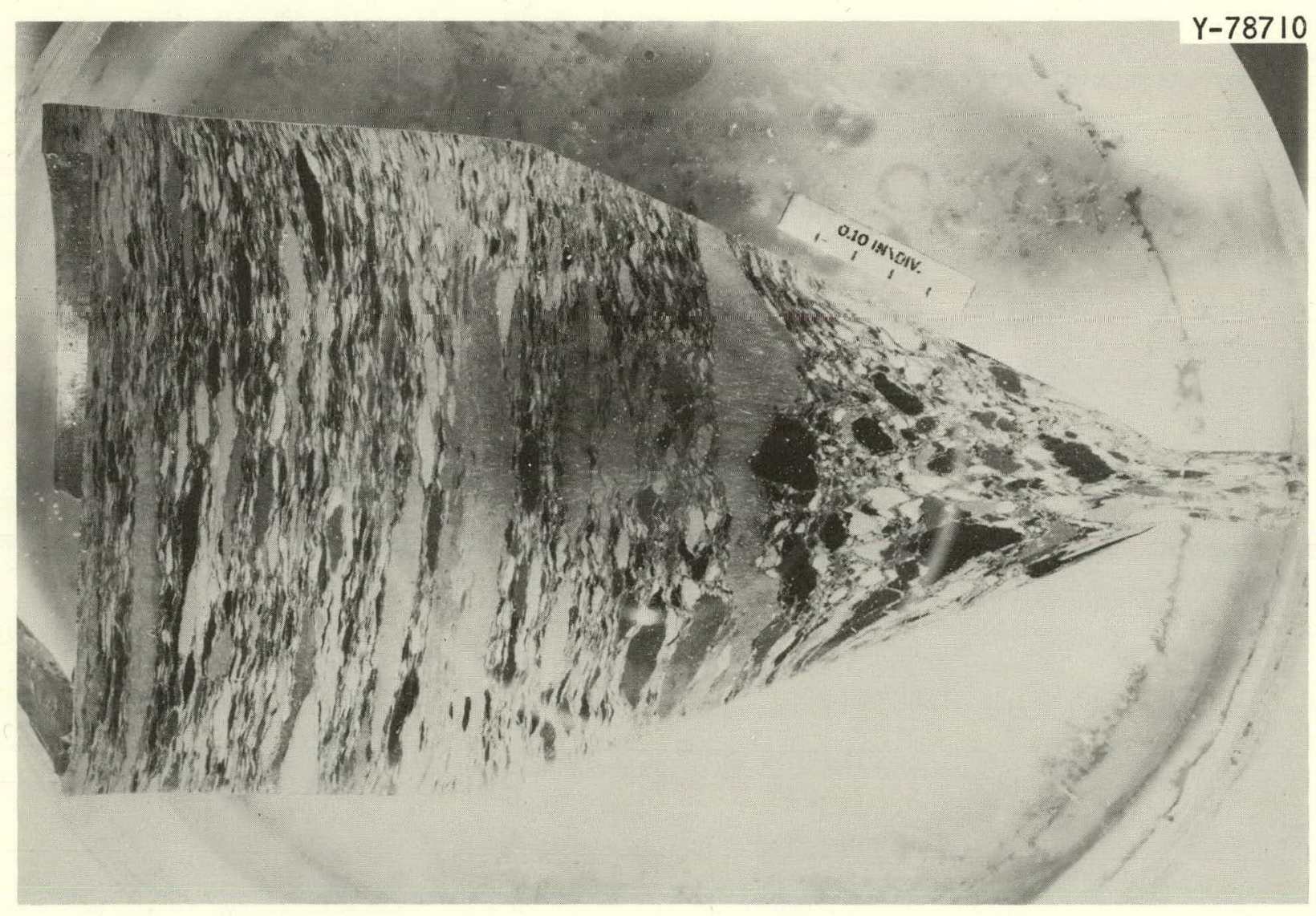

Fig. 4.6. Stalled 40:1 Reduction Ratio Hydrostatic Extrusion.

Mechanical properties from these billels are given in Table 4.6. Thenc properties indicate that cold hydrostatic extrusion would not be beneficial for improving SAP properties. 
Table 4.6. Mechanical Properties of Hydrostatically Extruded SAP ${ }^{a}$

\begin{tabular}{|c|c|c|c|c|}
\hline \multirow{4}{*}{$\begin{array}{l}\text { Reduction } \\
\text { Ratio }\end{array}$} & \multicolumn{4}{|c|}{$\begin{array}{l}\text { Properties at } 450^{\circ} \mathrm{C} \text { and } \\
\text { a Strain Rate of } 0.0002 \mathrm{~min}^{-1}\end{array}$} \\
\hline & \multirow{2}{*}{\multicolumn{2}{|c|}{ Elongation (\%) }} & \multirow{3}{*}{$\frac{\text { Strength }}{\text { Yield, }}$} & \multirow{3}{*}{$\begin{array}{l}\frac{(p s i)}{\text { Ultimate }} \\
\text { Tensile }\end{array}$} \\
\hline & & & & \\
\hline & Total & Uniform & & \\
\hline 10:1 & 0.45 & 0.45 & 6800 & 7400 \\
\hline $20: 1$ & 0.39 & 0.39 & 7050 & 7550 \\
\hline
\end{tabular}

${ }^{a}$ All values average of two tests.

Evaluation of Product

Commercial Alloys (M. M. Martin, D. H. Turner)

Recent commercially produced SAP 895, SAP 930, and XAP-005 samples were obtained from Atomics International and are being evaluated to provide base-line data for the SAP development effort. Sections from the nose, center, and tail of 2-in.-diam, l8-ft-long commercially extruded bars were obtained. These are being evaluated both in the asreceived condition and after reextruding the bar samples to 3/8-in.-diam rod. Only cursory evaluations of: SAP 930 and XAP-005 are being performed since the emphasis of the development program is upon developing a process yielding a product with properties equivalent to or better than SAP 895.

Mechanical properties of the reextruded commercial products were delermined al $450^{\circ} \mathrm{C}$ and a strain rate of $0.0002 \mathrm{~min}^{-1}$. 'l'he mechanical properties are summarized in Table 4.7. Expected variation of the ultimate strength at 95-95 confidence limits was calculated for the tests completed and are included in the table. The higher variability of the SAP 930 and XAP-005 is probably attributable to the fewer number of tests performed. Both the uniform and total elongation of the XAP-005 were surprisingly high. Chemical analyses of the commercial products are presented in Table 4.8. The high carbon content of the XAP-005, 0.593\%, does not appear detrimental when the mechanical properties of the various materials are compared. 
Table 4.7. Mechanical Properties of SAP Products Extruded at ORNL to 3/8-in.-diam Rod ${ }^{2}$

\begin{tabular}{|c|c|c|c|c|c|c|c|}
\hline \multirow{3}{*}{$\begin{array}{l}\text { Alloy and } \\
\text { Billet } \\
\text { Source }\end{array}$} & \multirow{3}{*}{$\begin{array}{l}\text { Number } \\
\text { of } \\
\text { Tests }\end{array}$} & \multicolumn{2}{|c|}{ Elongation (\%) } & \multicolumn{2}{|c|}{ Strength (psi) } & \multirow{2}{*}{\multicolumn{2}{|c|}{$\begin{array}{l}\text { Expected Varia- } \\
\text { tion of UTS } \\
\text { 95-95 Limits }\end{array}$}} \\
\hline & & \multirow[t]{2}{*}{ Uniform } & \multirow[t]{2}{*}{ Total } & \multirow{2}{*}{$\begin{array}{c}\text { Yield } \\
0.2 \% \text { Offset }\end{array}$} & \multirow{2}{*}{$\begin{array}{l}\text { Ultimate } \\
\text { Tensile }\end{array}$} & & \\
\hline & & & & & & (psi) & $(\%)$ \\
\hline \multicolumn{8}{|l|}{ SAP 895} \\
\hline Nose & 6 & 0.91 & 1.2 & 11,135 & 12,460 & & \\
\hline Center & 6 & 0.76 & 1.1 & 11,070 & 12,415 & & \\
\hline Tail & 6 & 0.65 & 1.0 & 11,470 & 12,130 & & \\
\hline \multicolumn{2}{|c|}{ average } & 0.77 & $\overline{1.1}$ & 11,225 & 12,335 & \pm 805 & \pm 6.5 \\
\hline \multicolumn{8}{|l|}{ SAF 930} \\
\hline Nose & 3 & 0.81 & 1.29 & 8,275 & 8,945 & & \\
\hline Center & 3 & 11.68 & 1.45 & $x, 460$ & $y, \perp 05$ & & \\
\hline Tail & 3 & 0.76 & 1.92 & $8,8 \cup 3$ & y, 363 & & \\
\hline \multicolumn{2}{|c|}{ average } & $\overline{0.75}$ & $\overline{1.56}$ & 8,495 & 9,205 & \pm 1165 & \pm 12.7 \\
\hline \multicolumn{8}{|l|}{ XAP- 005} \\
\hline Nose & 3 & 0.96 & 1.65 & 8,845 & 9,505 & & \\
\hline Center & 3 & 1.11 & 1.81 & 8,910 & 9,515 & & \\
\hline Tail & 3 & 1.12 & 1.94 & 8,975 & 9,910 & & \\
\hline \multicolumn{2}{|c|}{ average } & $\overline{1.06}$ & $\overline{1.80}$ & 8,910 & 9,645 & \pm 920 & 9.5 \\
\hline
\end{tabular}

$a_{\text {Tested at }} 450^{\circ} \mathrm{C}$ and $0.0002 \mathrm{~min}^{-1}$ strain rate.

$\mathrm{b}_{95 \%}$ confident that $95 \%$ of the material is within these limits.

Table 4.8. Chemical Analyses of Commercial SAP Products

\begin{tabular}{|c|c|c|c|c|}
\hline \multirow[b]{2}{*}{$\begin{array}{l}\text { Alloy and } \\
\text { Billet } \\
\text { Source }\end{array}$} & \multicolumn{4}{|c|}{ Chemira.7 Cnnt,ent, (wt, \%) } \\
\hline & $\begin{array}{c}\mathrm{Al}_{2} \mathrm{O}_{3} \\
\text { (Fast Neutron } \\
\text { Activation } \\
\text { Analysis) }\end{array}$ & $\mathrm{Fe}$ & $\mathrm{C}$ & $\mathrm{H}$ \\
\hline \multicolumn{5}{|l|}{ SAP 895} \\
\hline $\begin{array}{l}\text { Nose } \\
\text { Center } \\
\text { Tail }\end{array}$ & $\begin{array}{l}11.43 \\
11.79 \\
10.86\end{array}$ & $\begin{array}{l}0.060 \\
0.060 \\
0.057\end{array}$ & $\begin{array}{l}0.248 \\
0.144 \\
0.244\end{array}$ & $\begin{array}{l}0.0001 \\
0.0001 \\
0.0003\end{array}$ \\
\hline average & $\overline{11.36}$ & $\overline{0.059}$ & $\overline{0.212}$ & $\overline{0.0002}$ \\
\hline \multicolumn{5}{|l|}{$\mathrm{S} \Lambda \mathrm{P} \quad 230$} \\
\hline $\begin{array}{l}\text { Nose } \\
\text { Center } \\
\text { Tail }\end{array}$ & $\begin{array}{l}7.03 \\
6.97 \\
6.99\end{array}$ & $\begin{array}{l}0.053 \\
0.056 \\
0.050\end{array}$ & $\begin{array}{l}0.191 \\
0.173 \\
0.180\end{array}$ & $\begin{array}{l}0.0001 \\
0.0001 \\
0.0001\end{array}$ \\
\hline average & 7.00 & $\overline{0.053}$ & $\overline{0.181}$ & $\overline{0.0001}$ \\
\hline \multicolumn{5}{|l|}{ XAP-005 } \\
\hline Nose & 5.99 & $0.05 ?$ & 0.566 & 0.0005 \\
\hline Center & 6.04 & 0.050 & 0.693 & $0.0004_{4}$ \\
\hline Tail & 5.97 & 0.048 & 0.520 & 0.0004 \\
\hline average & $\overline{6.00}$ & $\overline{0.050}$ & $\overline{0.593}$ & $\overline{0.0004}$ \\
\hline
\end{tabular}


Thermal stability of SAP 895 was also evaluated. Mechanical properties of material reextruded and subsequently vacuum annealed for $3 \mathrm{hr}$ at $600^{\circ} \mathrm{C}$ were detcrmined at $450^{\circ} \mathrm{C}$ at a strain rate of $0.0002 \mathrm{~min}^{-1}$. No degradation of properties resulted from the 3-hr anneal. A 40-hr vacuum anneal at $600^{\circ} \mathrm{C}$, however, resulted in some degradation of ultimate strength but did not affect yield strength or ductility under the same test conditions. The results of these experiments are given in Table 4.9.

Table 4.9. Effect of Vacuum Annealing on the Mechanical Properties of Reextruded SAP $895^{\circ}$

\begin{tabular}{|c|c|c|c|c|}
\hline \multirow[b]{2}{*}{ Condition } & \multicolumn{2}{|c|}{ Strength (psi) } & \multicolumn{2}{|c|}{ Elongation (\%) } \\
\hline & $\begin{array}{l}\text { Ultimate } \\
\text { Tensile }\end{array}$ & $\begin{array}{r}0.2 \% \\
\text { Yield }\end{array}$ & Total & Uniform \\
\hline As extruded & 12,520 & 11,010 & 1.3 & 0.86 \\
\hline $\begin{array}{l}\text { Vacuum annealed } 3 \mathrm{hr} \text { at } \\
600^{\circ} \mathrm{C}\end{array}$ & 12,080 & 11,530 & 1.0 & 0.56 \\
\hline $\begin{array}{l}\text { Vacuum annealed } 40 \mathrm{hr} \text { at } \\
600^{\circ} \mathrm{C}\end{array}$ & 11,790 & 11,120 & 1.2 & 0.69 \\
\hline
\end{tabular}

a Properties determined at $450^{\circ} \mathrm{C}$ and a strain rate of $0.0002 \mathrm{~min}^{-1}$.

Fracture Studies (D. G. Harman, T. A. Nolan ${ }^{2}$ )

A unique fractographic analysis technique has been developed to study the initiation and propagation of the high-temperature fracture of SAP-type alloys. The formation of voids at the $\mathrm{Al}_{2} \mathrm{O}_{3}$ sites early in the high-temperature tensile test has been verified and their growth throughout the fracture process has been studied.

Essentially the study involves the fractographic analysis of lowtemperature fractures of XAP 001 specimens that were prestrained various amounts at elevated temperature. This technique is feasible because of the significant difference in appearance of fractures occurring at different temperatures for SAP alloys.

\footnotetext{
${ }^{2}$ Physics Group, Oak Ridge Gaseous Diffusion Plant.
} 


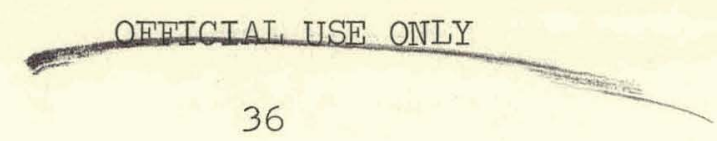

Electron micrographs obtained from the fracture replicas of the specimens tensile tested completely at 450 and $-200^{\circ} \mathrm{C}$ are shown in Figs. 4.7 and 4.8, respectively. A dramatic difference in size of the features is readily apparent as the two fractographs are the same magnification. Both specimens exhibit the same process of void linking but on a different size scale.

Figures 4.9 through 4.11 show fractographs of specimens that were prestrained $0.2,1.0$, and $1.6 \%$ at $450^{\circ} \mathrm{C}$ and then pulled to fracture at $-200^{\circ} \mathrm{C}$. These electron micrographs show fracture cavities ranging from 2 to $5 \mu$ in diameter with their size increasing with increasing strain at $450^{\circ} \mathrm{C}$. The larger features are areas that had fractured at the higher temperature and are surrounded by fine-scale $-200^{\circ} \mathrm{C}$ fracture features.

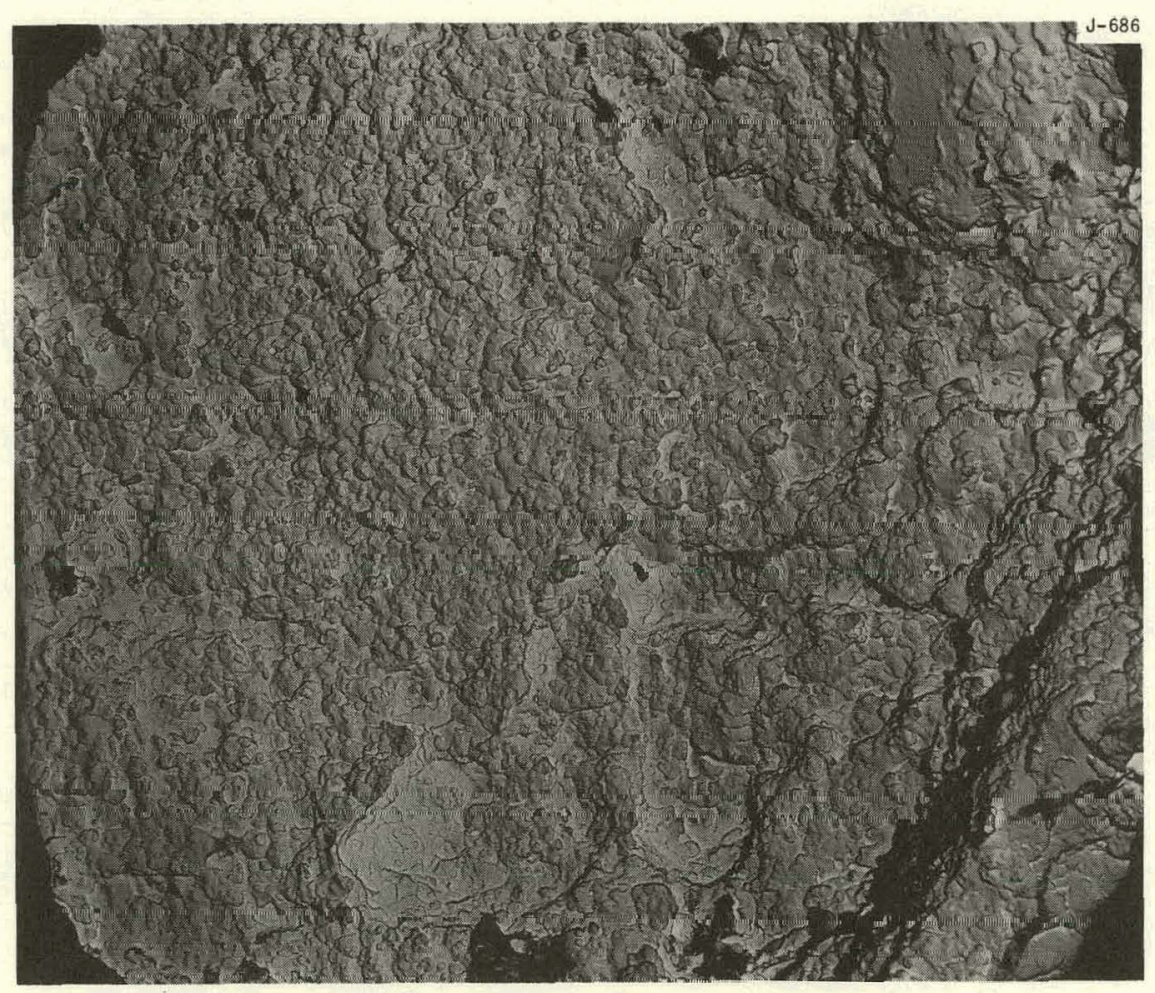

Fig. 4.7. Fractograph Showing Liquid Nitrogen $\left(-200^{\circ} \mathrm{C}\right)$ Fracture of SAP. Longitudinal specimen of commercia $\perp$ XAY 001 was tensile tested irl liquid nitrogen at $0.02 \mathrm{~min}^{-1}$. 6500x. Reduced 51\%. 


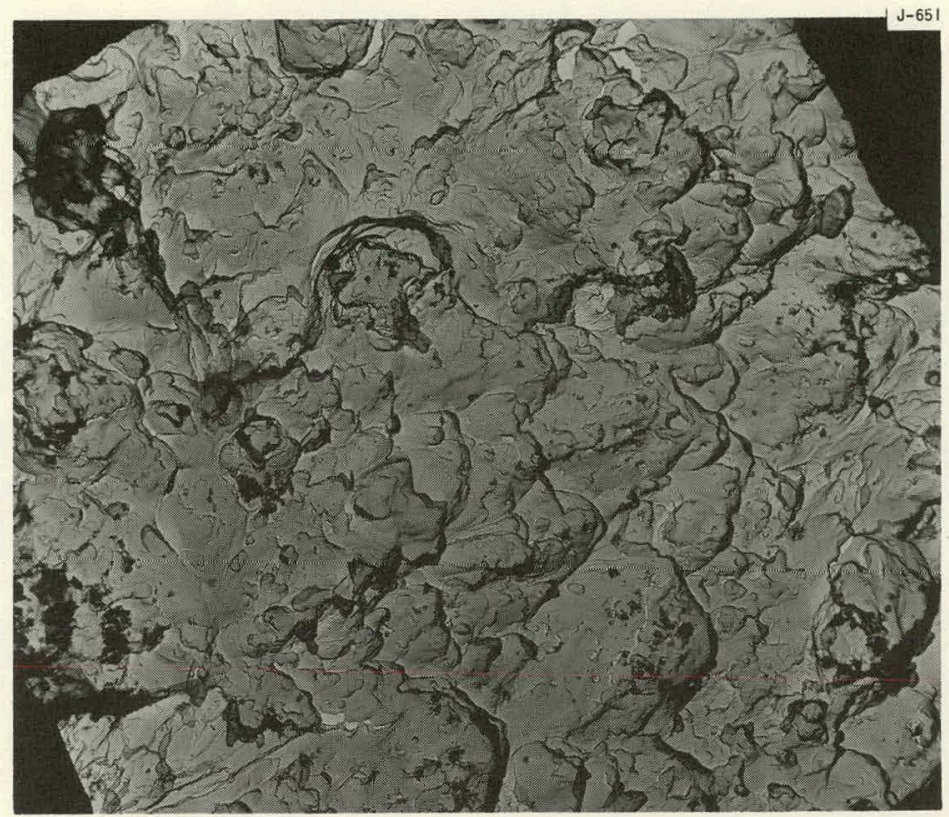

Fig. 4.8. Fractograph Showing $450^{\circ} \mathrm{C}$ Fracture of SAP. Longitudinal specimen of commercial XAP 001 was tensile tested at $450^{\circ} \mathrm{C}$ at $0.002 \mathrm{~min}^{-1}$. 6500x. Reduced 56.5\%.

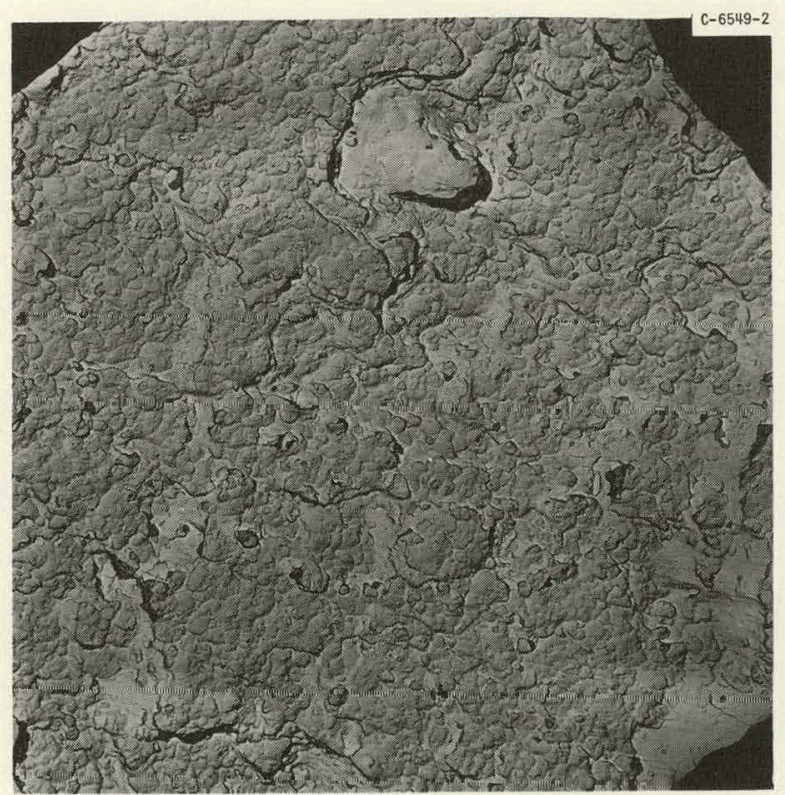

Fig. 4.9. Fractograph Showing Fracture Initiation after $0.2 \%$ Elongation. Commercial XAP 001 was strained $0.2 \%$ at $450^{\circ} \mathrm{C}$ and $0.002 \mathrm{~min}^{-1}$, then fractured in liquid nitrogen $\left(-200^{\circ} \mathrm{C}\right)$ at $0.02 \mathrm{~min}^{-1}$. The void at the upper center had opened up during the small amount of high-temperature deformation. 6500x. Reduced 58.5\%. 

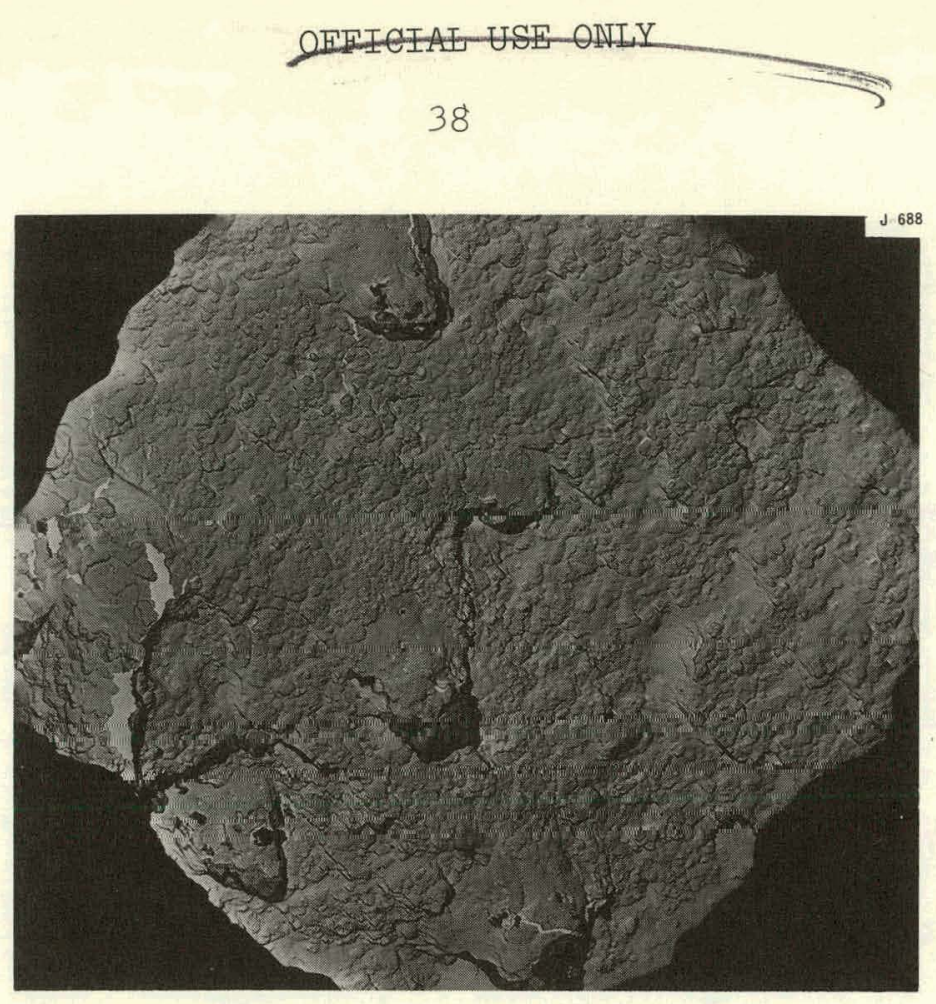

Fig. 4.10. Fractograph Showing Extent of Fracture after 1.0\% Elongation. Commercial XAP 001 was strained $1.0 \%$ at $450^{\circ} \mathrm{C}, 0.002 \mathrm{~min}^{-1}$, then fractured in liquid nitrogen $\left(-200^{\circ} \mathrm{C}\right)$ at $0.02 \mathrm{~min}^{-1}$. The hightemperature deformation voids have increased in both size and density. $6500 \times$. Reduced 59\%.

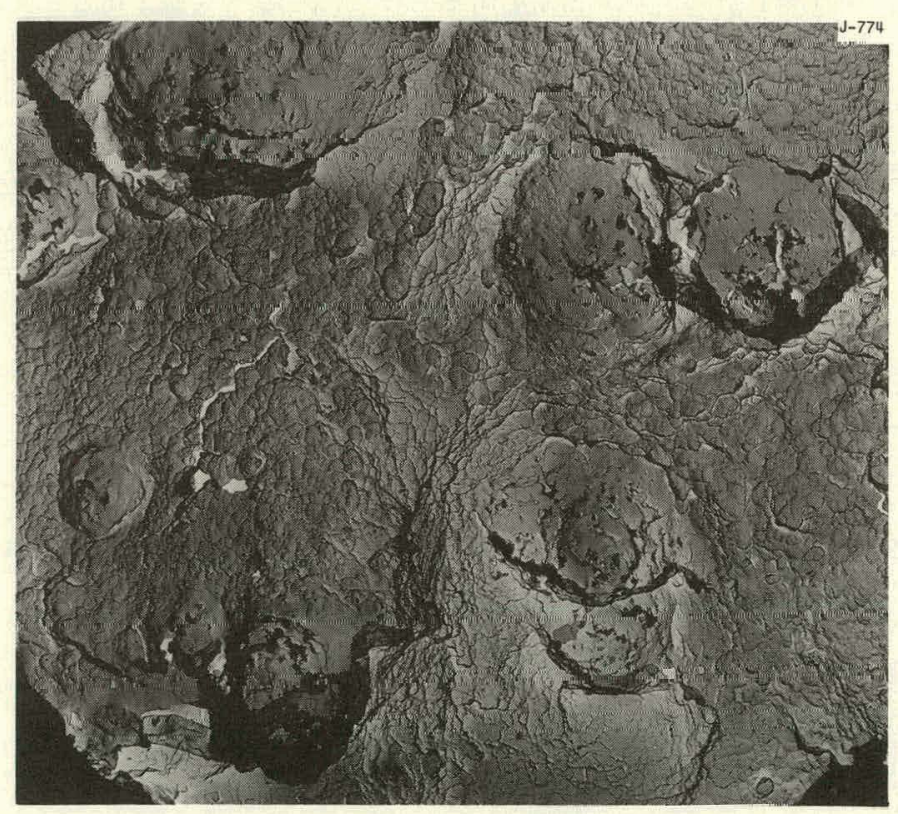

Fig. 4.11. Fractograph Showing Extent of Fracture after 1.6\% Elongation. Commercial XAP 001 was strained $1.6 \%$ at $450^{\circ} \mathrm{C} 0.002 \mathrm{~min}^{-1}$, then fractured in liquid nitrogen $\left(-200^{\circ} \mathrm{C}\right)$ at $0.02 \mathrm{~min}^{-1}$. The hightemperature strain has resulted in voids of up to $5 \mu$ in diameter. 6500x. Reduced 57.5\%. 
Figure 4.12 shows a fractograph from a specimen prestrained nearly to failure ( $2 \%$ elongation) at $450^{\circ} \mathrm{C}$ followed by the $-200^{\circ} \mathrm{C}$ fracture. Large voids are shown to have linked up over an extensive portion of the cross section during the high-temperature deformation. The flake particles visible in some of the cavities were found at all levels of prestrain and were identified as oxide particles that had adhered to the plastic replica during replication. Their presence and appearance illustrate that the high-temperature fracture of XAP 001 initiates at the oxide-rich sites and that the entire oxide-matrix interface has fractured.

Two MD 3100 specimens that had been creep tested at $450^{\circ} \mathrm{C}$ for 2150 and $3000 \mathrm{hr}$, respectively, and then fractured at $-200^{\circ} \mathrm{C}$ also showed the high-temperature voids.

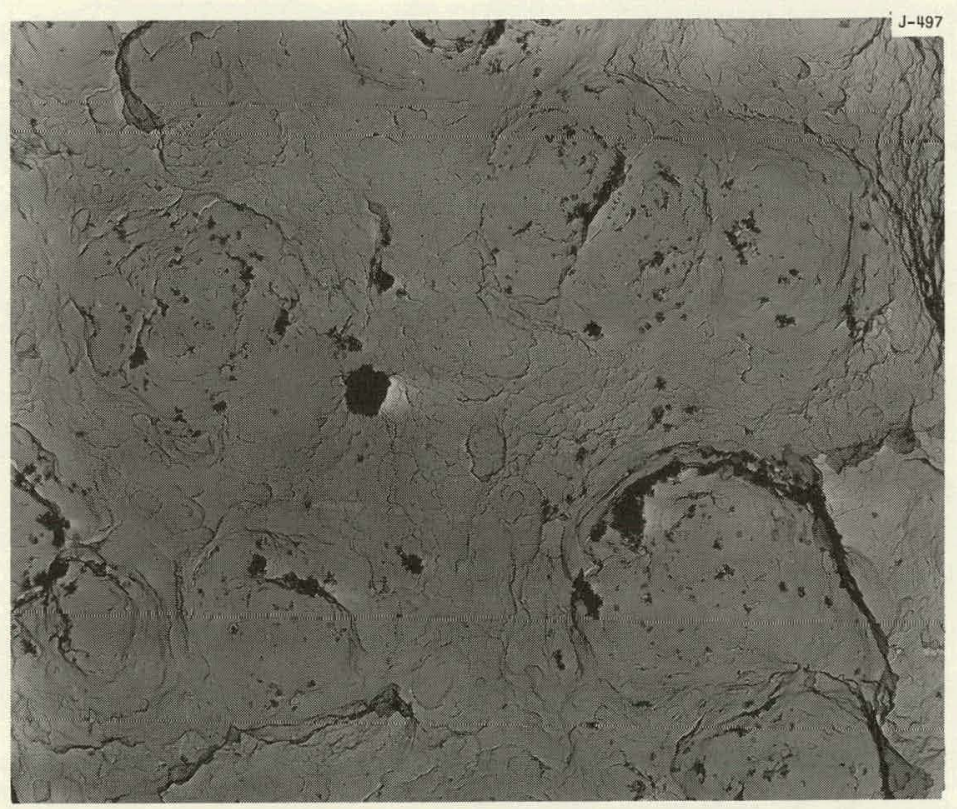

Fig. 4.12. Fractograph Showing Extent of Fracture after 2.0\% Elongation. Commercial XAP 001 was strained nearly to fracture at $450^{\circ} \mathrm{C}$ then fractured in liquid nitrogen $\left(-200^{\circ} \mathrm{C}\right)$. The voids have grown very large and linked up over much of the cross section. 6500x. Reduced 57\%. 


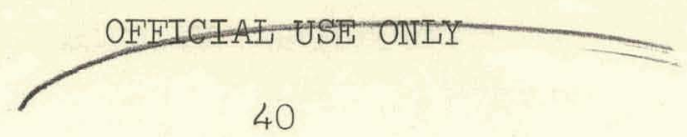

Nondestructive Test Development (H. L. Whaley)

We have been concerned with development of systems and techniques for determination of flake thickness and oxide content of the aluminum powders. An air-settling device is being developed for the flake-thickness measurements, and eddy-current conductivity measurements on fused compacts of SAP are being employed on the oxide content problem.

The low-pressure lucite $b_{0 x}{ }^{3}$ needed to facilitate quicker settling of the SAP flakes was received in early January and was readily sealed over the pressure range of interest (about -25 to -28 in. mercury). There were several obstacles associated with operation of the powder dispersing and collecting system at low pressure. A heat sink had to be devised to prevent overheating of the horizontal-air-flow fan when operated at low pressure. The high-speed brush-type alternating-current motor used for dispersing the powder became inoperative after several hours of use at about $-2 \%$. in. of mercury. This failure was traced to extreme armature wear because of the lack of sufficient oxygen. A small 12-v, 15,000-rpm motor designed for low-pressure applications was obtained. The original alternating-current dispersing motor had been used to rotate a small wire bristle brush to get the powder airborne. However, a balanced system could not be obtained using this brush with the $12-v$ direct-current motor because of the flexing of the bristles as the motor changed speed. Vibration which only caused an unpleasant noise level with the alternating-current motor could destroy the delicate bearings of the precision direct-current motor. A small propeller blade similar to that for a model boat was made and balanced for high speed with the direct-current motor. Using the propeller, dispersion could be initially obtained at the lowest desired pressures, but the flow of powder would essentially stop after only 1 or 2 min. Raising the pressure restored the flow only temporarily, and powder left in the dispersing chamber had a glossy, packed surface. To visually examine the difference in the powder dispersion with the brush and propeller, a small quantity

${ }^{3}$ H. L. Whaley, Fuels and Materials Development Program Quart. Progr. Rept. Dec. 31, 1966, ORNL-TM-1720, pp. 48-53. 


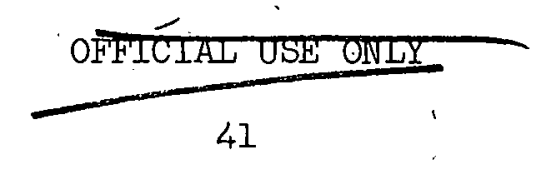

of powder was placed in a beaker, and both the propeller and brush were tested. The propeller produced a straight-ahead stream of air that tended to pack the powder while the brush created a corkscrew-type turbulence which sheared flakes off the surface of the powder, thus preventing packing.

An impeller device to produce a similar corkscrew turbulence was designed and machined. It worked well until the continued flexing of the blades caused metal fatigue and failure of the impeller. Finally, a heavy, 15,000-rpm, 24-v direct-current motor was obtained and fitted to the dispersing chamber to allow use of a brush with less concern about unbalance.

Samples of MD 3100 are now being successfully dispersed and collected at several pressures. Metallographic examination of the samples will allow establishment of the flake thickness versus settling position relationship.

A reproducible fusing technique for producing the SAP wafers for eddy-current determination of oxide content has not yet been achieved. Six fused wafers from the same batch of MD 3100 flake (nominal 6.3\% oxide, 1 in. in diameter, and approximately $0.100 \mathrm{in}$. thick, fused at $700^{\circ} \mathrm{C}$ for $15 \mathrm{~min}$ ) were examined. The geometrical density range was about 5\%. Radiographs revealed density variations on the order of 5 to 10\% within a given wafer. These variations in density cause corresponding variations in resistivity.

Resistivity measurements were performed at 50 and $500 \mathrm{ks}$. with the phase-sensitive eddy-current instrument. The average variation in the meter reading across the face of a wafer was seen to be equivalent to about a 3\% oxide variation (as determined by an earlier curve generated on sintered extrusion billets). This means that the apparent oxide content measured for a given wafer could vaiy as much as $3 \%$, depending upon the placement of the eddy-current probe on the sample. When the median value of the meter reading was taken for each wafer, the oxide range for the set of wafers from the same powder batch was about $4 \%$. When compacts can be reproducibly made at a given oxide content, compacts from powders of known oxide content over the oxide range of interest will be made for calibration purposes. 


\section{2 \\ Development of Advanced SAP Materials \\ G. L. Copeland' D. G. Harman}

The microstructure of the as-cast aluminum alloys ${ }^{4}$ containing molybdenum, iron, and zirconium showed relatively large intermetaliic compounds. Tensile tests of one of these alloys after swaging showed expected low strength. An attempt was made to reduce these intermetallics to a beneticial slze by ball milling filings of the cast alloy. The vacuum hot-pressed compacts containing this material broke during swaging so that no mechanical properties dala euuld bc obtained. Meliallography of the milled t'lake and pressed compact indicater that the intermetallics were still too large to enhance strength at high temperature. Thus, it appears that the alloys will have to be produced by a technique such as ribbon casting or atomizing to form fine particle size powder. An unsuccessful attempt was made to lucule a vondor willing to produce small batches of atomized aluminum alloys. Present plans are to build a small atomizer (approximately 5-1b batch) and to produce the alloys at URIVL.

${ }^{4}$ G. T. Copeland and D. G. Harman, Fuels and Materials Development Program Quart. Progr. Rept. Dec. 31, 1966, ORNL-TM-1720, p. 5T. 


\section{OFFICIAI USE ONIV}

5. ZIRCONIUM METALLURGY

\section{P. I. Rittenhouse}

This program is aimed at satisfying the increasingly severe service requirements being demanded of zirconium-base alloys in reactor environments. Most of our work is presently directed toward the effective use of the anisotropy of mechanical properties of alpha-zirconium alloys and the study of the oxidation-corrosion mechanisms. In particular, we are investigating: (1) the effects of fabrication variables on the resulting crystallographic texture; (2) the effect of texture on the anisotropy of mechanical properties in uniaxial and biaxial stress states; (3) the deformation systems operating in zirconium and its alloys as functions of stress relative to crystallographic directions, stress state, restraint to flow, temperature, and alloying additions; and (4) the mechanisms of the oxidation-corrosion processes from considerations of the mode of formation, rate of growth, composition, and structure of the corrosion films and the composition and crystallography of the underlying metal.

\section{Anisotropy in Zircaloy}

\section{P. L. Rittenhouse}

\section{Testing of Tubing}

Both of the electrohydraulice servo-controllers, the hcart of the testing apparatus, have developed serious stability deficiencies and have been returned to the manufacturer for complete overhaul. A new solid-state model servo-controller has been installed and allows us to. use the machine for testing in uniaxial stress states (tension, compression, or torsion). During the past quarter, compression tests have been run for six lots of Zircaloy tubing and tension and torsion tests are in progress on nine lots of this material. 
It is often more feasible to determine preferred orientation than to measure the mechanical properties in the thickness direction of thin sheet or the tangential and radial directions of tubing. Therefore, it is desirable that a correlation between mechanical properties and texture coefficients should be available. No quantitative correlations of this sort are found in the literature. We have used experimental tension and compression yield strengths from several lots of Zircaloy-2 sheet with known preferred orientation to provide the correlation shown in Fig. 5.1. Both the tension $\left(\sigma_{+i}^{\theta}\right)$ and compression $\left(\sigma_{-i}^{*}\right) 0.2 \%$ y'lelu sulumblis are given in terms of the texture coefficient $R_{(0001)}$, the intensity of basal poles parallel to the i direction. The least-squares fit for each set of data is shown in the figure. This correlation will be checked with data from tests on Zircaloy. tubing.

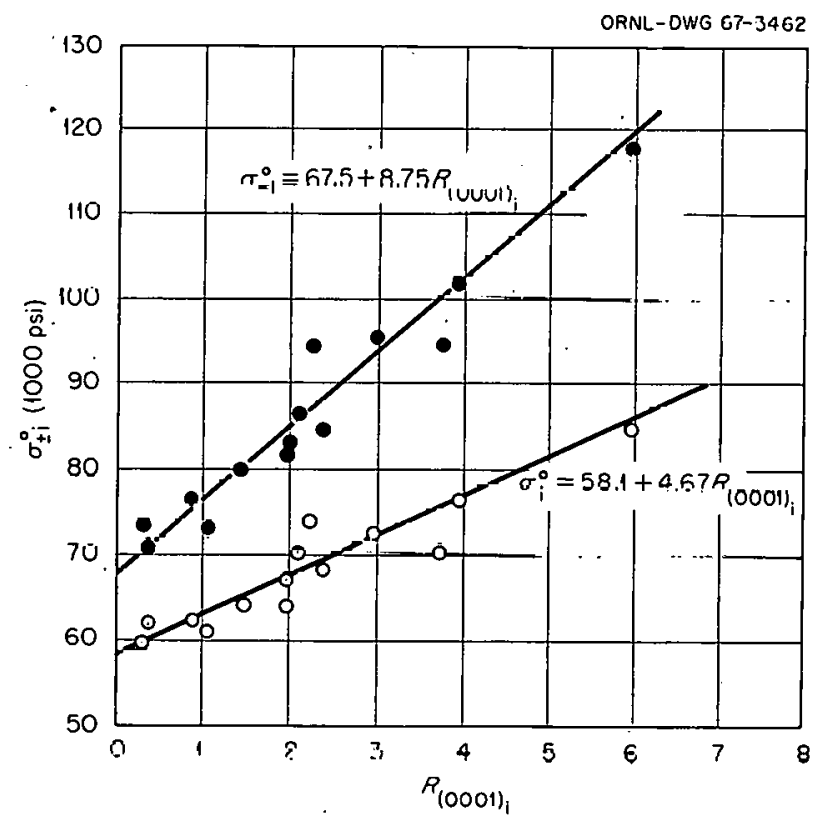

Fjg. 5.1. Correlation Between Yield Strength and Preferred Orientation for Zircaloy-2. 
Stress Orientation of Hydrides in Zircaloy

\author{
P. I. Rittenhouse
}

Temperature Cycling Under Load

Zirconium alloy components in reactor service will'be subjected to some unknown number of heating and cooling cycles during which hydrides may be dissolved and reprecipitated. It is also likely that the material will be under stress during the precipitation. In the past we have reported results for Zircaloy-2 specimens temperature cycled 20 times or less under an elastic stress of 15,000 psi (refs. 1-2). After 10 cycles and up to 20 cycles, the hydride pole intensity parallel to the stress direction increased threefold. We feared that this trend might continue and result in embrittlement with continued stress in the same direction. Specimens have since been run for as many as 88 cycles and indicate no further buildup of hydride platelets perpendicular to the stress direction.

Hydrides in Zircaloy Tubing

Pole figures for hydrides precipitated under no-load conditions have now been determined for 15 lots of annealed Zircaloy tubing. The recent results are consistent with the previously reported correlations between texture coefficients and hydride pole intensities. ${ }^{2}$ The fraction of hydride poles at any given orientation increases as the texture coefficient $\mathrm{R}_{(0001)}$ at that orientation increases. This is also consistent with results presented by Kearns and Woods. ${ }^{3}$

Specimens from these same lots of tubing have been tested for stress orientation of the hydrides. In each case, the hydrogen ( $150 \mathrm{ppm}$ ) was precipitated during cooling from $400^{\circ} \mathrm{C}$ under a tangential tensile

${ }^{1}$ P. I. Rittenhouse, Fuels and Materials Development Program. Quart. Progr. Rept. Sept. 30, 1965, ORNL-TM-1270, pp. 26-26.

'Ibid., Sept. 30, 1966, ORNL-TM-1700, p. 40.

${ }^{3}$ J. J. Kearns and C. R. Woods, "Effect of Texture, Grain Size, and Cold Work on the Precipitation of Oriented Hydrides in Zircaloy Tubing and P1ate," J. Nucl. Mater. 20, 241-261 (1966). 


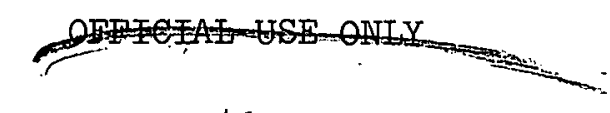

46

stress of $20,000 \mathrm{psi}$. The orientation of the hydride platelets (precipitated under zero stress) was essentially unchanged by the addition of the stress except when there was an appreciable concentration of basal poles parallel to the tangential direction $(\bar{\theta})$ and the ratio of the texture coefficient in the tangential direction to that in the radial direction $(\bar{R})$ was equal to or greater than unity. Figure 5.2 shows the distribution of hydride platelet traces on a section perpendicular to the tubing axis in two materials. Curves are shown for hydrides precipitated under zero stress and with a hoop stress of 20,000 psi. A random distribution of hydrides would have a uniform Normalized.Pole Zone Density 'of 1.0. Material WC-E has a tangential direction texture coefficient, $R_{(0001)}$, of 0.5 and $R(0001)-/ R(0001)-\frac{1}{\bar{R}}$ equal to 0.25 . For WC-G $\mathrm{R}_{(0001)_{\bar{\theta}}}$ is 1.5 and the texture coefficient $\mathrm{R}_{\text {ratio }}$ is 1.0 . The hydride trace distribution in WC-E is relatively unchanged by precipitation under stress, but that in WC-G is biased toward the hydrides being

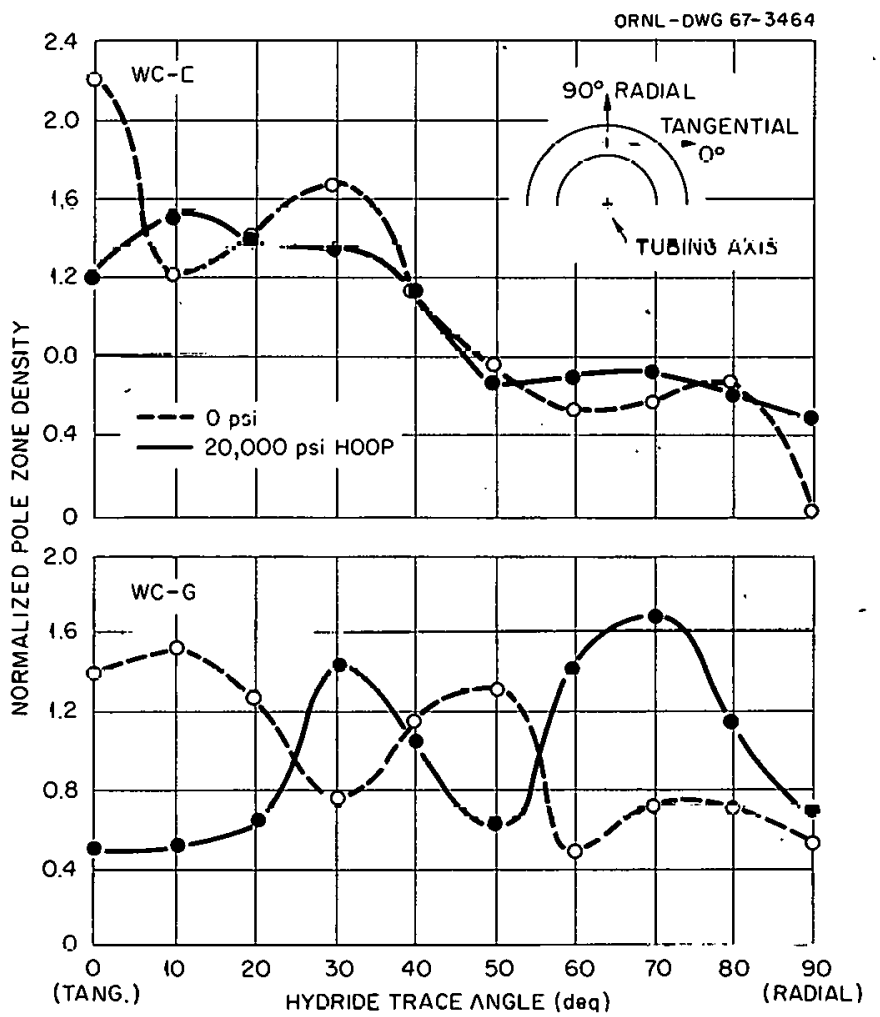
Tubing.

Fig. 5.2. Hydride Platelet Distribution in Two Lots of Zircaloy 
parallel to the radial direction. These observations are consistent with those which we have reported for sheet material ${ }^{4}$ and those reported for Zircaloy-4 tubing by Kearns and Woods. ${ }^{3}$

\section{Zirconium and Zirconium Alloy Deformation}

\section{O. Hobson}

\section{Equipment}

One of the problems associated with the testing of single crystals is the cutting and shaping of crystals without deformation. The electrical-discharge machine is admirably suited to such work since it applies little or no stress to the body of the specimen. A portion of this past quarter has been devoted to modifying our existing spark cutter to use a moving wire as the cutting tool rather than the previously used brass blades. This modification enables us to make cuts of more uniform width and to greater depths than was possible with the blades.

The circuitry of the spark cutter was modified to detect shorting between the wire and the specimen. After the short has been established for a predetermined length of time, the current through the short is cut and a vibrator is activated to break the short. This has greatly increased cutting speed.

The elevated-temperature shear jig discussed in the last report of this series should be ready for use during the next quarter. We believe that testing at elevated temperature will eliminate the profuse twinning that is encountered at room temperature and allow us to test for the existerice of. $\langle 11 \overline{2} 3\rangle$ slip.

\section{Single-Crystal Tests}

In addition to testing zirconium single crystals and polycrystalline specimens of zirconium and Zircaloy-2, we have begun to examine the deformation behavior of single.crystals of Zircaloy-2 and Zircaloy-4.

${ }^{4}$ P. L. Rittenhouse and M. I. Picklesimer, Precipitation of Hydrides in Zircaloy-2 as Affected by Preferred Orientation, Elastic Stress, and Hydrogen Content, ORNL=TM-1239 (Sept, ember 1965). 
The crystals were grown in tubular material by an electron-beam technique. ${ }^{5}$ Tensile specimens of "zircaloy-2 have been spark machined and two of them tested to determine yield strength and critical resolved shear stress. The first test was ended when the specimen slipped in the end grips but the second test was successful and gave the curve shown in Fig. 5.3. This, to our knowledge, is the first test of this kind performed on this alloy. There appears, to be a yield point at 39,000 psi. This is also the maximum engineering or ultimate strength. Past this point the load falls off slowly and then remains constant for elongation greater than $40 \%$. On rechecking the chart for the first specimen, we saw that yielding had occurred before the grips had slipped. The yield point was found to be 38,500 psi.

The schmid factors for the three $\{10 \overline{1} 0\}^{\prime}\langle 11 \overline{2} 0\rangle$ slip systems were calculated and the maximum was found to be 0.478 . This gave a critical resolved shear stress of $18,600 \mathrm{psi}$. This is very much higher than that

. ${ }^{5}$ J. C. Wilson, Fuels and Materials Development Program Quart. Progr. Rept. Mar. 31, 1966, ORNL-TM-1500, pp. 53-54.

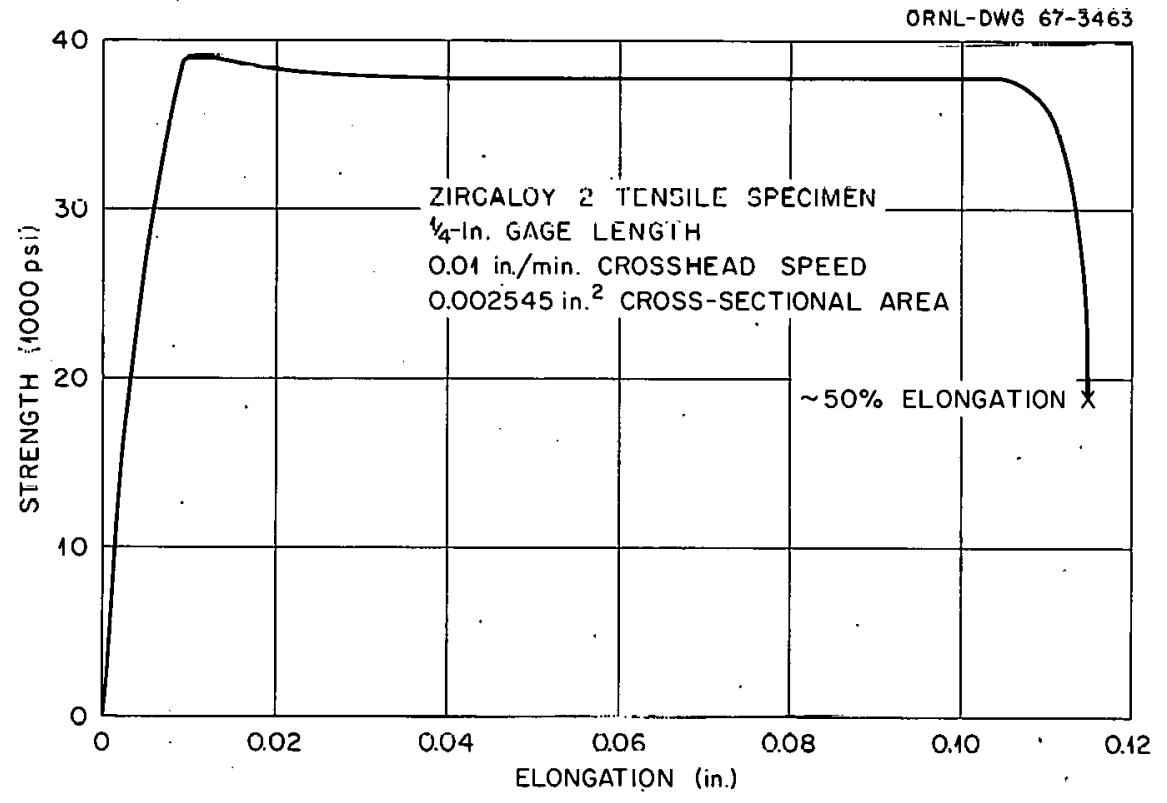

Fig. 5.3. Load-Elongation Curve for a Zircaloy-2 Single Crystal Tested in Tension. 
reported by Rapperport ${ }^{6}$ for unalloyed zirconium $\left(0.65 \mathrm{~kg} / \mathrm{mm}^{2}\right.$ or $\left.924 \mathrm{psi}\right)$. The value for Zircaloy-2 may not be unrealistic as $1 \%$ alloying additions to some pure materials raise the critical resolved shear stress by a factor of 12 to 15 . Zircaloy-2 contains almost $2 \%$ of deliberate additions of $\mathrm{Sn}, \mathrm{Fe}, \mathrm{Ni}, \mathrm{Cr}$, and $\mathrm{O}_{2}$. Additional tension and compression specimens of the Zircaloys are being prepared and will be tested in the next quarter.

Inhibition of Oxidation by Anodic Films

J. C. Wilson

Preliminary experiments ${ }^{7}$ had shown that the oxidation of zirconium in $500^{\circ} \mathrm{C}$ ( $1 \mathrm{~atm}$ ) steam could be inhibited by preanodizing the metal to incorporate phosphorus into the anodic oxide film. We have found that the inhibiting effect persists after $64 \mathrm{hr}$ (where weight gains for an unanodized sample exceed $70 \mathrm{mg} / \mathrm{dm}^{2}$ ) and that the morphology of the thermally formed oxide is altered by the anodizing.

Arc-melted crystal-bar zirconium sheet, $0.02 \mathrm{in}$. thick, was used in both as-rolled and annealed $\left(4 \mathrm{hr}\right.$ at $800^{\circ} \mathrm{C}$ in $5 \times 10^{-8}$ vacuum $)$ conditions. The specimen surfaces were prepared by chemical polishing in a mixture of $46 \% \mathrm{H}_{2} \mathrm{O}-46 \% \mathrm{HNO}_{3}-8 \% \mathrm{HF}$ or by electropolishing at $30 \mathrm{v}$ in a methanol-2\% $\mathrm{HClO}_{4}$ solution at $-70^{\circ} \mathrm{C}$. Anodizing was done in a phosphoric acid solution 8 at $30 \mathrm{v}$ or in $1 \%$ aqueous $\mathrm{KOH}$ at $21 \mathrm{v}$ to form films approximately $660 \mathrm{~A}$ thick $\left(I^{\circ} \mathrm{mg} / \mathrm{dm}^{2}\right)$.

Figure 5.4 shows that the weight gains for annealed specimens preanodized in the phosphoric acid solution are significantly reduced. After $64 \mathrm{hr}$ the weight gain is less than half that of unanodized specimens and those anodized in $\mathrm{KOH}$. A similar trend was observed for other combinations of epecimen condition and surface treatment. The data from

${ }^{6} \mathrm{E}$." J. Rapperport, "Room Temperature Deformation Processes in Zirconium," Acta Met. ㄱ, 254-261 (April 1959).

${ }^{7} \mathrm{~J}$. C. Wilson, Fuels and Materials Development Program Quart. Progr. Rept. Dec. 31, 1966, ORNL-TM-1720, p. 72

${ }^{8}$ M. T. Picklesimer, Anodizing as a Metallographic Technique for Zirconium-Base Alloys, ORNL-2296 (Apríl 26, 195\%). 


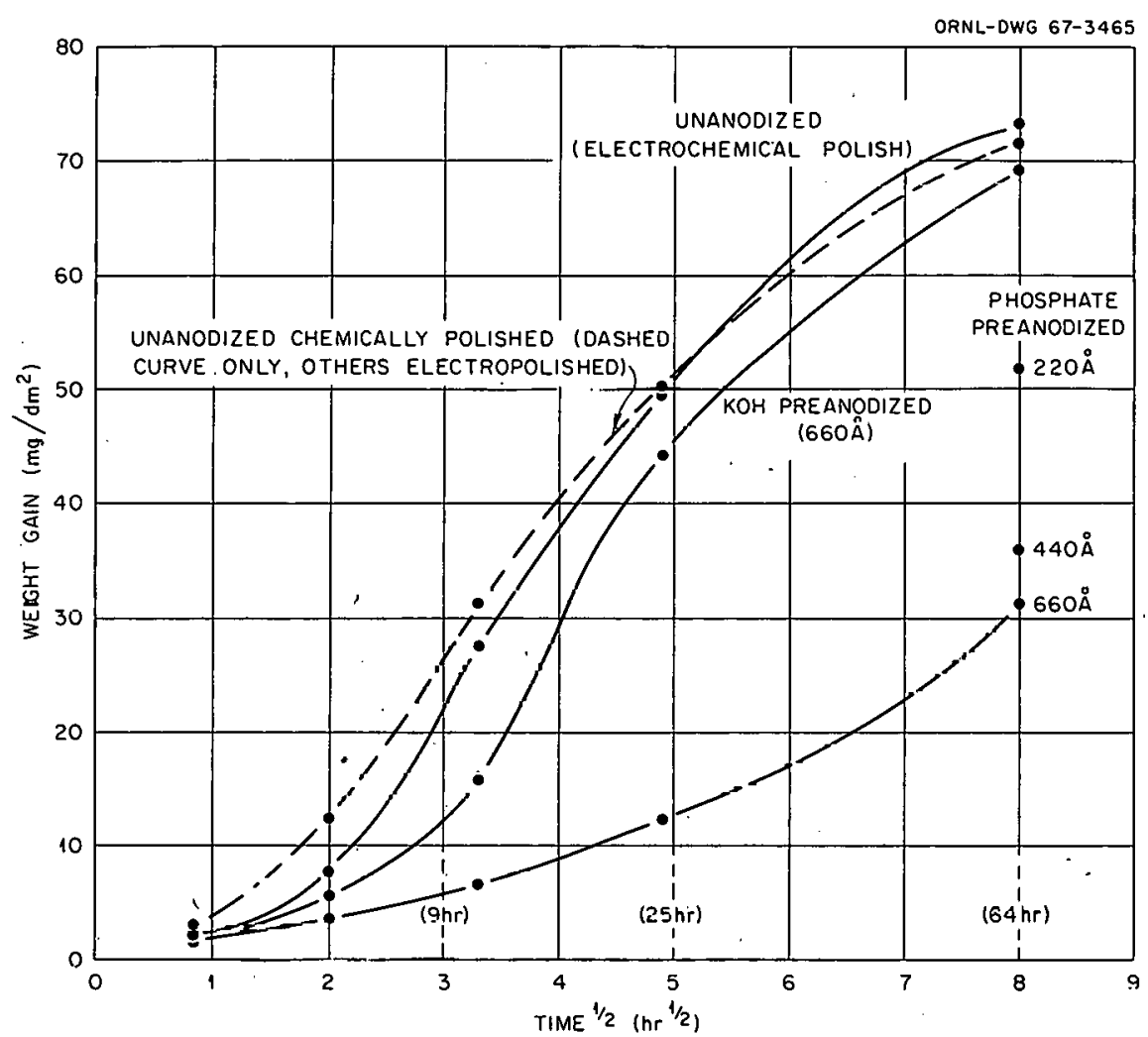

Fig. 5.4. Weight Gain in $500^{\circ} \mathrm{C}$ Steam for Annealed Zirconium Specimens. These curves demonstrate the inhibiting effect of a preanodized film (660 A, I mg/ $\mathrm{dm}^{2}$ ) containing phosphorus. The anodized film formed in $\mathrm{KOH}$ contains no detectable foreign elements, and little cffect on welght gain is observed. The two added points at $64 \mathrm{hr}$ show that phosphorus-containing films only 220 and $44 n$ A thick aldo reduce the wef ght. gain.

the annealed and electropolished specimens are thought to be the most representative of the true behavior. Extrapolation of the data suggests that the inhibiting effect of preanodizing should not be lost until times greater than $300 \mathrm{hr}$. Two additional points on Fig. 5.4 show that Eve'́n 220- and 44U-A-thick preanodized films significantly reduce the weight gains.

Microsicopic examination of specimens preanodized in phosphate solutions showed that both the number and size of the pustules (mounds of thick oxide that characteristically form on slowly oxidizing orientations after a few hours exposiure) were reduccd. The ralie of growth of the thick oxide network on or above grain boundaries was also reduced, and the time required for the formation of smooth gray oxide on 
orientations that oxidize rapidly was increased. The growth rate of the "uniform" film on initially slowly oxidizing orientations is probably less, but this must be confirmed by interference spectrophotometry.

In a separate experiment with coarse-grained (3- to 5-mm-diam grain) crystal-bar zirconium containing 500 to $1000 \mathrm{ppm} \mathrm{H}_{2}$ as large hydrides, we observed that the pustule-like growth of oxide on the hydrides was less for specimens preanodized in the phosphate solution.

From the above it appears that the inhibiting effect of preanodizing works to some extent on all of the several modes or forms of oxide growth that we have identified for zirconium in $500^{\circ} \mathrm{C}$ steam. How these thin films of phosphoms-containing oxide are able to inhibit oxidation in films 30 times thicker than the original preanodized film is not yet known. Sano' suggested that pentavalent or hexavalent cations should decrease the anion vacaricy concentration in the oxide and, therefore, transport of oxygen through the oxide to the metal. Phosphorus, if present in the pentavalent state, should slow the diffusion of oxygen through the oxide.

Banter 10 found that sulfur (as well as phosphorus) could be incorporated into the anodic film. Preliminary results on cold-worked chemically polished zirconium with a 660-A anodic film formed in $0.5 \mathrm{M} \mathrm{H}_{2} \mathrm{SO}_{4}$ indicate that a reduction in weight gain of $10 \%$ or more is possible. Under the same conditions $\left(500^{\circ} \mathrm{C}\right.$ steam, $19 \mathrm{hr}$ ) the weight gain is reduced at least $50 \%$ by preanodizing in the phosphate. Experiments are under way to incorporate selenium and tellurium into the anodized film. From at least one viewpoint, 9 these elements should be more effective than phosphorus in slowing the diffusion of oxygen through the oxide.

Tests in progress will evaluate the effectiveness of preanodizing after thermal oxidation, the effect of thickness of anodized film, and the important effects of surface preparation and contamination. Future tests will be conducted in $400^{\circ} \mathrm{C}$ ( $1500 \mathrm{psi}$ ) steam and $360^{\circ} \mathrm{C}$ water lu determine whether preanodizing is a practical method for reducing the. oxidation of zirconium, Zircaloy-2, and Zircaloy-4 in reactor service. $(1960)$

${ }^{9}$ T. Sano, S. Imoto, and M. Kan, Technol. Rept. Osaka Univ. 10, 129

$10 \mathrm{~J}$. C. Banter, Fuels and Material's Development Program Quart. Progr. Rept. Sept. 30, 1966, ORNL-TM-1700, p. 50 . 


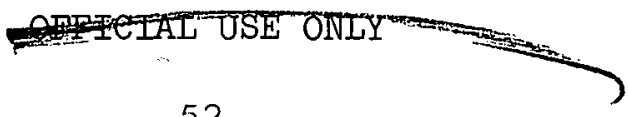

\title{
6. WELDABILITY OF NICKEL-BFARING ALLOYS
}

\author{
G. M. Slaughter
}

Studies are well under way on the program to determine the effects of minor elements, individually and combined, upon the cracking behavior and mechanical properties of welds in nickel-bearing alloys. Much of the effort in this reporting period, as well as the last, has been aimed at procuring high-purity raw materials and at fabricating spccial alloys for wcliability testing both at Rensselaer Pnlytechric Inslitute under Bubcuntract and at ORNL: Pluse matcrials prosurcmcnt and ailoy preparaliun phases of the investigation are relatively time-consuming and involve long lead times; the welding experiments are proceeding concurrently as specimens become available.

\section{Special Alloy Fabrication}

W. J. Werner R. E. McDonald

D. A. Canonico

Melting and fabrication have been completed on the experimental Incoloy 800 compositions (800-1 thruugh - $r$ ) for VAREBTRAINI and hotaut1lit.y testing. ${ }^{1}$ An additional set of experimental alloys of the nominal 800-3 composition plus trace amounts of sulfur and/or phosphorus have been melted for an evaluation of their weldabilit. using the hotductilit.y test. The ingots are currently being extruded to rod.

Tahie 6.1 ohows the nomind compositions of these alloys.

Melting was alos sumpleted on a series of selectively contaminated Inconel 600 alloys. ${ }^{2}$ Table 6.2 gives the nomillal compositions of the alloys that were meltied during inle repurt period.

${ }^{I}$ D. A. Canonico, R. E. McDonald, and W. J. Werner, Fuels and Materials Development Program Quart. Progr. Rept. Sept. 30, 1966, ORNL-TM-1'700, pp. 90-92.

${ }^{2}$ R. E. McDonald; W. J. Werner, and D. A. Canonico, Fuels and Materials Development Program Quart. Progr. Rept. Dec. 31, 1966, ORNL-TM-1720, pp. 80-82. 
Table 6.1. Nominal Compositions of Experimental Incoloy 800 Alloys

\begin{tabular}{|c|c|c|c|c|c|c|c|}
\hline \multirow{2}{*}{$\begin{array}{c}\text { Alloy } \\
\text { Designation }\end{array}$} & \multicolumn{7}{|c|}{ Composition (wt \%) } \\
\hline & $\mathrm{Ni}$ & $\mathrm{Cr}$ & Al & $\mathrm{Ti}$ & $S$ & $\mathrm{P}$ & $\mathrm{Fe}$ \\
\hline $800-1$ & 32.5 & 21.0 & 0.00 & 0.00 & 0.00 & 0.00 & bal \\
\hline-2 & 32.5 & 21.0 & 0.15 & 0.15 & 0.00 & 0.00 & bal \\
\hline-3 & 32.5 & 21.0 & 0.38 & 0.38 & 0.00 & 0.00 & bal \\
\hline-4 & 32.5 & 21.0 & 0.60 & 0.60 & 0.00 & 0.00 & bal \\
\hline-5 & 32.5 & 21.0 & 0.38 & 0.15 & 0.00 & 0.00 & bal \\
\hline-6 & 32.5 & 21.0 & 0.38 & 0.60 & 0.00 & 0.00 & bal \\
\hline-7 & 32.5 & 21.0 & 0.15 & 0.38 & 0.00 & 0.00 & bal \\
\hline-8 & 32.5 & 21.0 & 0.60 & 0.38 & 0.00 & 0.00 & bal \\
\hline $800-9$ & 32.5 & 21.0 & 0.38 & 0.38 & 0.01 & 0.00 & bal \\
\hline $800-10$ & 32.5 & 21.0 & 0.38 & 0.38 & 0.015 & 0.00 & bal \\
\hline-11 & 32.5 & 21.0 & 0.38 & 0.38 & 0.02 & 0.00 & bal \\
\hline-12 & 32.5 & 21.0 & 0.38 & 0.38 & 0.00 & 0.01 & bal \\
\hline-13 & 32.5 & 21.0 & 0.38 & 0.38 & 0.00 & 0.015 & bal \\
\hline-14 & 32.5 & 21.0 & 0.38 & 0.38 & 0.00 & 0.02 & bal \\
\hline-15 & 32.5 & 21.0 & 0.38 & 0.38 & 0.01 & 0.01 & bal \\
\hline-16 & 32.5 & 21.0 & 0.38 & 0.38 & 0.015 & 0.015 & bal \\
\hline
\end{tabular}

Table 6.2. Nominal Compositions of Inconel 600 Alloys for Hot-Ductility Testing

\begin{tabular}{cccccccccc}
\hline \multirow{2}{*}{$\begin{array}{c}\text { Alloy } \\
\text { Designation }\end{array}$} & Fe & Cr & C & Cu & Mn & Si & S & P & Ni \\
\hline $600-6$ & 8 & 15.5 & 0.03 & 0.04 & 0.20 & 0.20 & 0.00 & 0.005 & bal \\
-7 & 8 & 15.5 & 0.03 & 0.04 & 0.20 & 0.20 & 0.00 & 0.01 & bal \\
-8 & 8 & 15.5 & 0.03 & 0.04 & 0.20 & 0.20 & 0.00 & 0.015 & bal \\
-9 & 8 & 15.5 & 0.03 & 0.04 & 0.20 & 0.20 & 0.0025 & 0.0025 & bal \\
-10 & 8 & 15.5 & 0.03 & 0.04 & 0.20 & 0.20 & 0.005 & 0.005 & bal \\
-11 & 8 & 15.5 & 0.03 & 0.04 & 0.20 & 0.20 & 0.0075 & 0.0075 & ba1 \\
-15 & 8 & 15.5 & 0.03 & 0.04 & 0.80 & 0.20 & 0.01 & 0.01 & bal \\
\hline
\end{tabular}

Melting of seven 125-1b heats of high-purity Inconel 600 was initiated. Air-induction-melted electrodes are being processed from the highpurity melting stock discussed previously. ${ }^{l}$ Six-inch-diameter ingots will be produced by vacuum-consumable-melting and will be extruded to sheet bar by a commercial fabricator. Inconel 600 is scheduled for use in a factorial weldability experiment wherein the individual and combined effects of several elements will be assessed. 


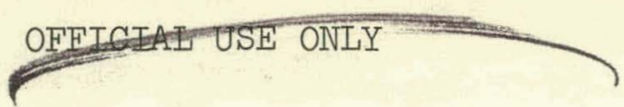

54

Hot-Ductility Testing (D. A. Canonico, W. J. Werner)

Hot-ductility tests ${ }^{3}$ of the experimental Incoloy 800 alloys (see Table 6.I) are currently under way using the Duffer's Gleeble. ${ }^{4}$ This test measures the mechanical properties of weld heat-affected zones at high temperature and, therefore, serves as a useful means for evaluating general weldability. For example, the ability of the heat-affected zone to withstand stresses without cracking is one indication of suitable behavior when welding under high restraint.

Figure 6.1 shows the results of studies completed to date; an experimental temary Incoloy 800 compusiliun (500-1) io compared to a

${ }^{3}$ E. F. Nippes et al., "An Investigation of the Hot-Ductility of HighTemperature Alloys," Welding J. (N.Y.) 34(4), 183s-196s (1955).

${ }^{4}$ Duffers Associates, Inc., Troy, New York.

ORNL-DWG 67-1154

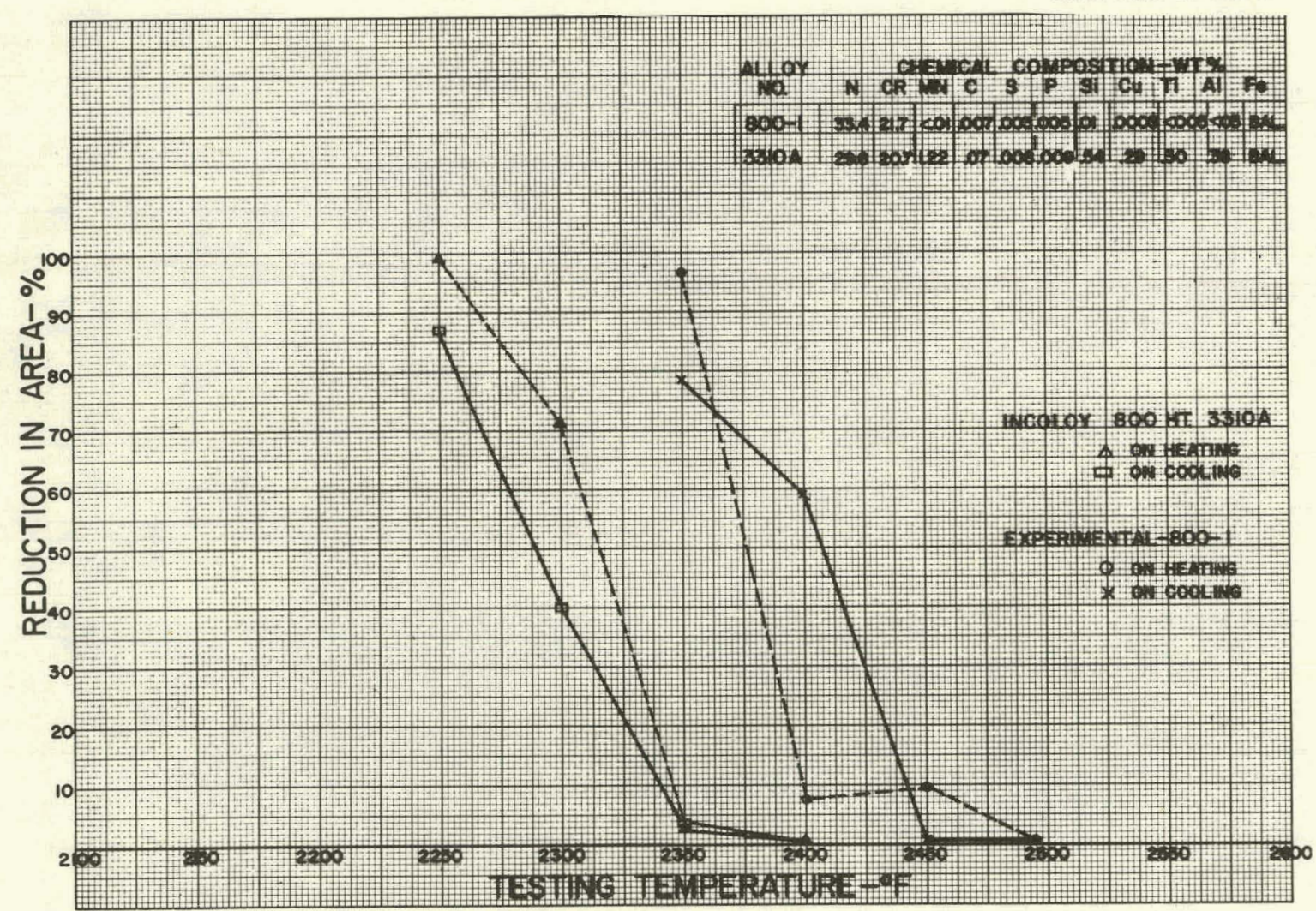

Fig. 6.1. The Pure Ternary Composition Retains Its Ductility at Higher Temperatures Than Does the Commercial Material. 
commercial heat of material. Both materials show excellent recovery, and consequently are categorized as weldable. The pure temary retains its ductility to a higher temperature than the commercial material and is therefore superior from that standpoint.

VARESTRAINT Testing Performed Under Subcontract at Rensselaer Polytechnic Institute (W. F. Savage, C. D. Lundin) ${ }^{5}$.

An investigation of the effect of welding heat input on VARESTRAINT testing was conducted. Commercial heats of Hastelloy $X$ (heat 2865) and Inconel 600 (heat 2806) were selected for study. Experiments on Hastelloy $X$ were performed at a heat input of approximately 60,000 joules/in. Heat input was held relatively constant while welding currents and travel speeds were varied. The fusion zone was held constant at a width of approximately. $0.75 \mathrm{in.}$ Welding parameters for the tests on both Hastelloy $X$ and Inconel 600 were:

\begin{tabular}{|c|c|c|}
\hline Parameter & $\begin{array}{l}\text { Hastelloy } X \\
\text { (heat 2865) }\end{array}$ & $\begin{array}{l}\text { Inconel } 600 \\
\text { (heat 2806) }\end{array}$ \\
\hline $\begin{array}{l}\text { Welding current, amp } \\
\text { Welding voltage, v } \\
\text { Travel speed, ipm } \\
\text { Arc length (cold), in. } \\
\text { Shielding gas, cfh }\end{array}$ & $\begin{array}{l}205 \text { to } 412 \\
9.5 \text { to } 13 \\
1.00 \text { to } 5.72 \\
3 / 32 \\
35 \text { argon }\end{array}$ & $\begin{array}{l}160 \text { to } 325 \\
13 \text { to } 15.5 \\
2 \text { to } 15 \\
3 / 32 \\
50 \text { helium }\end{array}$ \\
\hline
\end{tabular}

VARESTRAINT testing was performed at $2 \%$ augmented strain. An attempt was made to correlate the various dependent (maximum crack length, total crack length) and independent (current, travel epeed) variables. No correlation was found when the samples were in either the as-welded or polished conditions. An unusually large degree of scatter was encountered in the data which may have masked any influence of the parameters. The data scatter appeared to be a result of a combination of an abnormally wide fusion zone arid a large (2\%) augmented strain.

Tests on Inconel 600 were run at heat inputs of $20,000,30,000$, and 60,000 joules/in. with a constant fusion zone width of $0.5 \mathrm{in}$. and an augmented strain of $1 \%$. Three specimens were tested at each heat input,

${ }^{5}$ Department of Materials Engineering, Rensselaer Polytechnic Institute, Truy, New York. Subcontract is funded jointly with BONUS Core II Superheater Research and Development. 
and the results are summarized in Fig. 6.2. There appears to be a correlation between heat input-and length and maximum crack length; the intermediate heat input (approximately 30,000 joules/in.) exhibited the least resistance to hot cracking. These studies will be continued in order to more accurately determine the correlation at other values of heat input and to determine the reasons for the observed behavior. .
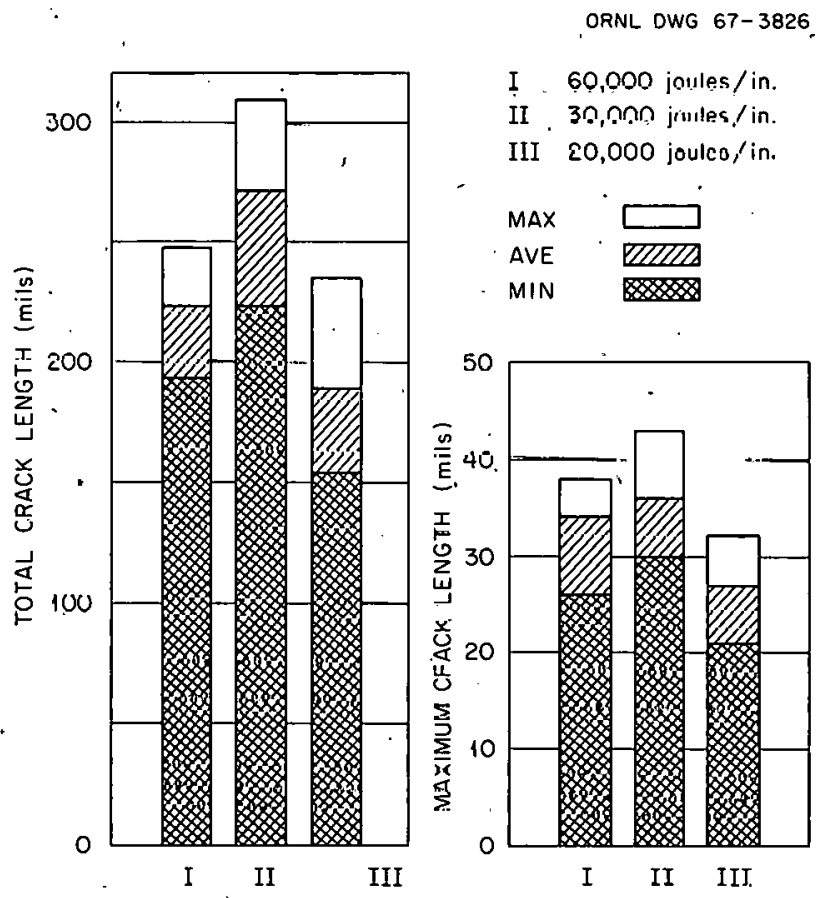

Fig. 6.2. The Effect of Heat Input on Hot Cracking of Inconel 600, Heat 2806. 
PART II.

REACTOR CHEMISTRY DIVISION 
THIS PAGE WAS INTENTIONALLY LEFT BLANK 


\title{
7. FISSION-GAS RELEASE AND PHYSICAL PROPERTIES OF - FUEL MATERIALS DURING IRRADIATION
}

\author{
R. M. Carroll R. B. Perez \\ J. G. Morgan O. Sisman
}

G. M. Watson

We are studying the response of fission gas from $\mathrm{UO}_{2}$ during irradiation in an effort to determine the fundamental mechanism by which the gas migrates and escapes from the fuel. To accomplish this we irradiate carefully selected and characterized specimens in an irradiation facility where the neutron flux and temperature are controlled independently. Fission gas is entrained in a constantly moving stream of sweep gas and carried outside the reactor where it is analyzed by gamma-ray spectrometry.

In fission-gas release studies, the specimen is oscillated sinusoidally in the reactor so as to oscillate the neutron flux and thus oscillate the fission rate in the specimen. The specimen temperature will. also oscillate in response to the changing fission power, producing waves of fission-gas release.

In thermal diffusivity studies, step changes of fission rate are made by abruptly inserting the specimen into a higher neutron flux. The time response of a thermocouple in the center of the specimen is studied to find values of the thermal diffusivity of the specimen.

\section{Fission-Gas Release}

The defect-trap model assumes that the rate-determining process for the release of fission gas from $\mathrm{UO}_{2}$ in the temperature-dependent region depends on the relative probabilities of the gas being trapped by and released from traps. Three categories of traps are postulated: (I) intrinsic traps, which do not move at temperatures below $1500^{\circ} \mathrm{C}$ and which are voids, grain boundaries, and other intrinsic defects of the material, (2) point defects which are formed by fission fragments, and (3) clusters of point defects. The point defects and clusters are formed

\footnotetext{
${ }^{1}$ Consultant from the University of Florida.
} 
by irradiation. Accordingly, the defect-trap model postulates the presence of both permanent traps and point defects to explain the fact that only a relatively smal. fraction of the fission gas is actually released from the sample. The relative independence of the release rate on fission density is accounted for by the assumption that the concentration of defect traps depends un the balanse hetween their production and their annealing.

An atom generated by fission will diffuse through a trapping matrix, decaying into a daughter which will continue to diffuse. The materialbalanse equations for llie coricentrations of mother, daughter, and point defects are given in gerteral by: ${ }^{2}$.

$\partial \psi / \partial t=P \psi+S$,

where the transposed vectors $\psi^{\mathrm{T}}, \mathrm{s}^{\mathrm{T}}$ are

$\psi^{\mathrm{T}}=\left[\mathrm{M}(\mathrm{z}, \mathrm{t}), \mathrm{H}(\mathrm{z}, \mathrm{t}), \mathrm{N}_{\mathrm{tr}}(\mathrm{t})\right]$,

$S^{T}=\left\{\left[\beta_{M} F(t)-g_{1}(t) M(z, t)\right],\left[\beta_{H} F(t)-g_{1}(t) H(z, t)\right], \alpha F(t)\right\}$.

$P$ is the linear matrix operator

$\left\{\begin{array}{ccc}{\left[D_{M} \frac{\partial^{2}}{\partial \mathrm{z}^{2}}-\left(\lambda_{M}+g_{O}\right)\right]} & 0 & 0 \\ +\lambda_{M} & {\left[D_{H} \frac{\partial^{2}}{\partial z^{2}}-\left(\lambda_{H}+g_{O}\right)\right\rfloor} & 0 \\ 0 & 0 & -\nu_{T}\end{array}\right\}$

Equation (7.1) in expl101l torm 1E

$$
\begin{aligned}
& {\left[D_{M} \frac{\partial^{2}}{\partial z^{2}}-\left(\lambda_{M}+g_{0}\right)\right] M(z, t)-h_{t r}(t) M(z, t)+\beta_{M} F(t)=\frac{\partial}{\partial t} M(z, t) .} \\
& {\left[D_{H} \frac{\partial^{2}}{\partial z^{2}}-\left(\lambda_{H}+g_{0}\right)\right]^{\prime} H(z, t)-h_{t r}(t) H(z, t)+\beta_{H} F(l)+\lambda_{M}(z, l)=\frac{\partial}{\partial t} H\left(z_{1}, t\right) .} \\
& \alpha F(l)-v_{T} N_{t r}(t)=\frac{\partial}{\partial t} N_{t r}(t),
\end{aligned}
$$

${ }^{2}$ R. B. Perez, "A Dynamic Method for In-Pile Fission-Gas Release Studies," Nucl. Appl. ? $\stackrel{7}{=}(2), 151$ (1966). 
where

$$
\begin{aligned}
& M(z, t)=\text { concentration of parent nuclei (atoms } / \mathrm{cm}^{3} \text { ) } \\
& \mathrm{H}(\mathrm{z}, \mathrm{t})=\text { concentration of daughter nuclei. (atoms } / \mathrm{cm}^{3} \text { ) } \\
& \mathrm{N}_{t r}(t)=\text { point defects }\left(\operatorname{traps} / \mathrm{cm}^{3}\right),\left(\mathrm{N}_{t r}\right)_{0}=\mathrm{N}_{t r} \text { at steady state } \\
& D_{M}, D_{H}=\text { diffusion coefficients for } M \text { and } H\left(\mathrm{~cm}^{2} \cdot \mathrm{sec}^{-1}\right)=D_{0} \exp -(\triangle E / R T) \\
& \triangle_{\mathrm{E}}=\text { activation energy for diffusion (cal } / \mathrm{mole} \text { ) } \\
& \beta_{M}, \beta_{H}=\text { fission yields (fission-fragments/fission) } \\
& \lambda_{M}, \lambda_{\mathrm{H}}=\text { decay constants }\left(\mathrm{sec}^{-1}\right) \\
& \nu_{\mathrm{T}}=\text { time constant for trap annealing }=\nu_{0} \exp -\left(\Delta \mathrm{E}_{\mathrm{tr}_{\mathrm{r}}} / \mathrm{RT}\right)\left(\mathrm{sec}^{-1}\right) \\
& \mathrm{AE}_{\mathrm{tr}}=\text { activation energy for trap annealing (cal/mole) } \\
& \alpha=\text { traps formed/fission } \\
& \mathrm{g}_{\mathrm{O}}=\text { trapping probability from intrinsic defects }\left(\mathrm{sec}^{-1}\right) \\
& \mathrm{h}=\text { second-order rate constant (for trapping processes) } \\
& \left(\mathrm{cm}^{3} / \text { trap } \times \mathrm{sec}\right) \\
& \mathrm{R}=\text { gas constant }\left(\operatorname{cal} \text { mole } e^{-1}{ }^{\circ} \mathrm{K}^{-1}\right) \\
& g(t)=h_{t r}(t)\left(\sec ^{-1}\right)=g_{1} \\
& \mathrm{~T}=\text { absolute temperature }\left({ }^{\circ} \mathrm{K}\right) \\
& t=\text { time }(\mathrm{sec}) \text {. }
\end{aligned}
$$

The products $\beta_{M} F, \beta_{H} F$, and $\alpha_{F}$ are production terms for the parent, daughter, and point defects, and terms of the form. $\left(D \partial^{2} / \partial z^{2}\right)$ correspond to ordinary diffusion processes. The loss terms correspond to: (a) radioactive decay terms such as $\lambda_{M} M(z, t), \lambda_{H} H(z, t)$; (b) trapping by permanent defects equals $g_{0} M(z, t), g_{0} H(z, t)$; and (c) trapping by point defects equals $h N_{t r}(t) M(z, t), h N_{t r}(t) H(z, t)$. The productiur rate of point defects was assumed to be proportional to the fission density. The rate of annealing was assumed to have the form of an Arrhenius factor involving the frequency of collision $\nu_{T}$ of the free atoms with the potential barrier surrounding the point defect.

The fiscion-gas release from the specimen during oscillations is measured by continuous gamma-ray analysis of the flowing sweep gas. The gamna-ray spectrometer is programmed to measure the time-dependent variation of a given isotope of the fission gas (usually ${ }^{88} \mathrm{~K} r$ ). The delay time required for the fission gas to flow out of the reactor is determined by using sweep gas that contains argon and by measuring tho 
time lapse between position oscillations and argon-activity oscillations. A precise record of time temperature or time flux is kept with a digital recording clock voltmeter. The f'ission-gas release-rate measurements are thus synchronized with the temperature of flux oscillations of the specimen. .

The solutions that will be discusscd apply to a thin plate of material with spatially uniform temperature and fission density distribution. The boundary conditions associated with the problem are symmetry of the concentration profiles with respect to the midplane of the sample and ranishing of the parent-daughter concentrations at the boundaries of the specimen.

SoliltinPl uf the $3 c t$ of Eq. (7.I) a.t constant temperature and oscillating flux was obtained by the use of first-order perturbation theory.? The solution predicted experimental diff'erences in the amplitude and phase shifts of the transfer function of the fission-gas release as a function of the frequency of oscillation. However, due to experimental difficulties in maintaining constant specimen temperature, these isothermal tests have been unsatisfactory.

Solutions have also been obtained for the set of Eq. (7.1) for the case where both the flux and temperature oscillate. The solutions are in the form of series expressions in space-time configurations. To obtain the solutions, the space dependence and the time dependence were eliminated and Eq. (7.I) was converted into a set of algebraic equationo in terms of the Fourier coefficients of the concentrations of parent, $M$, daughter, $\mathrm{H}$, and traps, $\mathrm{N}_{t, r}$. Finally the release rates $\mathrm{B}_{\mathrm{M}}$ and $\mathrm{R}_{\mathrm{H}}$ were obtained in terms of the Fourier coefficients of $M, H, N_{t r}, D, v, F$, and $\mathrm{T}$.

$$
\begin{array}{r}
R_{0}^{(1)}=\sum_{n}^{\sum_{n}(-1)^{n}}\left[D_{0}^{(1)} M_{n o}^{(1)} k_{n}+\frac{1}{2} \sum_{\sigma, \alpha}\left(D_{\sigma}^{(1)} M_{n \alpha}^{(1)}+D_{\sigma}^{(2)} M_{n \alpha}^{(2)}\right) k_{n} \delta_{\sigma \alpha}\right] \\
R_{\beta}^{(1)}=\sum_{n}(-1)^{n}[k_{n}\left(D_{0}^{(1)} M_{n \beta}^{(1)}+D_{\beta}^{(1)} M_{n o}^{(1)}\right)+\frac{1}{2} \underbrace{\sum_{n}}_{\sigma, \alpha}\left(D_{\sigma}^{(1)} M_{n \alpha}^{(1)} c_{\beta \sigma \alpha}^{(1)}\right. \\
\left.\left.+D_{\sigma}^{(2)} M_{n \alpha}^{(2)} c_{\beta \sigma \alpha}^{(4)}\right)\right]
\end{array}
$$




$$
\begin{aligned}
R_{\beta}^{(2)}=\sum_{n}(-1)^{n}\left[k_{n} \cdot\left(D_{0}^{(1)} M_{n \beta}^{(2)}+D_{\beta}^{(2)} M_{n o}^{(1)}\right)\right. & +\frac{1}{2} \sum_{\sigma, \alpha} k_{n}\left(D_{\sigma}^{(1)} M_{n \alpha}^{(2)} s_{\beta \sigma \alpha}^{(2)}\right. \\
& \left.\left.+D_{\sigma}^{(2)} M_{n \alpha}^{(1)} s_{\beta \sigma \alpha}^{(3)}\right)\right],
\end{aligned}
$$

where the superscripts (1) and (2) denote sin and cos functions, respectively, except that $c^{(1)}, c^{(4)}, s^{(2)}$, and $s^{(3)}$ denote integrals of sin, $\cos$ functions which have values of 0,1 , or $-1 . \mathrm{K}_{\mathrm{n}}$ is an eigenfunction solution resulting from elimination of the space dependence.

These algebraic equations have been placed in a computer program designed to make an empirical fit of the measured data to obtain values for the parameters of the equations. A test run of the computer program has been made. A hand check of the program revealed only a few; easily corrected errors.

\section{Electrical Measurements}

As previously reported, ${ }^{3}$ we have found some unusual responses of the $\mathrm{UO}_{2}$ single crystal to an applied electrical potential. In the capsule containing a $\mathrm{UO}_{2}$ single-crystal. cylinder, one of three central

- thermocouples located at the axis of the cylinder was used as one electrode (see Fig. 7.1) and the other electrode was the rhenium foil reflector surrounding the specimen. The specimen was insulated from electrical ground by the thermal insulation.

The original purpose of this test was to see if an electrical potential would act as a. Ariving force for the release uf flssion gas. However, when a potential field of a few volts was placed across the specimen, the nearby thermocouples registered an emf large enough to drive the 35-mv recorders off scale. Since the recorders were attached to our safety system, this resulted in a reactor setback. Moreover, the nearby thermocouples continued to register spurious temperatures even after the potential had been removed. Only a few microamperes of current were drawn during this time.

${ }^{3}$ R. M. Carroll, J. G. Morgan, R. B. Perez, and O.' Sisman, Fuels and Materials Development Program Quart. Progr. Rept. June 30, 1966, ORNL=TM-1570, pp. 75-95. . 


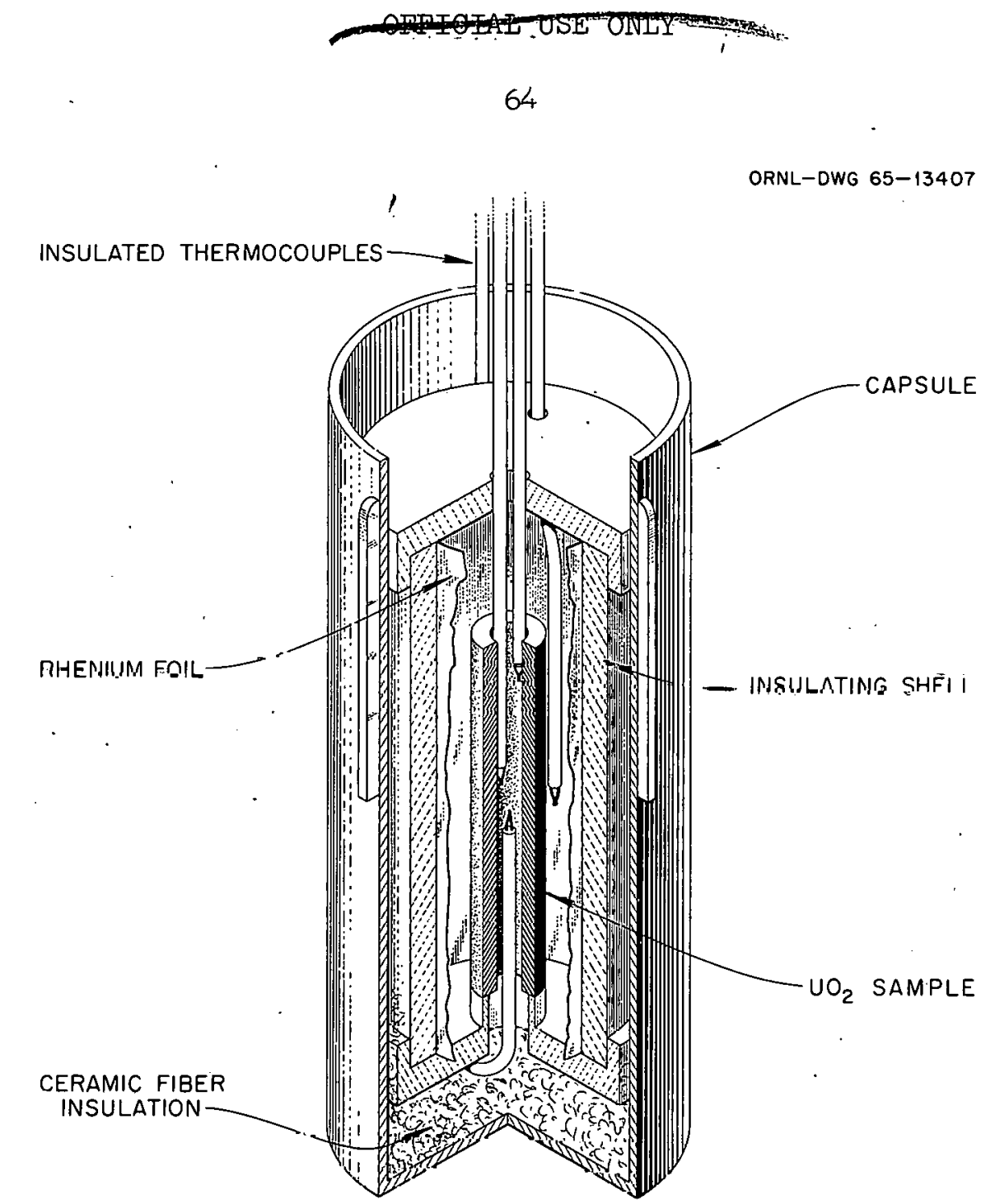

Fig. 7.1. Capsule Used for Electrical Fotential Tesls.

Two aspects of these phenomena were of great interest. Why do the thermocouples register spurious temperatures, and why dues the spccimen appear to store and then release electrical energy over a periud of hours and days? To study these problems we cunducted a sericc of inreactor and bench tests. We did not obtain a satisfactory explanation from these tests, hut a number of tentative explanations were eliminated.

our first suspicion was that the experiment instrumentation was somehow causing this effect, either by feeding electrical impulses.into the specimen or by the lead lines acting as capacitors: A duplicate capsule was constructed and connected to the same instrumentation (the in-reactor capsule was temporarily isolated). No response of any type 
was detected from the out-of-reactor capsule under the maximum potential field. Also, grounding the thermocouple leads did not. reduce the storage-discharge effect from the in-reactor specimen.

A tentative theory was advanced that irradiation-created ions in. the sweep gas were being collected on the specimen, the ions being driven by the potential field. However, when the helium sweep gas was replaced by a vacuum, the specimen had the same response. Also, temperature changes produced no effect.

The next hypothesis was that irradiation was providing the energy for charge carriers to pass into normally nonconducting bands of the $\mathrm{UO}_{2}$ specimen. Energy could be both stored and released in this manner. This would also explain why the effect was not temperature dependent (thermal motions did not have enough energy to pass the potential barrier). However, we placed the duplicate capsule in a strong gamma-ray field and could see no effect. Also, changing the fission rate of the in-reactor specimen had no measurabie effect on the electrical response.

We now suspect that the thermocouple response may have, been caused by the bare wire junctions being coated with a thin film of $\mathrm{UO}_{2}$, evaporated from the specimen by surface fission. Under an electrical potential, charges can flow around and through the thermocouple junction, thus creating an emf that will add to or subtract from the thermal emf. We think it is plausible that the storage-battery effect is a result of disassociation of the $\mathrm{UO}_{2}$ into uranium and oxygen ions under the influence of irradiation, combined with the electrical field. J. L. Bates ${ }^{4}$ has observed such disassociation at high temperatures.

\section{Thermal Diffusivity of $\mathrm{UO}_{2}$ During Irradiation}

We have completed the installation of all the equipment to make transient tests. ${ }^{5}$ In the transient tests the specimens are moved suddenly from one steady state flux to another. The response of the specimen temperature to this step change of fission rate can be analyzed in terms of series of amplitudes and frequencies.

${ }^{4}$ J. L. Bates, private communication, April 1967.

${ }^{3}$ R. M. Carroll, J. G. Morgan, R. B. Perez, and O. Sisman, Fuels and Materials Development Program Quart. Progr. Rept. Dec. 31, 1966 , ORNL-TM-1720, pp. 91-96. 


\section{THIS PAGE}

WAS INTENTIONALLY

LEFT BLANK 
PART III.

SOLID STATE DIVISION 
THIS PAGE

WAS INTENTIONALLY

LEFT BLANK 


\section{IRRADIATION EFFECTS ON ALLOYS AND STRUCTURAL MATERIALS}

D. S. Billington, M. S. Wechsler, and J. T. Stanley

The major emphasis of research in the Radiation Metallurgy Section is the study of radiation-hardening and radiation embrittlement in the bicc metals and alloys. These metals have in common the tendency toward low-temperature brittleness which can be characterized by the ductile brittle transition temperature. The increase in ductile-brittle transition temperature upon irradiation is of concern in reactor technology because of the possible catastrophic failure of reactor pressure vessels in service. The work described in this report. shows the influence of metallurgical variables, i.e. internal stmucture such as grain boundaries and distribution of various phases as determined by heat treatment, in determining the response of a steel to irradiation hardening. Of course this is a very complex problem and in order to study certain aspects it is necessary to work with somewhat simpler systems than pressure vessel steel. High purity iron polycrystalline specimens and high purity niobium single crystals are being used to study dislocation motion and interaction with radiation produced defects. Since the interaction of interstitial impurities with radiation produced defects may play an important role in radiation hardening mechanisms, studies of these interactions are being made.

\section{Radiation Effccti on Fressure-Véssel Slets}

$$
\text { R. G. Berggren W. J. Stelzmain }
$$

T. N. Jones

We have previously reported on the effect of fast neutron dose and irradiation temperature on the Charpy V-notch transition temperature of three heats of ASTM A-212 Grade B base plate and synthetic heat-affected 
zone samples. ${ }^{1,2}$ Additional ductile-brittle transition temperature data have been obtained; these, with the previous data, are presented in Table 8.1.

In the unirradiated condition, the particular weld thermal cycles and stress relief imposed upon these three heats of A-2l2B steel increased the ductile-brittle transition temperatures. The largest increase (SSD Item 147-HAZ - 2B) has been attributed to the presence of continuous networks of proeutectoid ferrite at prior austenite grain boundaries. 3,4 Comparison of the irradiated base plate and heat-affected zone specimens for each of the three heats at a 60 to $74^{\circ} \mathrm{C}$ irradiation temperature and a dose range of 8 to $10 \times 10^{18}$ neutrons $/ \mathrm{cm}^{2}$ ( $\mathrm{E}>1 \mathrm{Mev}$ ) indicates that the sensitivity of each condition to irradiation is related to the cooling rate encountered in each thermal cycle. When one considers that the base plates have the slowest cooling rates, then the samples from all three heats with the highest cooling rates showed the least shift in transition temperature and the slowest cooling rates (normalized base plates) the highest shift. Similar behavior has been noted by Carpenter, Knopt', and Byron. 5

Normalization of these data to a dose of $9 \times 10^{-18}$ neutrons $/ \mathrm{cm}^{2}(\mathrm{E}>1$ Mev) following the trend band for $A-212 B$ irradiations yields the change in transition temperature at the $20 \mathrm{ft}$. Ib. energy level for various

${ }^{1}$. G. Berggren, W. J. Stelzman, and T. N. Jones, 'Radiation Effects on Pressure-Vessel Steels," Radiation Metallurgy Section Solid State Division Progress Report, February, 1966, ORNTL-3949, p."2.

?.K. G. Berggren, W. J. Stelzman, and T. N. Jones, "Radiation Effects on Pressure-Vessel Steels," Radiation Metallurgy Section Solid State Division Progress Report, July, 1966, ORNL-4020, p. l.

3 E. F. N1ppes, W. F. Savage, and"W. A. Bruwn, "Sludy of the Weld HeatAffected Zone of A-2l2B Steel," Rensselaer Polytechnic Institute, Troy, N. Y. (February 1961).

4. F. Savage and F. C. Breimeister, "A Further Study of the Weld HeatAffected Zone in A-2l2B Steel," Rensselaer. Polytechnic Institute, Troy, N. Y. (January 1964).

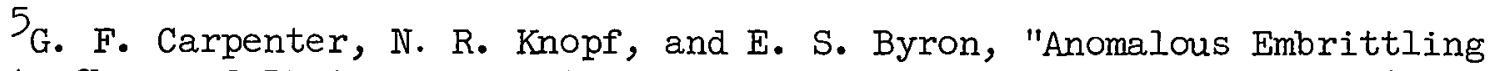
Effects Observed During Irradiation Studies on Pressure Vessel Steels," Nuclear Science and Engineering 19, 18-38,. (1964). 
Table 8.1. Effect of Irradiation Temperature and Dose on Charvy V-Notch Ductile-Brittle Transition Temperature of ASTM A-2l2 Grade B.

Base Plate and Heat-Affected-Zone Specimens

\begin{tabular}{|c|c|c|c|c|c|c|c|c|c|c|}
\hline $\begin{array}{c}\text { SSD Item No. } \\
\text { Thermal Cycle } \\
\text { Cocling Rate at } 538^{\circ} \mathrm{C}\end{array}$ & $\begin{array}{l}147 \\
\text { None }\end{array}$ & $\begin{array}{r}147 \\
4 \mathrm{~B} \\
24.4^{\circ} \mathrm{C} / \mathrm{S}\end{array}$ & $\begin{array}{r}147 \\
2 \mathrm{~B} \\
7.8^{\circ} \mathrm{C} /\end{array}$ & & $\begin{array}{l}156 \\
\text { None }\end{array}$ & $\begin{array}{r}156 \\
2 \\
12.2^{\circ} \mathrm{C}\end{array}$ & $\begin{array}{c}156 \\
3 \\
5.2^{\circ} \mathrm{C} / \mathrm{Sec}\end{array}$ & $\begin{array}{l}157 \\
\text { None }\end{array}$ & $\begin{array}{c}157 \\
2 \\
12.2^{\circ} \mathrm{C} /\end{array}$ & $\begin{array}{c}157 \\
3 \\
\text { ec } 5.2^{\circ} \mathrm{C} / \mathrm{sec}\end{array}$ \\
\hline $\begin{array}{lc} & \text { Irradiation } \\
\text { Temp. } & \text { Dose } \\
\left({ }^{\circ} \mathrm{C}\right) & (\mathrm{E}>1 \mathrm{MeV})\end{array}$ & '. & & & & & \multicolumn{5}{|c|}{ DBTT at $20 \mathrm{ft}-\mathrm{lb},\left({ }^{\circ} \mathrm{C}\right)$} \\
\hline $\begin{array}{cc} & \left(\mathrm{x} 10^{18} \mathrm{n} / \mathrm{cm}^{2}\right. \\
-- & 0 \\
60-74 & 5 \\
11 & 7\end{array}$ & $\begin{array}{r}-20 \\
62 \\
82\end{array}$ & -18 & $\begin{array}{r}60 \\
150\end{array}$ & - & -12 & 7 & 8 & 5 & 53 & 43 \\
\hline $\begin{array}{c}8 \\
9-9.3 \\
10\end{array}$ & 97 & $\begin{array}{l}80 \\
92\end{array}$ & 172 & & & 127 & 145 & 108 & 135 & 137 \\
\hline $\begin{array}{rr}" 1 & 11 \\
233 & 8.5 \\
260 & 6\end{array}$ & 38 & & & & 148 & & & 93 & & \\
\hline
\end{tabular}


T.э. 8.1 (Continued)

\begin{tabular}{|c|c|c|c|c|c|c|c|c|c|}
\hline $\begin{array}{c}\text { SSD Item No. } \\
\text { Thermal Cycle } \\
\text { Cooling Rate at } 538^{\circ} \mathrm{C}\end{array}$ & $\begin{array}{l}147 \\
\text { None }\end{array}$ & $\begin{array}{c}147 \\
4 \mathrm{~B} \\
24.4^{\circ} \mathrm{C} / \mathrm{Se}\end{array}$ & $\begin{array}{c}147 \\
2 \mathrm{~B} \\
7.8^{\circ} \mathrm{C} / \mathrm{sec}\end{array}$ & $\begin{array}{l}156 \\
\text { Fone }\end{array}$ & $\begin{array}{c}156 \\
2 \\
12.2^{\circ} \mathrm{C} /\end{array}$ & $\begin{array}{c}156 \\
3 \\
5.2^{\circ} \mathrm{C} / \mathrm{Sec}\end{array}$ & $\begin{array}{l}157 \\
\text { None }\end{array}$ & $\begin{array}{c}157 \\
2 \\
12.2^{\circ} \mathrm{C} /\end{array}$ & $\begin{array}{c}157 \\
3.2^{\circ} \mathrm{C} / \mathrm{sec}\end{array}$ \\
\hline \begin{tabular}{lc}
\multicolumn{2}{c}{ Irradiation } \\
Temp. & Dose \\
$\left({ }^{\circ} \mathrm{C}\right)$ & $(\mathrm{E}>$ I Mev $)$
\end{tabular} & & & $\therefore$ & & \multicolumn{5}{|c|}{$\mathrm{DBTT}$ at $20: \mathrm{t}-1 \mathrm{~b},\left({ }^{\circ} \mathrm{C}\right)$} \\
\hline $\begin{array}{lc} & \left(\times 10^{18}{ }_{\mathrm{r} /} \mathrm{cm}^{2}\right) \\
260 & 9.6 \\
277-283 & 7 \\
11 & 8\end{array}$ & 18 & & ' & $\begin{array}{l}62 \\
62\end{array}$ & & & 1 & & 132 \\
\hline $\begin{array}{cc}\prime \prime & 11 \\
288-291 & 9 \\
" & 10-10.3\end{array}$ & & & & 72 & 75 & 70 & $\begin{array}{l}55 \\
53\end{array}$ & 98 & 107 \\
\hline $\begin{array}{r}9 \\
8 \\
7\end{array}$ & $\begin{array}{r}2 \\
20\end{array}$ & & 72 & & & & & ' & \\
\hline $\begin{array}{c}9-10 \\
10 \\
8\end{array}$ & 10 & $\begin{array}{r}9 \\
-5\end{array}$ & 70 & & 2 & & 23 & & \\
\hline $\begin{array}{l}471 \\
474\end{array}$ & 3 & & - & & & 15 & & & \\
\hline
\end{tabular}


irradiation temperatures shown in Figs. 8.1-8.4. A comparison shows that the effects of irradiations vary considerably for the three heats and, for the case in hand, show that it is minimized in heat A-2056 (SSD Item 157) for both the base plate and heat-affected zone specimens. Not enough is known of the normalization histories of these heats to reach any conclusions regarding the difference in irradiation sensitivities.

It is also apparent that for the high temperature irradiation, there is little or no decrease or "recovery" of the transition temperature in the irradiation temperature range up to $250^{\circ} \mathrm{C}$; however, recovery of the major portion of irradiation-induced transition temperature shifts for all conditions occurs within a fairly narrow band of less than $100^{\circ} \mathrm{C}$ ( 260 to $350^{\circ} \mathrm{C}$ ), leaving $10 \%$ or less of the original damage remaining.

A cursory comparison of the high temperature irradiations with the post irradiation heat treatment data presented previously ${ }^{1,2}$ indicates that a heat treatment of $12 / 3$ to $3 \mathrm{hrs}$. may afford as much recovery as the high temperature irradiations at the same temperature. Further post irradiation recovery studies are planned on materials already irradiated.

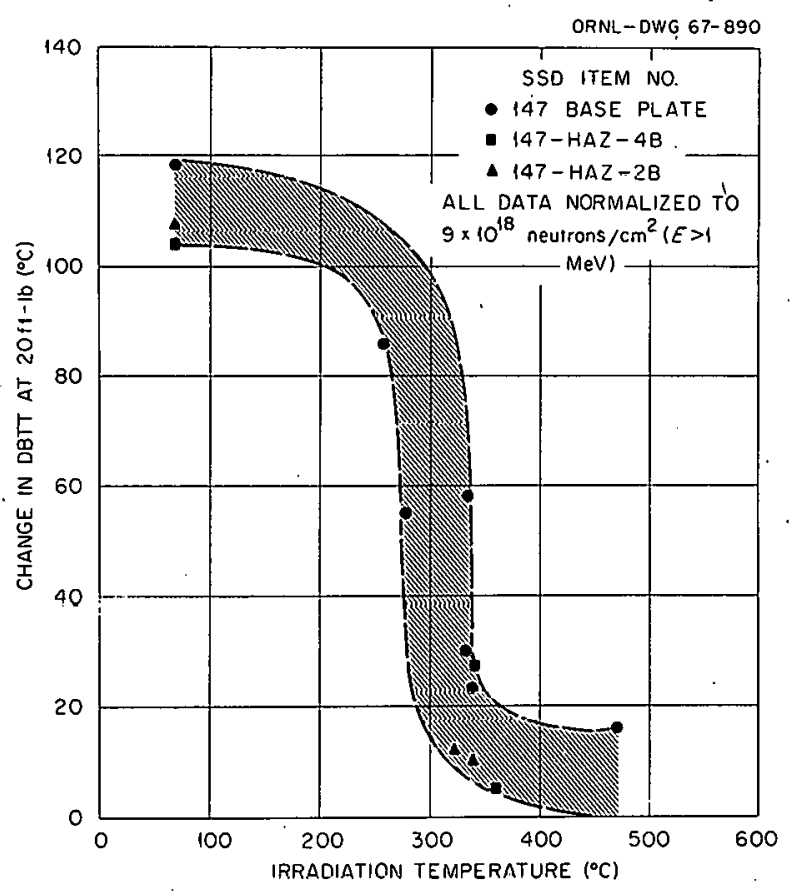

Fig. 8.1. Change in Charpy V-Notch Transition Temperature for Heat 15900 (SSD ltem 147) of ASTM-A212-B Steel. 


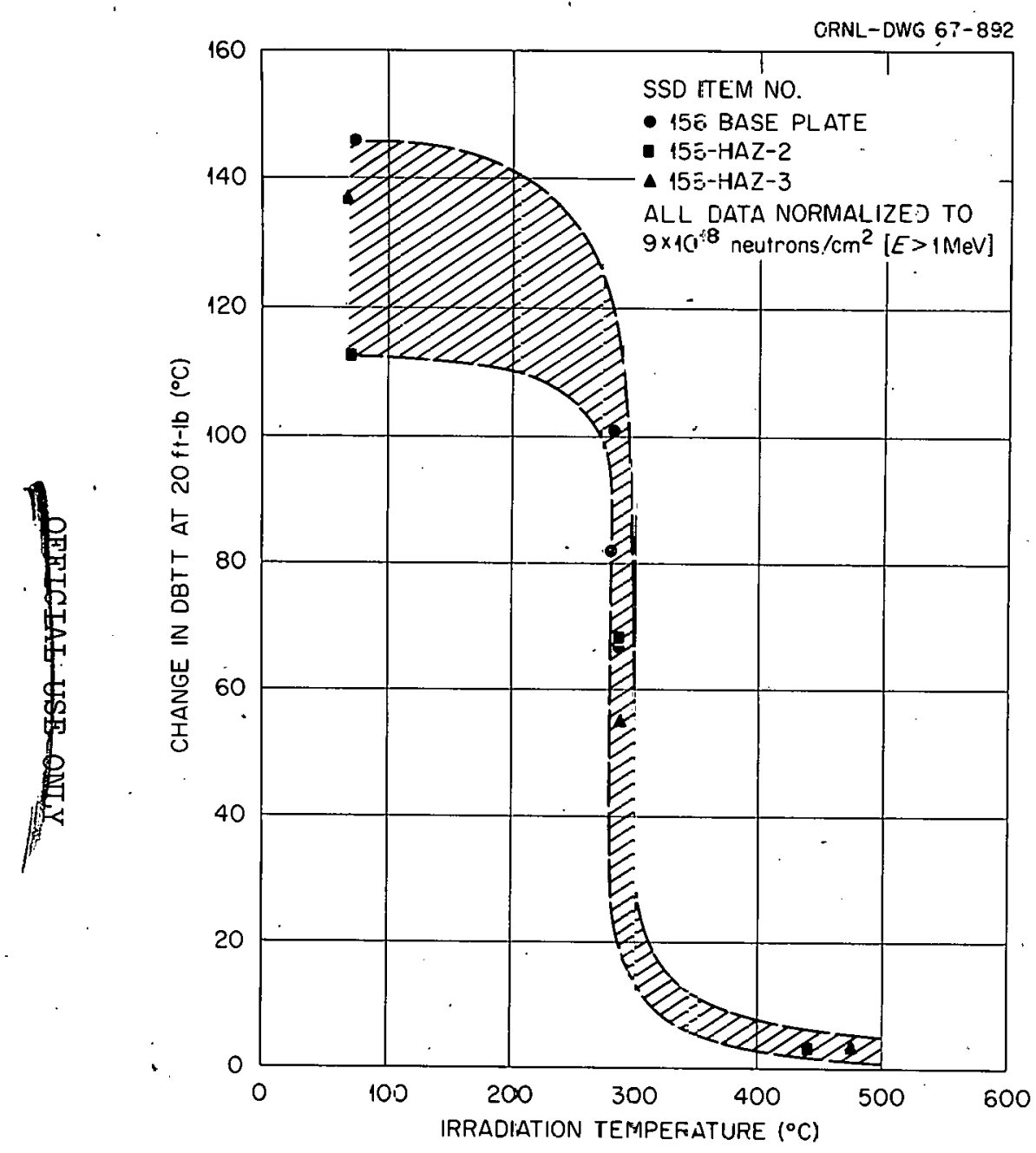

Fig. 3.2. Chanze ir Charpy V-Notch Transition Temperature for Heat A-2lIC (SSD Item 156) of ASTM A-2l2-B Steel.

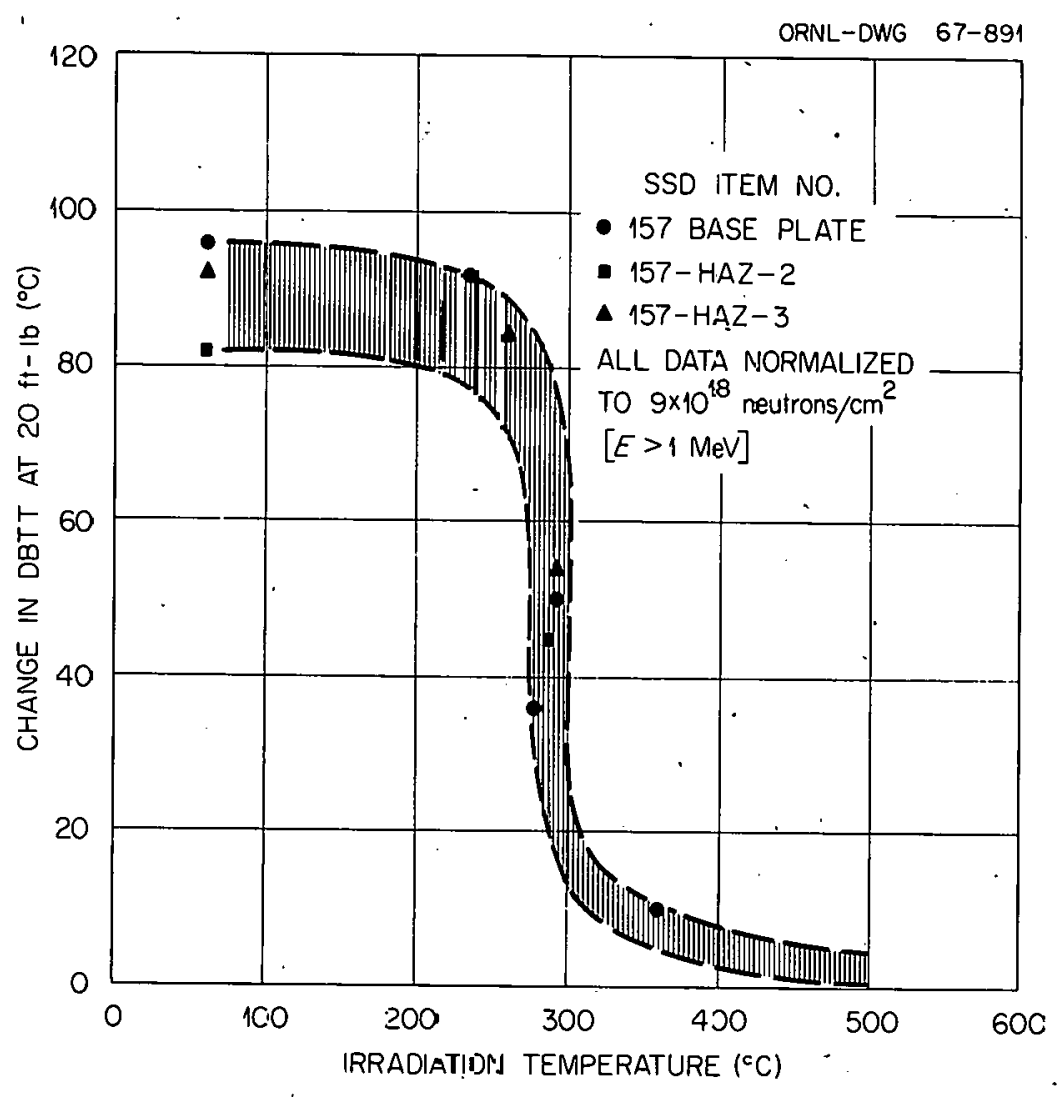

1

Fig. 3.3. Change in Charpy V-Notch Transition Temperature for Heat -2056 (SSD Item 157) of ASTM A-212-B Steel. 


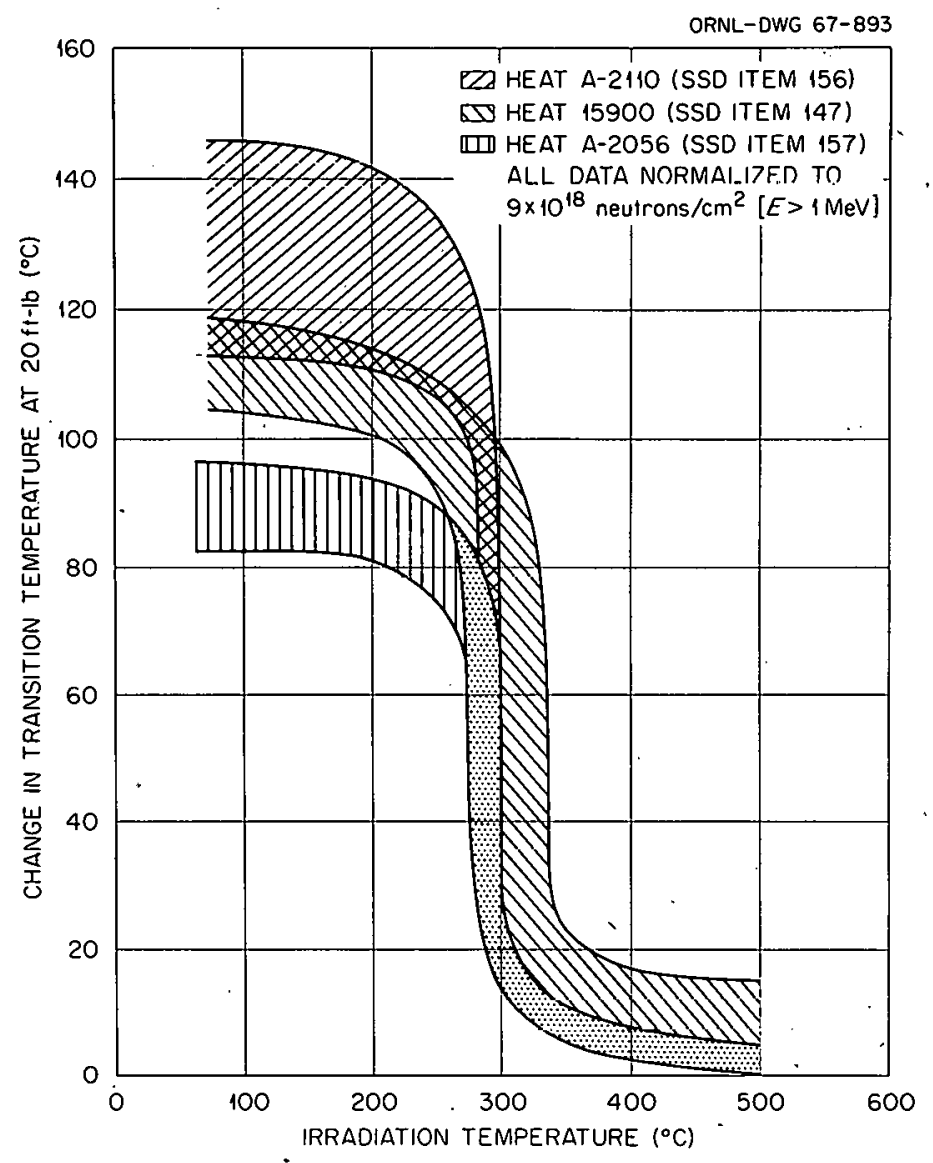

Fig. 8.4. Change in Charpy V-Notch Transition Temperature for Three Heats of ASTM A-212-B Steel. Both. Base Plate and Synthetic Heat-Affected Zone Specimens.

\section{Tensile Tests on Irradiated Iron}

\section{N. E. Hinkle N. K. Smith}

The effect of neutron dose rate on the tensile properties of a high purity vacuum-melted iron (Ferrovac-E) has been studied. The importance of understanding the effect of dose rate may be realized when it is pointed out that materials irradiations are performed in research reactors having neutron dose rates of $10^{12}$ to $5 \times 10^{13}$ neutrons $/ \mathrm{cm}^{2} \cdot \mathrm{sec}(\mathrm{E}>\mathrm{I}$ Mev) whereas the structural material of the pressure vessel of a power reactor is subjected to dose rates of $10^{9}$ to $10^{11}$ neutrons $/ \mathrm{cm}^{2}$. sec $(\mathrm{E}>1 \mathrm{Mev}) .6$

6J. J. DiMunno and A. B. Holt, "Radiation Embrittlement ot Reactor Vessels," Muclear Safety 4, 34 (1962). 
The experimental details of the irradiations and some preliminary results have been described in previous reports of this series. 7-9 To briefly summarize, tensile samples of f'errovac-E iron, vacuum annealed and furnace cooled to obtain a grain size of $130 \mu$, were irradiated to a dose of about $5 \times 10^{18}$ neutrons $/ \mathrm{cm}^{2}(\mathrm{E}>1 \mathrm{Mev}$ ) in experiment assemblies located at increasing distances from the Oak Ridge Research Reactor. The irradiation temperature was $95^{\circ} \mathrm{C}$ and the neutron dose rates ranged from about $2 \times 10^{11}$ to $2 \times 10^{13}$ neutrons $/ \mathrm{cm}^{2} \cdot \sec (\mathrm{E}>1 \mathrm{Mev}$ ). Tensile testing of as-irradiated samples from each assembly has been completed. The results of this study, as shown in Fig. 8.5, indicate that there is no dose rate effect within the range of dose rates used at the neutron dose of $5 \times 10^{\perp 8}$ neutrons $/ \mathrm{cm}^{2}$.

7N. E. Hinkle and N. K. Smith, "Tensile Tests on Irradiated Iron," Quarterly Progress Report: Irradiation Effects on Reactor Structural Materials, May, June, July, 1965, BNWL-218, pp. 10.25-10.35, August, 1965.

8. E. Hinklc, N. K. Smith, and M. S. Wechsler, "Tensile Tests on Irradiated Iron," Quarterly Progress Report: Irradiation Effects on Reactor Structural Materials, November, December, 1965, January, 1966, BNWL-CC-510, pp. 10.8-10.27, February, 1966.

9N. E. Hinkle and N. K. Smith, "Tensile Tests on Irradiated Iron and Iron Alloys," Quarterly Progress Report: Irradiation Effects on Reactor Structural Materials, November, Jecember, 1964, January 1965, HW-84618, pp. 10.31-10.43, F'ebruary 15, 1965.

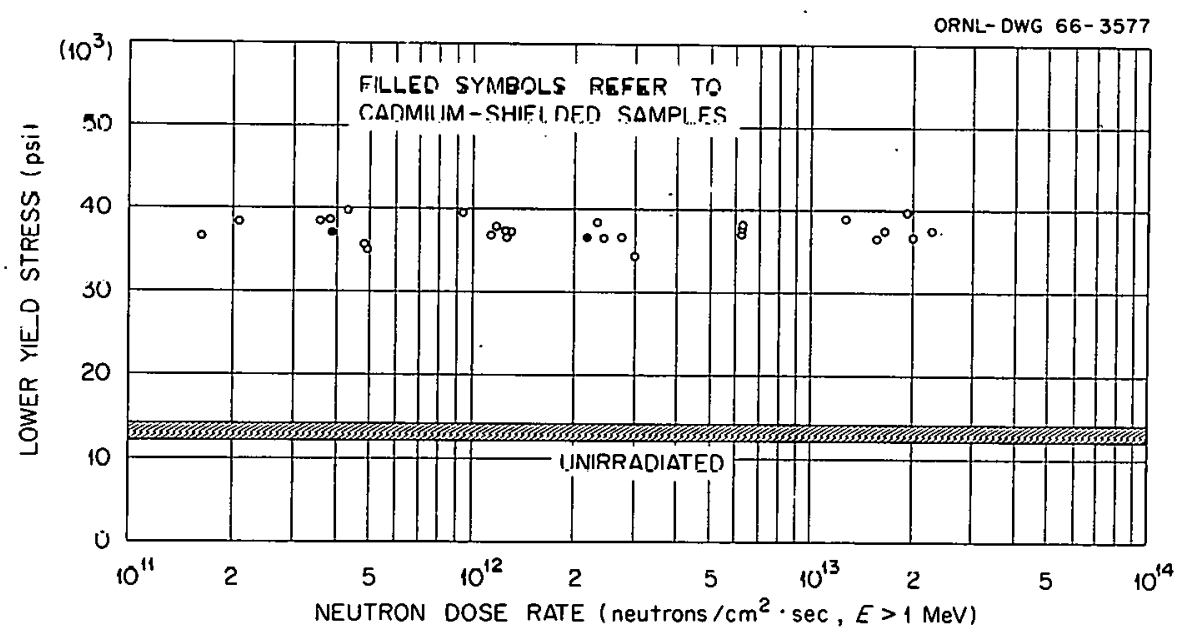

Fig. 8.5. Lower Yield Stress Versus Dose Rate for Ferrovac-E Iron. Grain size, $130 \mathrm{\mu}$. Irradiation Dose and Temperature, $4.6 \times 10^{18}$ neutrons $/ \mathrm{cm}^{2}(\mathrm{E}>1 \mathrm{Mev})$ at $95^{\circ} \mathrm{C}$. Test temperature, $30^{\circ} \mathrm{C}$. 
Post-irradiation annealing has been performed on samples irradiated at about $95^{\circ} \mathrm{C}$ to neutron doses of $4.5 \times 10^{17}$ to $5 \times 10^{18}$ neutrons $/ \mathrm{cm}^{2}$ $(\mathrm{E}>1 \mathrm{Mev})$. The results are shown in Figs. 8.6-8.8 as percent recovery versus annealing time at indicated annealing temperature. In Fig. 8.6 the different slopes for the data at various annealing temperatures indicate damage recovery at the lowest dose does not occur by a unique recovery process. The annealing studies on samples irradiated to a slightly greater dose, as shown in Fig. 8.7, appear to support the viewpoint that the damage recovery is not singly. activated. Bryner ${ }^{10}$ has presented evidence from studies of post-irradiation annealing of Ferrovac$E$ that indicate that more than one thermally activated process is responsible for the damage recovery in iron. The data in Fig. 8.8 for the highest neutron dose show that for a given annealing time, the recovery percentage decreases with increasing dose. This is especially true for

$10 \mathrm{~J}$. S. Bryner, "Electron-Transmission Microscope Study of Defects in Neutron Irradiated Iron, "Quarterly Progress Report: Irradiation Effects on Reactor Structural Materials, May, June, July, 19.66, BNWLCC-784, pp. 5.1-5.3, August, 1966.

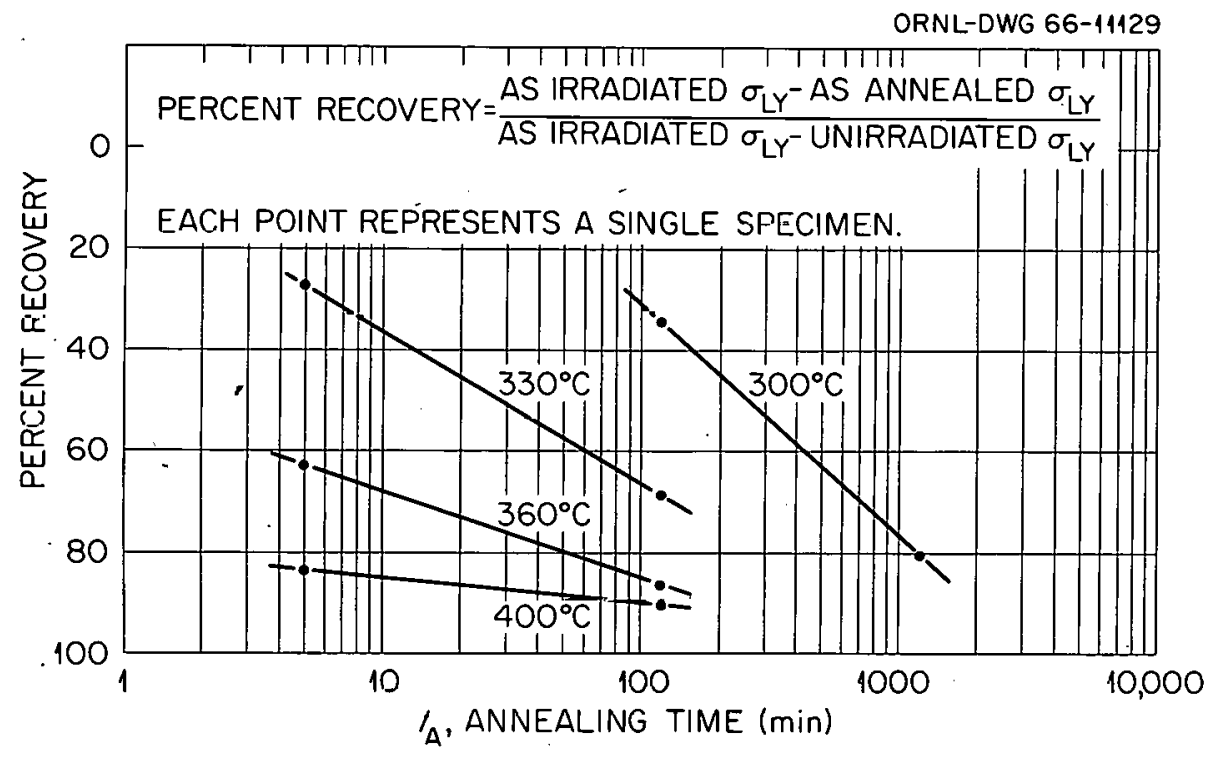

Fig. 8.6. The Percent Recovery of Radiation Induced Strengthening by Post Irradiation Annealing at the Given Temperatures. Test Temperature $=30^{\circ} \mathrm{C}$. Strain Rate $=0.02 \mathrm{~min}^{-1}$. Neutron Flux $=2 \times 10^{\prime \prime 2}$ to 2.9 $x 10^{12} \mathrm{n} / \mathrm{cm}^{2} \cdot \sec (E>1 \mathrm{Mev})$. Neutron Dose $=4.5 \times 10^{17}$ to $6.4 \mathrm{x}$ $1017 \mathrm{n} / \mathrm{cm}^{2}$ ( $\left.\mathrm{E}>1 \mathrm{Mev}\right)$. 


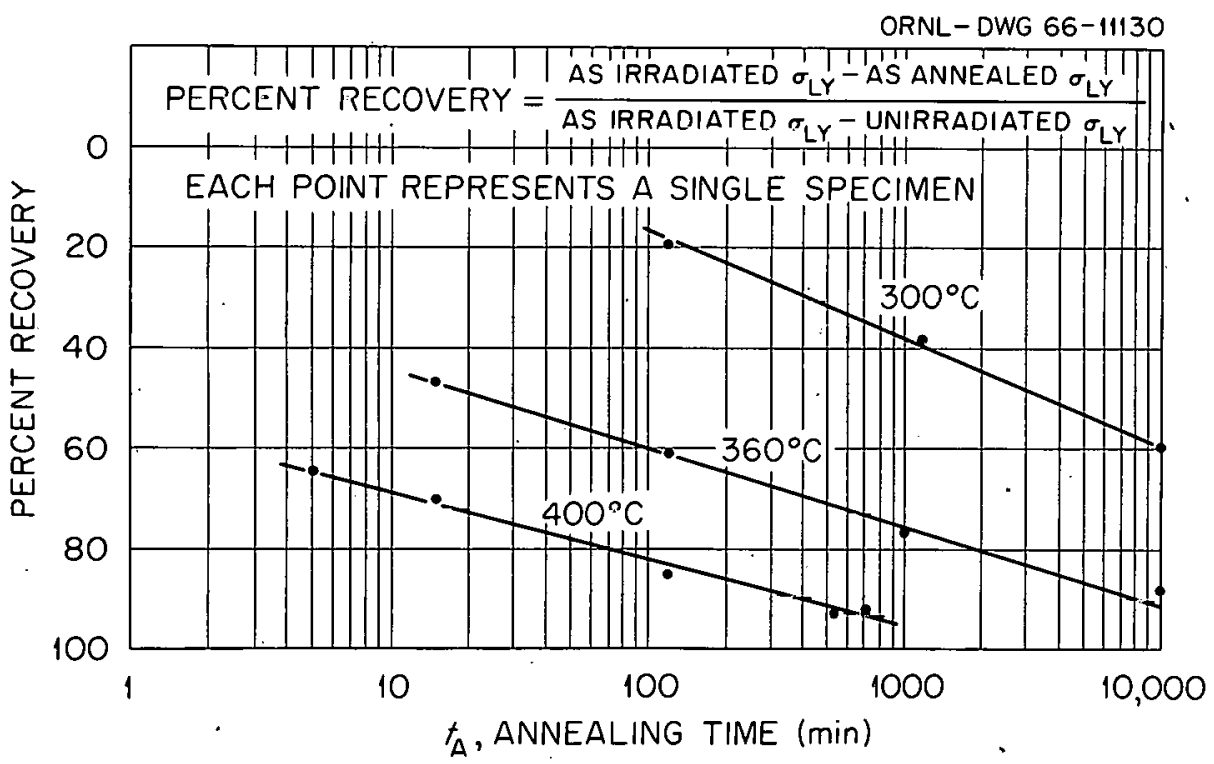

Fig. 8.7. The Percent Recovery of Radiation Induced Strengthening by Post Irradiation Annealing at the Given Temperatures. Test Temperature = $30^{\circ} \mathrm{C}$. Strain Rate $=0.02 \mathrm{~min}^{-1}$. Neutron Flux $=(3.1$ to 6.2$) \times 10^{12}$ $\mathrm{n} / \mathrm{cm}^{2} \cdot \sec (\mathrm{E}>1 \mathrm{Mev})$. Neutron Dose $=(6.8$ to 13.7$) \times 10^{17} \mathrm{n} / \mathrm{cm}^{2}$ $(\mathrm{E}>\mathrm{Tev})$.

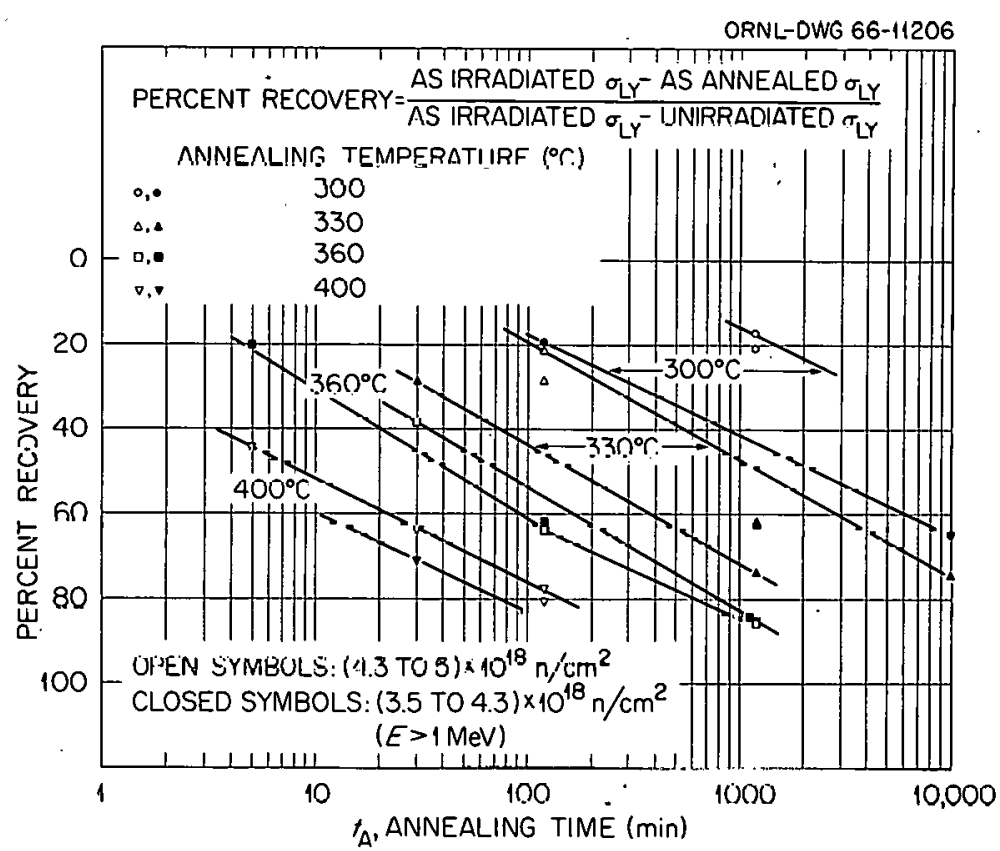

Fig. 8.8. The Percent Recovery of Radiation Induced Strengthening by Post Irradiation Annealing at the Given Temperatures. Test Temperature $=$ $30^{\circ} \mathrm{C}$. Strain Rate $=0.02 \mathrm{~min}^{-1}$. Neutron Flux $=1.7 \times 10^{11}$ to $2.25 \mathrm{x}$. $1013 \mathrm{n} / \mathrm{cm}^{2} \cdot \sec (\mathrm{E}>1 \mathrm{Mev})$. Neutron Dose $=(3.5$ to 5$) \times 1018 \mathrm{n} / \mathrm{cm}^{2}$ $(\mathrm{E}>1 \mathrm{Mev})$. 
annealing temperatures of $300^{\circ}$ and $330^{\circ} \mathrm{C}$. Additional testing has confirmed this trend. The apparent increased stability of the radiation damage with increasing neutron dose may be explained by the existence of two or more defect types having different activation energies for recovery and whose relative hardening effects change with increasing neutron dose. It is also likely that the relative effects of such defect types may be changed as a function of the irradiation temperature.

A possible explanation for the unusual damage recovery results presented above is that the interstitial impurities carbon, nitrogen, and oxygen, being mobile at the irradiation temperature of $95^{\circ} \mathrm{C}$, may be combining with radiation induced defects to produce various defect arrangements each. of which have a different hardening effect on the base material and different activation energy for recovery. As a first step . toward resulving some of these problems, four vacuum annealed and furnace cooled tensile samples of $46 \mu$ grain diameter Ferrovac-E were irradiated at $-130^{\circ} \mathrm{C}$ in the Bulk Shielding Reactor (BSR) to a neutron dose of 7.8 $x 10^{16}(\mathrm{E}>1 \mathrm{Mev})$. This irradiation temperature is well below the $0^{\circ} \mathrm{C}$ minimum predicted mobility temperature of any of these interstitial atoms. After irradiation, these samples were stored in liquid nitrogen before testing. In addition four identical samples were irradiated at about $90^{\circ} \mathrm{C}$ in a hydraulic tube in the Oak Ridge Research Reactor (ORR) to a dose of $1.25 \times 10^{17}$ neutrons $/ \mathrm{cm}^{2}$ ( $\mathrm{E}>1 \mathrm{Mev}$ ). These samples and the controls were stored at room temperature before testing.

These samples were tested in an Instron tensile machine a.t, a. strain rate of $2 \%$ per minute and at a test temperature of $0^{\circ} \mathrm{C}$ at which the interstitials were not expected to be mobile. The results of the tests, shown in Fig. 8.9, indicate that only a small percentage of the damage accumulated in the irradiations at $90^{\circ} \mathrm{C}$ is attributable to the low temperature neutron bombardment and subsequent thermal rearrangements occurring below $0^{\circ} \mathrm{C}$. It is also shown that a large part of the increased yield strength found after the irradiation at $90^{\circ} \mathrm{C}$ may be induced in the samples irradiated at very low temperatures by a $10 \mathrm{~min}$. anneal at $100^{\circ} \mathrm{C}$. Similar anneal hardening has been observed by Makin and Minter ${ }^{11}$ in

IIM. J. Makin and F. J. Minter, "The Mechanical Propertica of Irradiated Molybdenum," Acta Met. 7, pp. 361-366 (1959). 


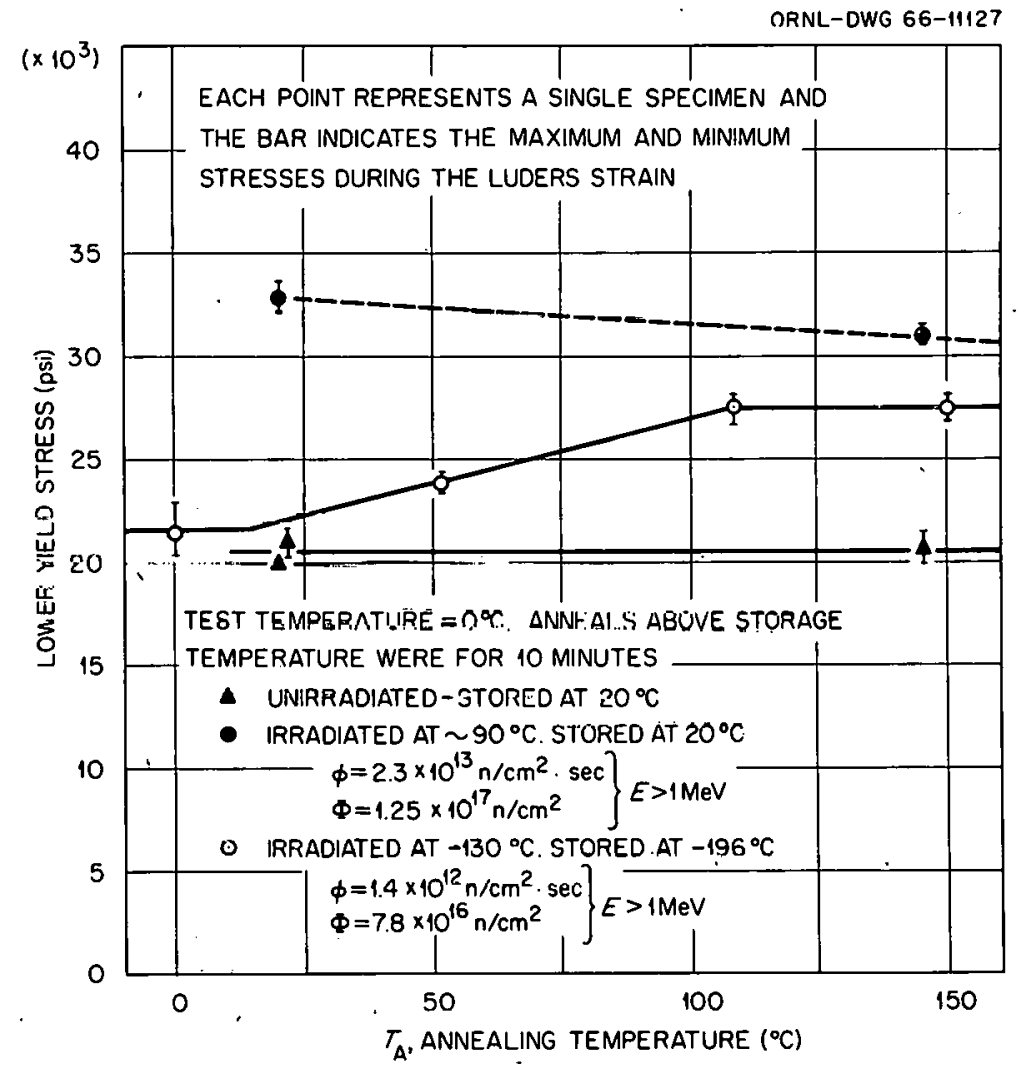

Fig. 8.9. Lower Yield Stréss at $0^{\circ} \mathrm{C}$ as a Function of Irradiation Temperature and Post-Irradiation Annealing for Tensile Specimens of Vacuum-Melted Iron Vacuum Annealed at $815^{\circ} \mathrm{C}$ t'or 5 Hours and Furnace Cooled. Grain Diameter 46 . Strain Rate $=0.02 \mathrm{~min}^{-1}$.

niobium and by Moteff $f^{12}$ and co-workers for tungsten and molybdenum. 'The interstitial content of the Ferrovac-E iron samples was not controlled; therefore, it is not possible to relate the anneal lidrdening to the presence or absence of certain interslilials. Howevcr, it it clear that some thermally activated rearrangement occurs belwetn $0^{\circ}$ and $100^{\circ} \mathrm{C}$ and, it is helieved that interaction of the interstitial elements with the radiation induced defects is responsible for the observed effect. More detailed experiments, using controlled additions of nitrogen and carbon to iron and sensitive physical techniques to detect the effects of the interstitial element mobility and activity, are in the preliminary stage and will be discussed fully in a future report.

12 J. Moteff, "Radiation Damage in Body-Centered Cubic Metals and Alloys," in Radiation Effects in Materials, New York, Gordon and Breach, 1966. 
The absence of a dose rate effect in our studies may be a result of the complications arising out of the interactions of the interstitial impurities with the radiation induced defects. Also, the wide variation in the dose dependence of the radiation damage previously reported in our studies may be ascribed to the same problem.

On The Temperature And Strain Rate Dependence of Radiation Hardening In Iron

$$
\text { S. M. Ohr E. D. Bolling }
$$

The strong temperature and strain rate dependence of the yield and flow stresses of the body-centered-cubic metals indicates that the thermal activation of dislocation motion plays a significant role in the deformation process. Although the thermal activation of dislocation motion has been the subject of a number of investigations, 13,14 no attention has so far been given to neutron irradiated body-centered-cubic metals. An understanding of the rate processes as reflected by the strong temperature and strain rate dependence of the yield stress is of considerable interest because of the influence which these factors have on the ductile-brittle transition in the body-centered-cubic metals. In this report, a preliminary account of an investigation of the temperature and strain rate sensitivity of the yield stress of neutron irradiated and unirradiated Ferrovac-E iron is. given.

Small tensile samples of 1/2-gage-length were prepared from cold rolled sheets of 0.01 -in.-thickncss. These samples were annealed in vacuo to achieve a uniform average grain diameter of approximately $30 \mu$. The tensile samples, shielded with cadmium, were irradiated at temperatures between $57^{\circ}$ and $90^{\circ} \mathrm{C}$ in the poolside facility of the ORR at a dose rate of approximately $3 \times 10^{12}$ neutrons $/ \mathrm{cm}^{2}$ sec. to a dose of $1.2 \times 10^{16}$

13 H. Conrad, "Yielding and Flow of the B.C:C. Metals at Low Temperatures," p. 4:6 in The Relation Between the Structure and Mechanical Properties of Metals, Her Majesty's Stationery Office, London, 1963.

14H. Conrad, "On the Mechanism of Yielding and Flow in Iron, "J. Iron and Steel Inst. 364, 198 (1961). 
neutrons $/ \mathrm{cm}^{2}$ ( $\mathrm{E}>1 \mathrm{Mev}$ ). Tensile deformation was carried out at various temperatures in baths of liquid nitrogen $\left(77^{\circ} \mathrm{K}\right)$, dry ice - acetone $\left(195^{\circ} \mathrm{K}\right)$, Freon $12\left(243^{\circ} \mathrm{K}\right)$, ice water $\left(273^{\circ} \mathrm{K}\right)$, and at room temperature $\left(298^{\circ} \mathrm{K}\right)$. In order to measure the strain rate sensitivity, the crosshead speed of the Instron tensile machine was cycled by an order of magnitude between the strain rates of $6.56 \times 10^{-5} \mathrm{sec}^{-1}$ and $6.56 \times 10^{-4}$ $\sec ^{-1}$. In some of the tests, a change in test temperature was made on a given sample to measure the temperature dependence of the yield stress at a constant dislocation configuration. In addition, stress relaxation tests were carried out at room temperature tu debermlle ducuralely lle athermal component of the yield stress, as well as to measure the rate sensitivity at small effective stresses.

Figure 8.10 shows the temperature dependence of the lower yield stress for unirradiated and irradiated iron, tested at a strain rate of $6.56 \times$ $10^{-5} \mathrm{sec}^{-1}$. The overall effect of neutron irradiation is an upward shift of the yield stress curve without an appreciable change in its shape. 'It may be noticed, however, that the gap between the two curves

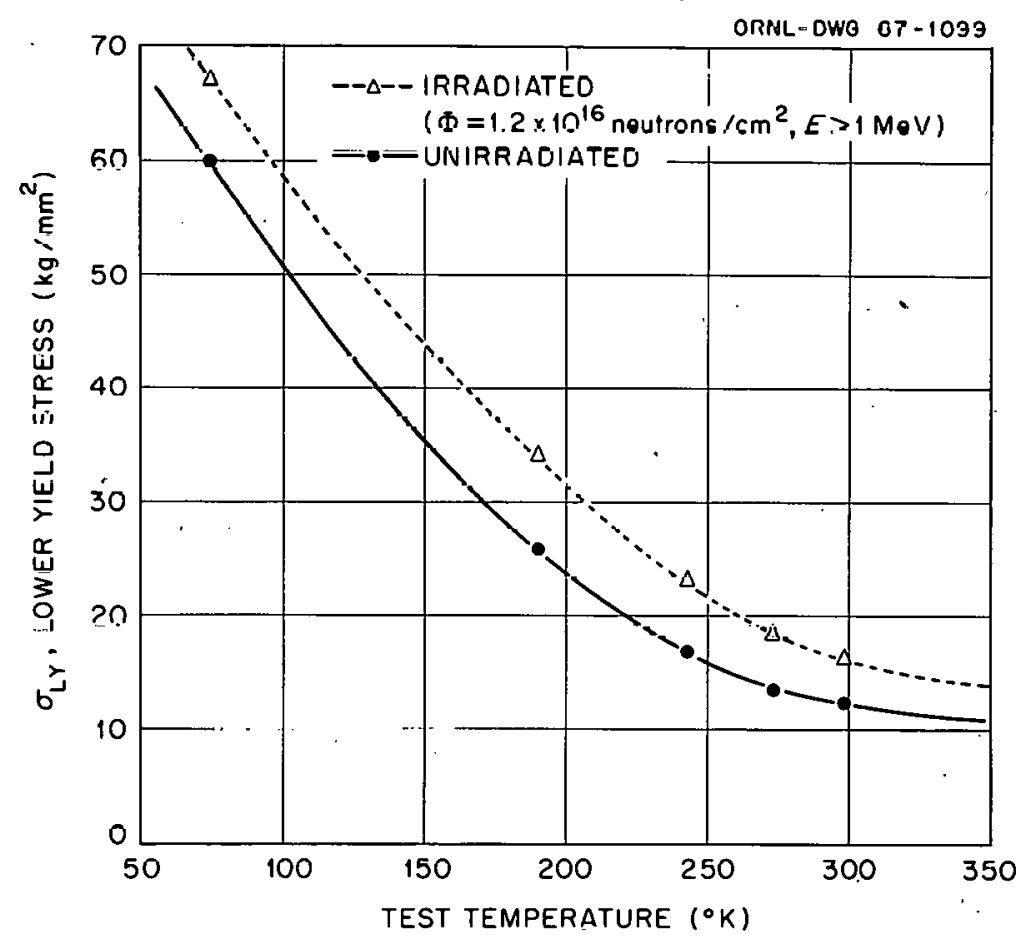

Fig. 8.10. Temperature Dependence of Lower Yield Stress for Unirradiated and Neutron Irradiated Polycrystalline Ferrovac-E Iron. 


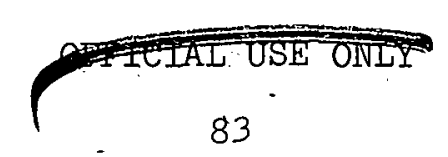

does gradually narrow as the temperature is increased. Thus neutron irradiation seems to have slightly modified the temperature dependence of the yield stress.

It is generally accepted that the yield stress consists of two components, namely thermal and athermal. It is the thermal component of the stress, or the effective stress, that varies with test temperature. The effective stress is a measure of the degree of thermal activation in overcoming the short range obstacles to dislocation motion. Also, it is the stress that is effective in moving dislocations. The athermal component defines the stress level that has to be supplied by the applied stress in overcoming the long range internal stress in the crystal. To determine the thermal component of yield stress, it is necessary to determine the athermal component and to subtract it from the applied stress. In earlier works, 14 the athermal component has been taken as the yield stress at a sufficiently high temperature. Recently, $\mathrm{Li}^{15}$ has suggested a method of determining the internal stress from a stress relaxation test by utilizing equations governing dislocation dynamics. When his method is applied to the stress relaxation data, obtained from both unirradiated and irradiated samples; the stress dependence of dislocation velocity, $\mathrm{m}^{*}$, is found to be approximately 4.0 and it is not affected by neutron irradiation. It is also found that the athermal component of the stress is increased by approximately $3.4 \mathrm{~kg} / \mathrm{mm}^{2}$ upon irradiation. This change can account for almost all of the increase in the yield stress at room temperature due to neutron irradiation. At low temperatures, the effective stress has also been increased by irradiation. This is shown in Fig. 8.11 in which the effective stress is plotted as a function of temperature. This increase in the effective stress in irradiated samples may be due to either a difficulty in generating fresh dislocations, a

15J. C. M. Li, "Dislocation Dynamics in Deformation and Recovery," to be published in the Canadian Journal of Physics. 
decrease in the eftective gage length of the sample arising from dislocation channeling, 16, 17 or a modification of the rate processes.

One of the parameters of interest in thermal activation analysis is the activation volume. The activation volume, $v$, represents the strain rate sensitivity of yield or flow stress, and it can be determined experimentally through. the expression 13

$$
\mathrm{v} \equiv \mathrm{k} T\left(\frac{\partial \ln \epsilon}{\partial \tau}\right)_{\mathrm{T}}
$$

16B. Mastel, H. E. Kissinger, J. J. Laidler, and T. K. Bierlein, 'Dislocation Channeling in Neutron Irradiated Molybdenum," J. Appl. Phys. 34, 3637 (1963).

17R. J. Arsenault, "The Possibility of Irradiation Dambe Affecting the Rate-Controlling Mechanism for Slip in Body-Centered-Cubic Metals and Solid Solutions," ORNL Report No. 3993, 1966.

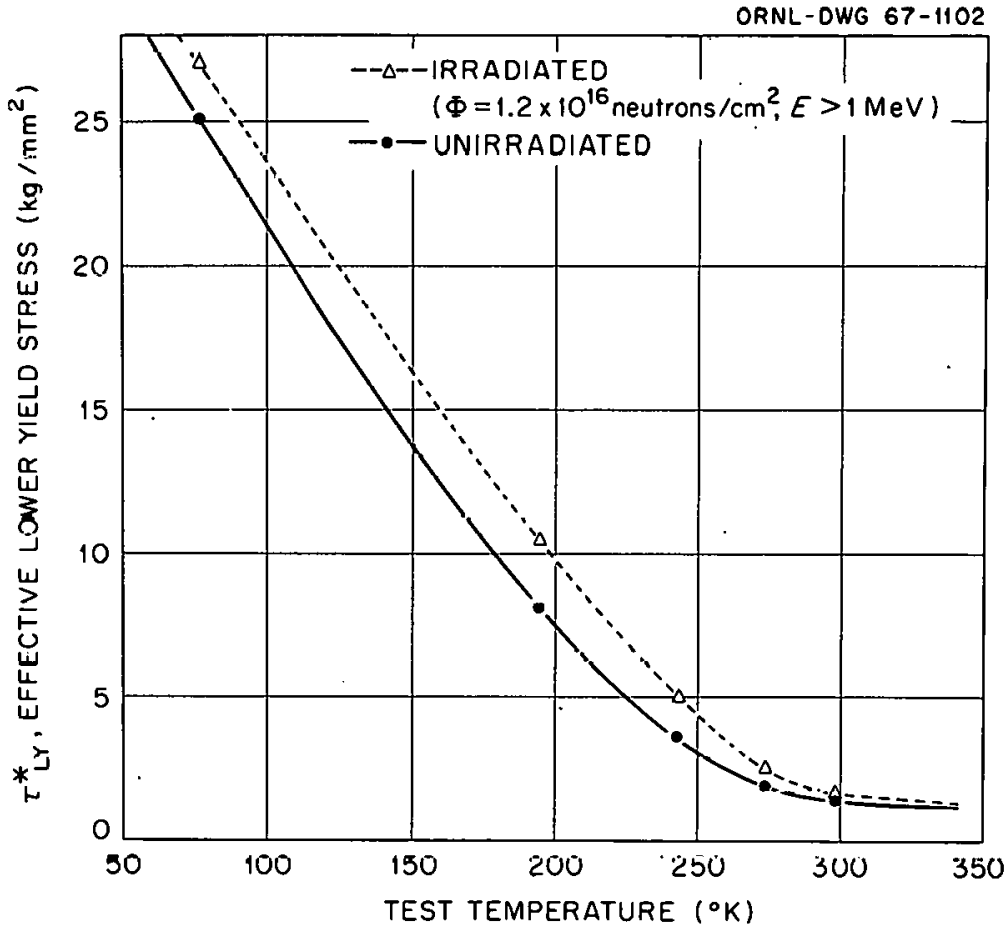

Fig. 8.11. Temperature Dependence of Effective Lower Yield Stress for Unirradiated and Neutron Irradiated Iron: 
On the other hand, the activation volume is related to the following microscopic quantities,

$$
\mathrm{v}=\mathrm{b} \quad \mathrm{d} l,
$$

where $\mathrm{b}$ is the Burgers vector and $\mathrm{d}$ and $b$ are the size and the average spacing, respectively, of the barriers that give rise to the short range resistance to dislocation motion. In determining the activation volume, both the rate change test and the stress relaxation method are employed. In the rate change test, the increment in stress accompanying a sudden change in the cross-head speed is measured. In the stress relaxation method, the cross-head motion is halted and the subsequent decrease in stress is measured continuously as a function of time. It has been shown 18 that the rate of stress relaxation is directly proportional to the plastic strain rate due to the motion of dislocations. It is, therefore, possible to measure the strain rate dependence of the applied stress from the analysis of the relaxation curve.

Figure 8.12 shows a plot of the activation volume as a function of the effective stress for both unirradiated and irradiated iron. It is found that data obtained by the two methods are in good agreement. It can be seen from the plot that, although there is an indication of a very slight increase in the activation volume particularly at high effective stresses, data from both unirradiated and irradiated samples fall along a single smooth curve. The results are also in good agreement, with those obtained by conrad ${ }^{14}$ for unirradiated iron. It may be stated that the effect of neutron irradiation is to raise the effective stress for deformation but when the activation volume is compared at the same level of effective stress there is no change due to irradiation. According to the definilion of the activation volume, this behavior implies that the neutron irradiation does not introduce new barriers to dislocation motion, in addition to those that are already present in unirradiated crystals.

18.S. M. Ohr, "A Study of Radiation Hardening in Iron by Stress Relaxation Techniques," p. 10.15 in Quarterly Progress Report: Irradiation Eff'ects on Reactor Structural Materials, May-July 1965, Pacific Northwest Laboratory, Richland, Washington, BNWL-128, 1965. 


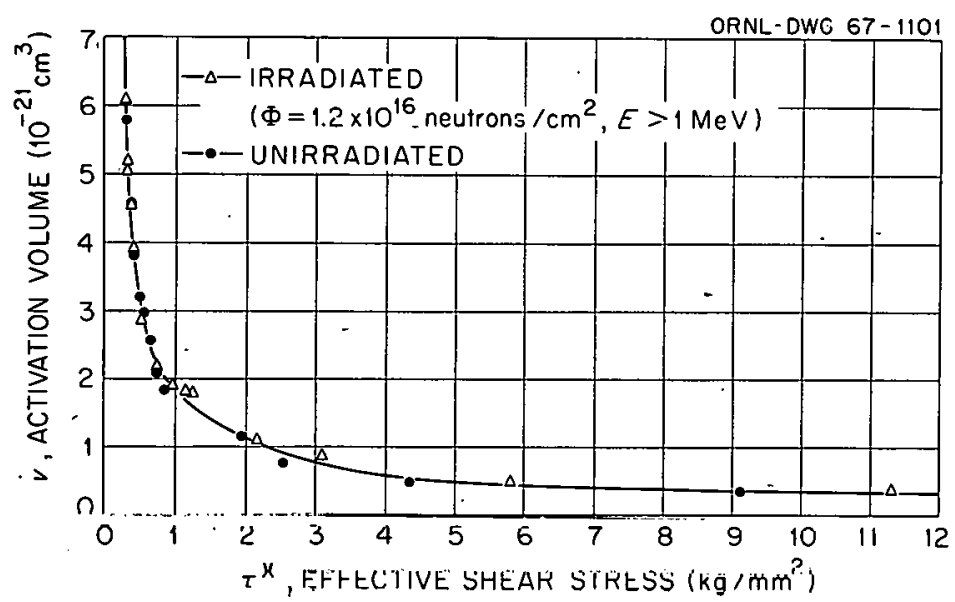

Fig. 8.12: Activation Volume Versus Effective Shear Stress for Unirradiated and Neutron Irradiated Iron.

Another parameter of interest is the activation energy, $\mathrm{H}$, associated with the thermal activation of dislocation motion. The activation energy is defined as

$$
\mathrm{H}=\mathrm{H}_{\mathrm{O}}-\mathrm{V} \tau^{*} \text {, }
$$

where $\mathrm{H}_{0}$ is the total activation energy, or the maximum interaction energy between the barriers and the moving dislocations. The second term on the right hand side, $v \tau^{*}$, corresponds to the work done by the applied stress during the thermal activation. The total activation energy, $\mathrm{H}_{\odot}$, is further defined as

$$
\mathrm{H}_{\mathrm{O}}=\mathrm{F}_{\mathrm{o}} \mathrm{d} / 2
$$

where $F_{0}$ is the maximum force required for a segment of dislocation to surmount a barricr of the almeler d. The abtivation encrgy, H, io determined experimentally through an expréssion ${ }^{13}$

$$
H=-v T\left(\frac{\partial \tau}{\partial T}\right) \dot{\epsilon} \text {, }
$$

where $(\partial \tau / \partial T)_{\dot{\epsilon}}$ is the temperature dependence of the yield or flow stress. 
Figure 8.13 shows a plot of the activation energy as a function of the effective stress. It shows that the activation energy is consistently higher after neutron irradiation. The values of the total activation energy, $H_{0}$, may be estimated from Fig. 8.13 by extrapolating the curves to. zero effective stress. The estimated values of $\mathrm{H}_{\mathrm{O}}$ are approximately $0.87 \mathrm{ev}$ and $0.97 \mathrm{ev}$ for unirradiated and irradiated crystals, respectively. The value of $\mathrm{H}_{\mathrm{O}}$ for unirradiated iron is somewhat higher than that previously given by Conrad. 14 The discrepancy can be attributed to the method by which the effective, stress is assigned. In Conrad's analysis, the effective stress was evaluated with respect to the stress at $300^{\circ} \mathrm{K}$. . This has an effect in underestimating the effective stress and hence the value of $\mathrm{H}_{\mathrm{O}}$, since the activation energy increases rapidly as the effective stress approaches zero. The present data also yields a value for $\mathrm{H}_{\mathrm{O}}$ of approximately $0.7 \mathrm{ev}$ at $300^{\circ} \mathrm{K}$, in. agreement with Conrad's data. From the preliminary nature of the present work, a question remains as to whether the observed increase in the activation energy upon irradiation is real. In order to establish the effect of irradiation on the activation energy, $H_{0}$, more accurately, a more careful measurement of the temperature and strain rate dependence of the yield stress particularly in the low range of effective stresses is needed. This is the range that will greatly influence the value of

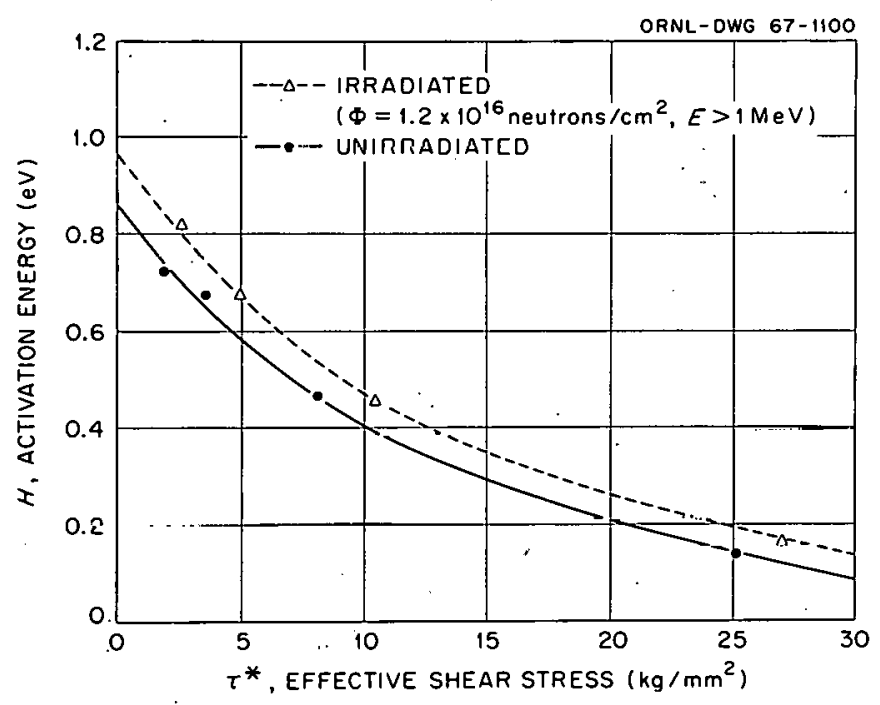

Fig. 8.13. Activation Energy Versus Effective Shear Stress for Unirradiated and Neutron Irradiated Iron. 


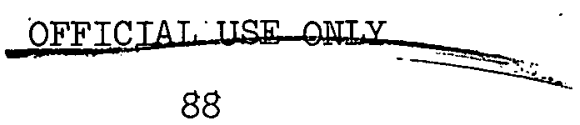

$\mathrm{H}_{\mathrm{O}}$, but unfortunately the activation volume and the temperature dependence vary too rapidly to permit accurate determination.

Although an effort is being made to supplement these experimental data, it now appears that neutron irradiation does not seem to alter the size and density of barriers to dislocation motion in iron. It is recalled that even unirradiated iron exhibits a strong temperature dependence of yield stress. Therefore, it has been șuggested that barriers present prior to neutron irradiation can interact strongly with moving dislocations. The defects introduced by irradiation are not sufficlenlly effective to interrere wilis alsluvalius motion a a now ooparato entity, The apparent increase in the activation energy implies that the irradiation induced defects merely strengther the barriers thul are already present in unirradiated crystals.

\section{Niobium: Purification and Perfection *}

R. E. Reed

This report will describe work which produced the purest niobium single crystals obtained in the Research Materials Program at ORNL during the past six months. An annealing treatment which resulted in niobium single crystals with good crystalline perfection will also be described.

A. Purification

\section{Experimental Procedure}

Niobium metal was obtained from the Parma Research Laboratory, Union Carbide Corporation, Parma, Ohio. It was in the form of electrodeposited metal cut from the edge of a cathodic plate deposit. In this case, the nioblum melal was electrodepositcd from a colution about, in weight per cent $\mathrm{NbF}_{5}$ in a mixture of alkali rluorides at a temperature of about $775^{\circ} \mathrm{C}$ and a current density of about $50 \mathrm{ma} / \mathrm{cm}^{2}$ with commercially pure niobium as anode material. 19

*Work sponsored by the Research Materials Program of the A.E.c.

19 G. W. Mellors and S. Senderoff, "Electrodeposition of Coherent Deposits of Refractory Metals: I. Niobium, "J. Electrochem. Soc. 112, 266 (1965). 
The metal was then electron beam drop cast into a water cooled copper mold with a I/2-inch inside diameter. This casting was then cold swaged to 3/16-inch-diameter rod.

Table 8.2 lists the impurity levels of this material before and after the drop casting operation. The oxygen level was reduced from 200-300 ppm to $95 \mathrm{ppm}$. The hydrogen level was also lowered from 5-30 ppm to 1 ppm while the nitrogen content remained about the same. However, the carbon content increased from i-6 pin to 30 pju. Also, there was an increase in the $\mathrm{Ta}$ and $\mathrm{W}$ content. Fe was reduced from $70 \mathrm{ppm}$ to $<1 \mathrm{ppm}$ during the drop casting operation. All other impurities. were also less than 1 ppm after the drop casting. operation.

Table 8.2

Impurity Analysis of Parma Niobium

After Various Melting Operations

In Weight Parts Per Million

\begin{tabular}{crrr}
\hline Impurity & $\begin{array}{r}\text { Electro- } \\
\text { Deposited }\end{array}$ & $\begin{array}{c}\text { Drop } \\
\text { Cast }\end{array}$ & $\begin{array}{c}\text { Zone } \\
\text { Refined }\end{array}$ \\
\hline $\mathrm{C}$ & $1-6^{*}$ & 30 & 32 \\
$\mathrm{O}$ & $200-300^{*}$ & 95 & 3 \\
$\mathrm{IN}$ & $5-10^{*}$ & 5 & 1 \\
$\mathrm{H}$ & $5-30^{*}$ & 1 & 1 \\
$\mathrm{Ta}$ & 5 & 18 & 1 \\
$\mathrm{~W}$ & 1 & 14 & 15 \\
$\mathrm{Fe}$ & 70 & $<1$ & $<1$ \\
$\mathrm{Fe}$ & & & 19 \\
\hline
\end{tabular}

*These values were taken from reference 19. 
The 3/16-inch-diameter niobium rod was then electron-beam floatingzone refined in a bakeable stainless steel system which has been described in reference 20. The rod was given 10 zoning passes at a speed of 5.0 in./hr. The vacuum was $1 \times 10^{-6}$ torr during much of the first pass but steadily improved until it attained $8 \times 10^{-10}$ torr during the last two passes. The rod was a single crystal which was seeded such that the rod axis was near the center of the unit triangle. Table 8.2 lists the impurity analyses after this operation. The oxygen and nitrogen levels were 3 and 2 ppm, respectively. The other impurities were relatively unchanged.

The resistance ratio of the rod was measured between room temperature and liquid hydrogen temperature and was found to be: $\mathrm{R} 300^{\circ} \mathrm{K} / \mathrm{R}$ $20^{\circ} \mathrm{K}=256$. This ratio was also taken between room temperature and liquid helium temperature with the latter being done in a $12 \mathrm{~K}$ gauss magnetic field. This ratio was: $\mathrm{R} 300^{\circ} \mathrm{K} / \mathrm{R} 4.2^{\circ} \mathrm{K}(12 \mathrm{~K}$ gauss $)=1420$.

A compression test was made on a specimen cut from the rod with a 3:1 length-to-diameter ratio. The ends were lapped flat and perpendicular to the rod axis. After a light chemical polish, this specimen was tested at a strain rate of $2.3 \times 10^{-4} \mathrm{sec}^{-1}$ on a table model Instron machine. The flow stress resolved on the (101)[11I] slip system was $900 \mathrm{gm} / \mathrm{mm}^{3}$.

\section{Discussion}

All pure niobium previously reported with $\mathrm{R} 300^{\circ} \mathrm{K} / \mathrm{R} 4.2^{\circ} \mathrm{K}$ (magnetic field) $>1000$ has been prepared using a technique involving an anneal in high vacuum ( $<10^{-8}$ torr) at temperatures above $2200^{\circ} \mathrm{C}$. Stromberg and Swenson ${ }^{21}$ and Fawcett, Reed, and Soden ${ }^{22}$ used this technique on wire type specimens to obtain resistance ratios of 1900 and 1600 , respectively.

${ }^{20}$. E. Reed, "Electron Beam Floating Zone Refining of Niobium," Proceedings of the Second International Conference on Electron and Ion Beam Science and Technology, April 17-20, 1966, New York, Gordon and Breach, to be miblished.

${ }^{2} I_{T}$. F. Stromberg, and C. A. Swenson, "Negative Surface Free-Energy Effects in Superconducting Niobium," Phys. Rev. Letters 9, 370 (1962).

22E. Fawcett, W. A. Reed, and R. R. Soden, "High-Field Galvanomagnetic Properties of Ta and Nb, "Bull. Am. Phys. Soc. 11, 170 (1966). 
Neither group reported any mechanical properties. However, Taylor and Christian 23 using the annealing procedure on $3 \mathrm{~mm}$-diameter single crystals of niobium reported a resolved yield stress in compression of $850 \mathrm{gm} / \mathrm{mm}^{2}$ for a strain rate of $6 \times 10^{-4} \mathrm{sec}^{-1}$. They also reported a resistance ratio of $\sim 4000$ for this material.

The niobium single crystals produced by electron beam-float-zonerefining from the Parma material at ORNL apparently approach the purity obtained by Taylor and Christian using their anncaling technique. Further studies on this material involving high temperature anneals in high vacuum are in process.

B. Perfection

\section{Experimental Procedure}

A niobium single crystal seeded such that the rod axis was near a $<2 l 1>$ crystallographic direction was grown using the electron-beam floating-zone technique. The niobium metal was obtained from wah Chang Corporation. The effect of float-zone-refining upon the purity of this material has been previously described. 20 The 3/16-inch-diameter crystal was zoned one pass at $3.8 \mathrm{in.} / \mathrm{hr}$ at $1-2 \times 10^{-6}$ torr vacuum.

A section 3/4-in.-long was cut from the rod using a high speed abrasive.cut-off wheel. Parallel flats about $1 / 2$-in.-long and $1.5 \mathrm{~mm}$ apart were spark cut along the [112] growth axis such that the (110) plane was perperuicular to the flats. The flat surface was thus a (III) surface. After chemically polishing the specimen until the flats were $0.7 \mathrm{~mm}$ apart, an anomalous transmission $\mathrm{x}$-ray topograph. (Borrmann topograph) was taken using molybdenum $\mathrm{K}_{\alpha}$ radiation from (i10) reflection planes.

The specimen was then annealed for $2 \mathrm{hrs}$. $42 \mathrm{mins}$. at $2200^{\circ} \mathrm{C}$ in a $2 \times 10^{-8}$ torr vacuum. R. F. induction heating was used. The specimen was placed in a 3/8-inch. I.D. niobium susceptor which was inside a 1 1/4-inch-diameter tantalum split radiation shield. The 4-inch-diameter

23.G. Taylor, and J. W. Christian, "The Effect of High Vacuum Puriflcation on the Mechanical Properties of Niobium Single Crystals," Acta Met. 13, 1216-1218 (1965). 
induction coil was outside the.2 1/2-inch. I.D. pyrex water cooled vacuum jacket which surroinded the work. The temperature was measured using an optical pyrometer sighted on one end of the specimen. After annealing, another Borrmann topograph was taken.

\section{Discussion}

Figure $8.14 \mathrm{a}$ is a Borrmann topograph showing the as-grown dislocation structure. The substructure consisted of sub-boundarica of less Lhan 180 sec misorientation elongated in the growth direction. In aridition, . Luere were nther areas showing ratlies dellse langles of dislocations.

Figure $8.14 \mathrm{~b}$ is the same specimen after annealing. The subgrain boundaries have become very sharp compared to the as-grown condition. However, they still have a misorientation < 180 sec. The interiors of the subgrains have a low dislocation density which approaches $10^{2}$ lines/ $\mathrm{cm}^{2}$. Anneals at $1800^{\circ} \mathrm{C}$ to $2000^{\circ} \mathrm{C}$ for times of about 2 hours did not result in any detectable change in the perfection of other similar specimens. Evidently, temperatures above $2200^{\circ} \mathrm{C}$ in a vacuum $<10^{-8}$ torr are necessary to obtain appreciable chanees in crystalline perfection for annealing times of a few hours. It may be significant that these same annealing conditions are those usen by other investigators $21-23$. to obtain resistance ratios ( $\mathrm{R}, 300^{\circ} \mathrm{K} / \mathrm{R} 4.2^{\circ} \mathrm{K}$ (menctic field) > 1000 and resolved yield stresses below $1000 \mathrm{gm} / \mathrm{mm}^{2}$. Fawcett, Reed, and Soden $^{22}$ have noted that high values for the resistance ratio do not necessarily imply high chemical purity. Tt is suggested here that high. crystalline pertection may be a factor in obtaining large resistance ratios toor niobium in addition to high purity.

\section{Conclusions}

Niobium metal prepared by electrodeposition from a solution of $\mathrm{NbF}_{5}$ in molten alkali metal fluorides was an excellent starting material for obtalning high purlty niobium single crystals using electron-beamfloating-zone-refining. The low $\mathrm{Ta}$ and $\mathrm{W}$ contents were very important since the zone refining, does not reduce the level of these impurities. A resistance ratio $\mathrm{R} 300^{\circ} \mathrm{K} / \mathrm{R} 4.2^{\circ} \mathrm{K}(12 \mathrm{~K}$ gauss $)=1420$ and a resolved 


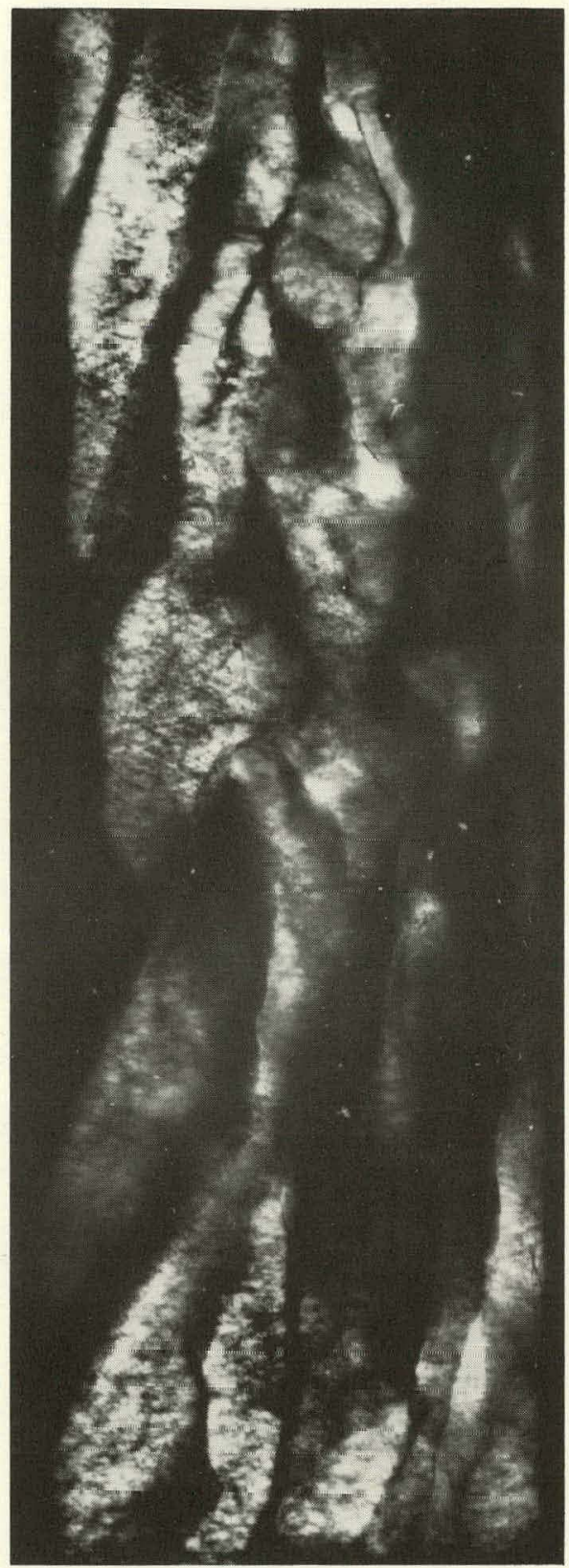

(a) $\Lambda$ s-Grown (18X)

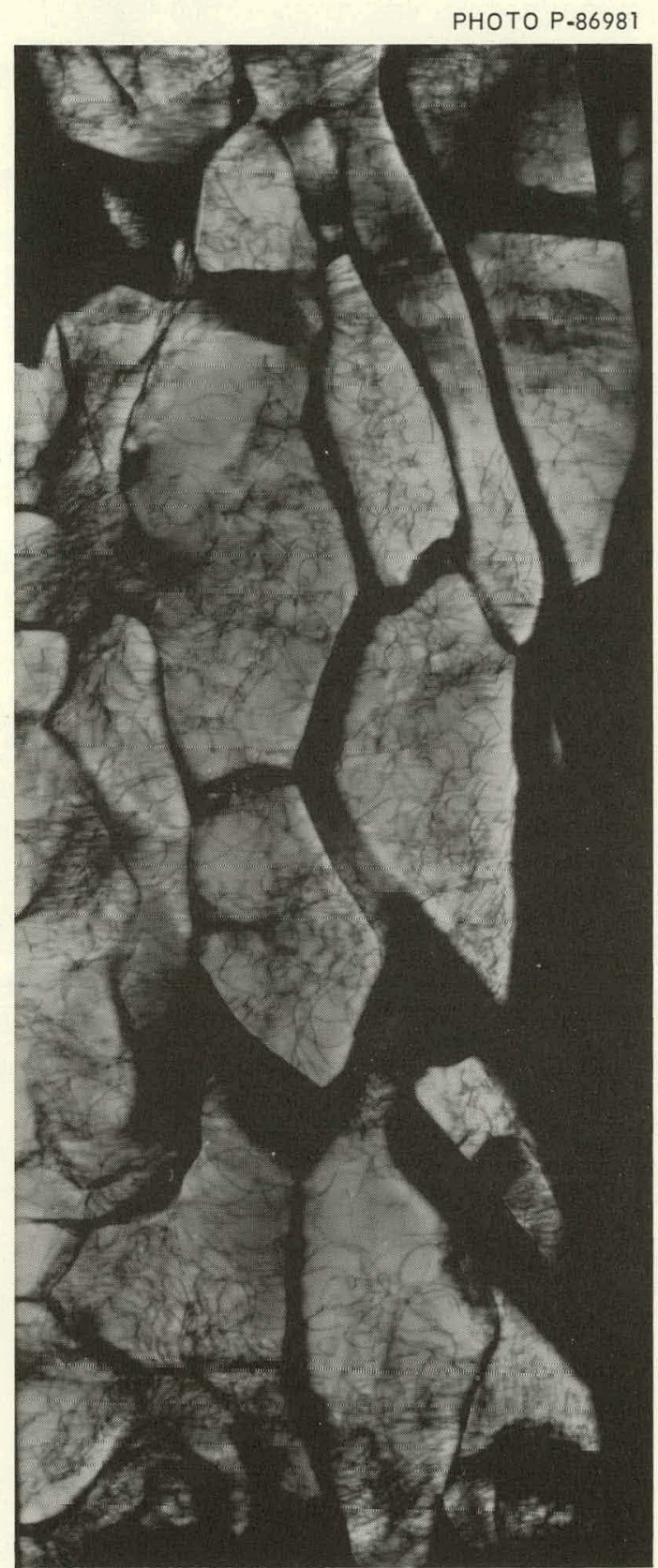

(b) Annealed (18x)

Fig. 8.14. Borrmann Topographs Using MoK Radiation from the (1) Reflection of a Niobium Single Crystal in (a) the As-Grown Condition and (b) after Annealing at $2200^{\circ} \mathrm{C}$ for $23 / 4$ hours at $2 \times 10^{-8}$ Torr Vacuum. 
shear stress for yielding in compression $=900 \mathrm{gm} / \mathrm{mm}^{2}$ was obtained for this material after 10 float zone refining passes at $5 \mathrm{in} / \mathrm{hr}$. in a final vacuum of $8 \times 10^{-10}$ torr. The perfection of as-grown niobium single crystals can be improved by annealing 4 hours at temperatures above $2200^{\circ} \mathrm{C}$ in vacuums better than $5 \times 10^{-8}$ torr.

Concerning the Etching of Dislocations in Niobium

\section{H. D. Guberman}

As has been demonstrated, etch pits may he produced in niobium which are associated with dislocations. 24 In all cases studied the dislocations associated with grown-in sub-boundaries and those randomly distributed throughout the sub-grain were easily etched. In addition, fresh dislocations introduced by either deforming through the yield point or stressing elastically near the yield point were also etched with apparent ease. Recently however, it became all but impossible to produce etch pits at new dislocations in the accustomed manner. Investigations indicate that the ability to etch dislocations in niobium is affected by the state of the material and in certain instances is directly associated with the presence of carbon at the dislocations.

All the samples studied were ostensibly identical. The earlier polycrystalline material and single crystals, which etched satisfactori$1 y, 25$ and the later single crystals, which etched poorly, were prepared. from the same Wah Chang starting stock in the manner described by Reed. 26 The difference in the behavior of the material thus suggested that it had somehow been altered during preparation. This was corroborated by

${ }^{24}$ H. D. Guberman, "Dislocation Etch Pits in Niobium," Radiation Metallurgy Section Solid State Divison Progress Rept., Feb. 1966, ORNL3949, p. 56

25 H. D. Guberman, "Dislocation Etch Pits in Niobium," Radiation Metallurgy Section Solid State Division Progress Rept., Aug. 1965, ORIVL3878, p. 49.

${ }^{26}$ R. E. Reed, "High Vacuum Electron Beam Floating Zone Refiner," Radiation Metallurgy Section Solid State Division Progress Rept., Feb. 1966, ORIL-3949, p. 35. 
observations on the superconducting properties of niobium single crystals prepared during the period in which the non-etching samples were grown. It was found that, compared to material grown earlier, the transition temperature decreased while the upper critical field at $4.2^{\circ} \mathrm{K}$ increased indicating an increase in the impurity content. 27 It was subsequently determined that the vacuum system in which the crystals were grown was operating at a higher pressure due to a fault; this could conceivably be the cause of the anomalous behavior though the precise nature of the contamination is not known.

This suggests that impurities play a significant role which was not apparent earlier. At about this time it became known that oxygen played. no part in the etching but that carbon significantly enhanced dislocation etching in niobium. 28

This was immediately verified by depositing a flash coating of carbon in a vacuum onto a sample which had been indented and then aged at $1050^{\circ} \mathrm{C}$ for $10 \mathrm{l} / 2$ hours. Prior to the carbon deposition and aging, the usual etching treatment did not show any new dislocations (Fig. 8.15) but afterwards showed them quite clearly (Fig. 8.16).

Aging temperatures substantially lower than $1000^{\circ} \mathrm{C}$ with or without carbon deposition, did not aid in etching dislocations. Annealing for 18 hours at $400^{\circ} \mathrm{C}$ or 16 hours at $600^{\circ} \mathrm{C}$ after carbon deposition did not significantly enhance the etching of fresh dislocations. However, in the first case, subsequent redeposition of carbon and aging at $1050^{\circ} \mathrm{C}$ for 11 hourc revealed the pitis clearly. In the second case, re-aging at $1025^{\circ} \mathrm{C}$ for 17 hours without prior carbon deposition did not reveal any but grown-in dislocations as before.

The above experiments are significant for two reasons. First, they establish that it is the carbon and not the aging treatment which. is of primary importance in revealing the dislocation site by etching. Secondly, in the material a.t hand, it is not possible to cause a redistribution of carbon by low temperature aging as was done by Evans 29 to

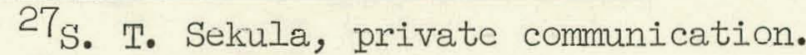

${ }^{28}$ R. Vardiman, Naval Research Laboratory, Washington, D. C., private communication.

29P. R. V. Evans, "Dislocation Etch Pit Studies in Annedled and Deformed Polycrystalline Niobium," J. Less-Common Metals 6-, 253 (1964). 


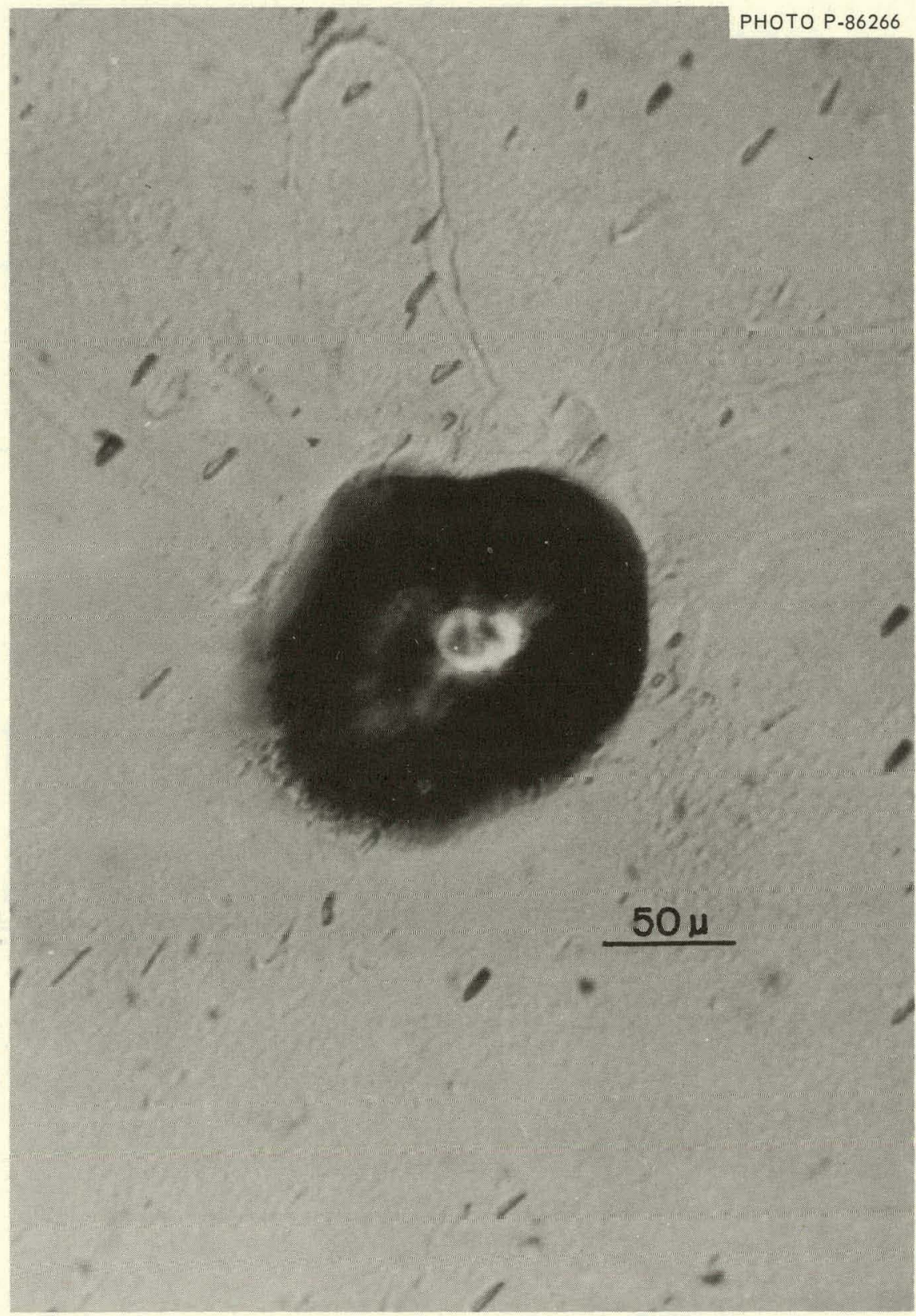

Fig. 8.15. Area Surrounding Indentation in a Niobium Sample Shows Apparently no Fresh Dislocation Pits after Usual Etching Procedure. 


\section{OHFTOATUE ONTY}

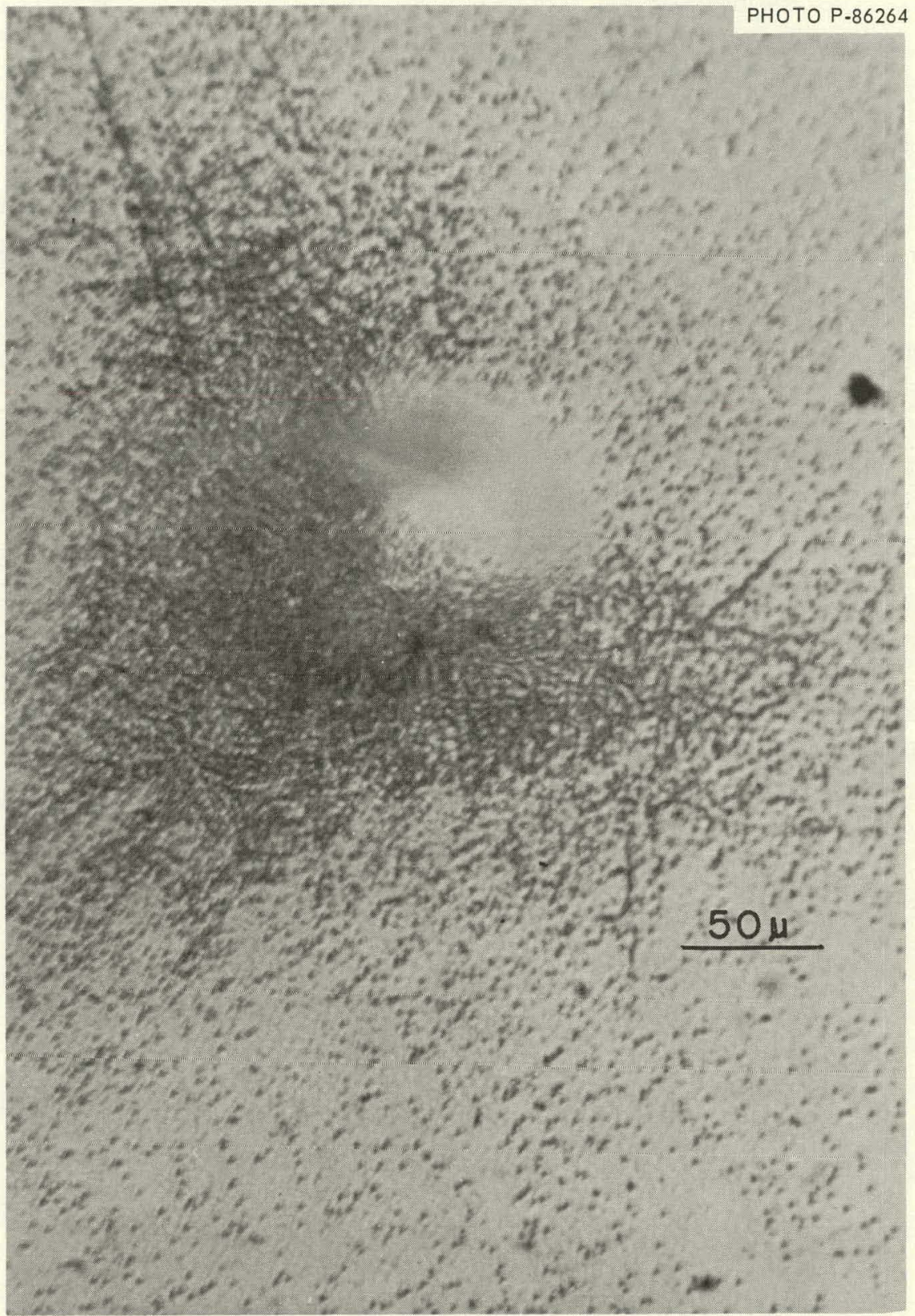

Fig. 8.16. Fresh Pits Associated with Deformation in the Vicinity of the Indentation were Easily Brought out after a Flash Carbon Deposition and High Temperature Aging Treatment Prior to Chemical Etching. 
decorate fresh dislocations, possibly because the present material is of much higher purity.

It was subsequently determined that $3 / 4$ hour aging at $1000^{\circ} \mathrm{C}$ after carbon deposition is sufficient to introduce the impurity into solution and decorate the dislocations.

It is particularly noteworthy that this carbon decoration treatment enables the fresh dislocation patterns to be revealed with greater clarity and detail than before in the single crystal material. For example, in making dislocation velocity measurements it was possible to ohserve fieslı pils divne a traction of the potential source length anly. Now however, pits are uncovered along the length of the scratch at every point (Fig. 8.17). Thus it would seem to be desirable to decorate the dislocations in this manner in every instance for velocity measurements, etc. However, the treatment raises certain problems; in particular, it must be established that a one hour $1000^{\circ} \mathrm{C}$ anneal does not substantially affect the arrangement, for example, of fresh dislocations emanating from a surface source.

Finally, since it is known that carbon is not sufficiently mobile to decorate rapidly moving, fresh dislocations at room temperaturc, 30 it would be of interest to know what permitted the fresh dislocation to be etched principally in the poly-crystalline niobium in the first place.

The Interaction of Radiation Produced Defects and. Interstitial Impurity Atoms in Niobium

$$
\begin{gathered}
\text { J. M. Williams } \\
\text { W. E. Brundage }
\end{gathered}
$$

'the annealing of radiation damage in the temperature interval near 15 per cent of the melting temperature is a particularly important anncaling stage for b.c.c. metals since it has been shown that additional

30 R. W. Powers and Margaret V. Doyle, "Diffusion of Interstitial Solutes in the Group V Transition Metals," J. Appl. Phys. 30, 514 (1959). 


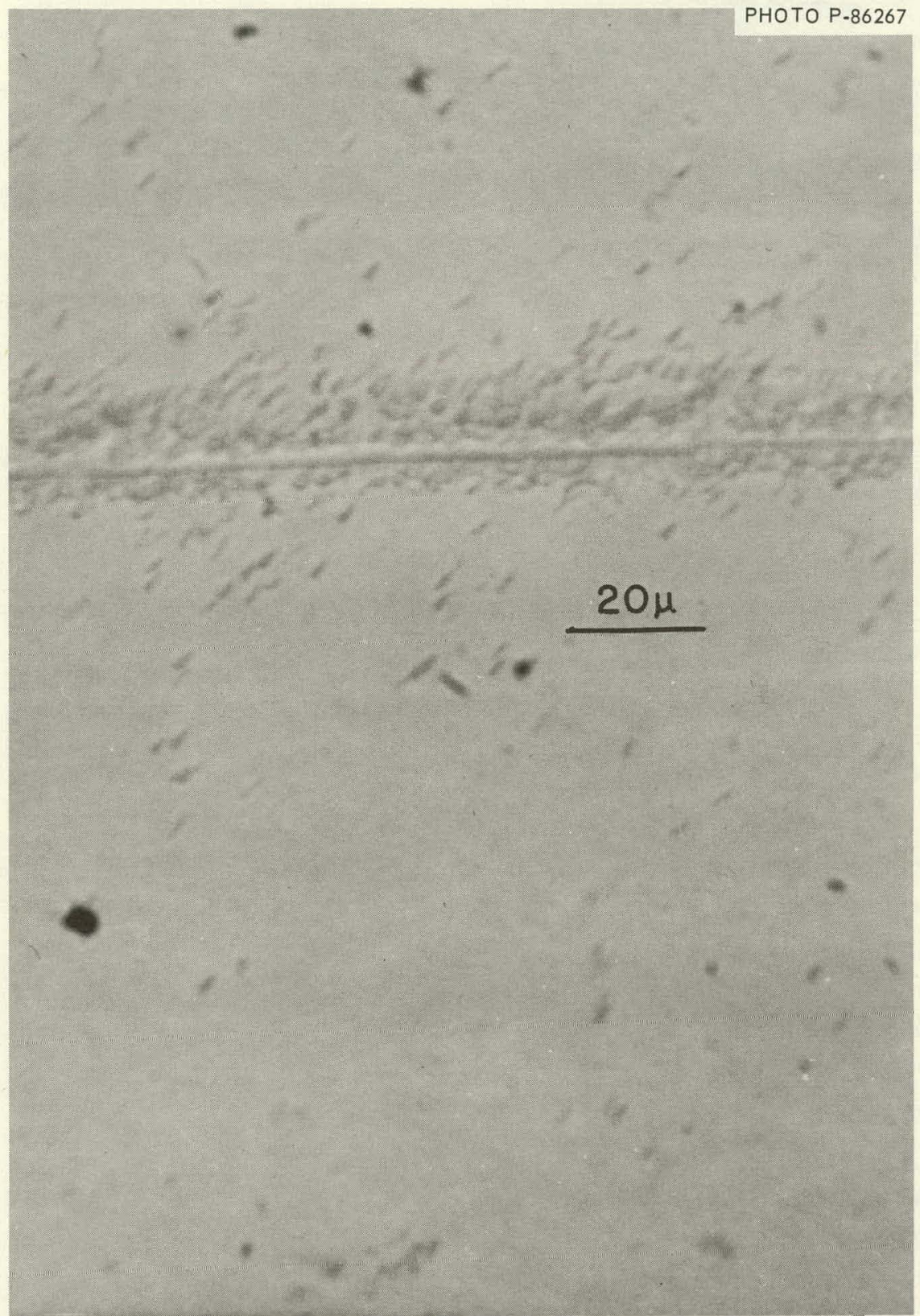

Fig. 8.17. Pits Along a Scratch in Niobium Revealed by the Carbon Deposition Technique. 
radiation hardening is produced by annealing in this range.31-33 Annealing in this temperature interval is called stage III annealing by most authors. Stage III annealing in b.c.c. metals has been attributed to either vacancy migration, 34 interstitial migration 35 or interstitial impurity migration. 36,37 As pointed out in the previous report 38 we believe that stage III annealing is due to interstitial impurity migration, and we presented evidence obtained from internal friction measurements to verify that oxygen atoms do migrate to irradiation produced defects in the temperature range of stage III amealing. In this report additional evidence obtained from resistivity and internal friction measurements is presented to show that the Stage III annealing In uiobium is caused by oxygen migrating to rudiation produced de fects.

\section{Specimen Preparation}

The samples used in these experiments were prepared by swaging and drawing zone refined niobium 39 rods to 0.030 inch diameter wire suitable for both internal friction and resistivity measurements. The wires were

${ }^{3 I_{M}}$. J. Makin and H. J. Minler, "The Mcchonical Prnperties of Irradiated Niobium," Acta Met. 1, 361 (1959).

32A. S. Wronski and A. A. Johnson, "A Iardening Et'tect Assuclaled with Stage III Recovery in Neutron Irradiatcd Molybdenum," Phil. Mag. $\underline{8}$, 1067 (1963).

$33_{\mathrm{N}}$. E. Hinkle, this report.

${ }^{34}$ D. E. Peacock and A. A. Johnson, "Stage III Recovery in Neutron Irradiated Molybdenum and Niobium," Phil. Mag. 8, 563 (1963).

$35 \mathrm{~J}$. Nihoul, "The Recovery of Radiation Damage in Molybdenum," Phys. Stat. Sol. ', (1962).

36 A. R. Rosenfield, "Recovery of Cold Worked Body Centered Cubic Metals, "Acta Met. 12, 119 (1964).

37F. Schlat and A. Kothe, "Einfluss des Sauerstoffgehalts auf die Erholung von Kalwerformtem Fantal," Acta Met. 14, 425 (1966).

$38 \mathrm{~J}$. T. Stanley and W. E. Brundage, "The Interaction of Radiation Produced Defects and Interstitial Impurity Atoms in Niobium, "Radiation Metallurgy Section Solid State Divisiun Progress Rcport for Perind Ending July 1966, ORNL-4020, Sept. 1966, p. 49.

39R. E. Reed, "Electron Beam Floating Zone Refining of Niobium," Proceedings of the Second International Conference on Electron and Ion Beam Science and Technology, Gordon and Breach Publishers, New York, April 17-20, 1966. To be published. 
then annealed and outgassed at various temperatures ranging from 1800 to $2200^{\circ} \mathrm{C}$ by resistive heating in vacua ranging from $5 \times 10^{-6}$ to $3 \times 10^{-9}$ torr. These treatments resulted in samples with various concentrations of the three principal interstitial impurities, $\mathrm{C}, \mathrm{O}$, and $\mathrm{N}$. Since the purpose of these experiments is to focus attention on the role of oxygen in the radiation annealing, an attempt was made to add oxygen to two of the samples, $D$ and $F$, following the original outgassing treatment. This was done by reheating the samples to a temperature lower than the outgassing temperature in an atmosphere of $\mathrm{O}_{2}$. For sample $\mathrm{F}$ the resulting oxygen concentration was $\sim 260 \mathrm{ppm}$ by weight. However, for sample $D$ the conditions necessary for adding oxygen were not acbieved and some carbon was. inadvertently added instead.

The interstitial impurity levels of these specimens were characterized by means of internal friction and resistivity measurements. The data of Powers and Doyle 40 provide a quantitative correlation between internal friction peak heights and concentration for $O$ and $N$. The resistivity contribution of oxygen was taken as $0.0039 \mu \Omega-\mathrm{cm} / \mathrm{wt} \mathrm{ppm}^{41}(6.7 \mu \Omega-\mathrm{cm} / \mathrm{at}$ $\%)$ and that of nitrogen was $0.005 \mu \Omega-\mathrm{cm} / \mathrm{wt} \mathrm{ppm}(10 \mu \Omega-\mathrm{cm} / \mathrm{at} \%)$. 2 . Neither the damping effect nor the resistivity of carbon is known, but estimates of the carbon concentration were obtained under the assumption that the values for $O$ and $N$ are at least representative of those for carbon. Attempts to measure carbon concentration were further limited by the fact that carbon has a very low solubility at low temperatures. Thus, some of the carbon may precipitate out during cooling and any carbon retained in solution rapidly precipitates during the time required for making internal friction measurements.

${ }^{40} \mathrm{R}$. W. Powers and Margaret V. Doyle, "Diffusion of Interstitial Solutes in the Group V Transition Metals," J. Appl. Phys. 30, 514 (1957).

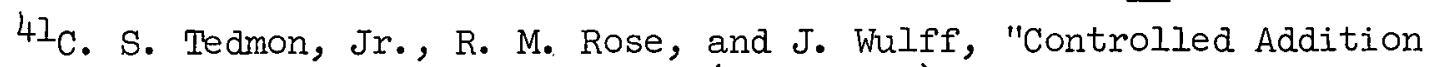
of small Amounts of Oxygen to Niobium (Columbium)," Trans. AIME 230, 1732 (1964).

42. A. Pasternak and B. Evans, "The Effect of Dissolved Nitrogen on the Electrical Resistance of Niobium (Columbium), "Trans. AIME 233,'1194 $(1965)$. 


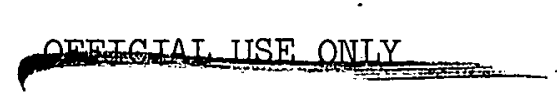

102

In general, the total interstitial impurity concentrations predicted from the resistivity data were in good agreement with those obtained from internal friction measurements. These methods and some preliminary measurements will be presented in more detail later, but a summary of the annealing information, resulting impurity concentration and resistivity data are given in Table 8.3.

The principal metallic impurities are $\mathrm{Ta}$ and $\mathrm{W}$. The concentration of these impurities depends only on the source of the pre-zoned starting material, since zoning has no effect on their concentrations. 39 Material from two sources was used in these experiments and the apprupriate levels of $\mathrm{Ta}$ and $\mathrm{W}$ are also indicated in Table 8.3 .

Measurement Techniques

A description of the internal friction equipment and procedures has been given in a previous report. 38 For purposes of resistivity measurements, primary potential contacts of 0.010 in. diameter $\mathrm{Nb}$ wire were spotwelded to the samples. These contacts remained with the samples throughout the preliminary measurements, irradiation, and subsequent isochronal annealing to be described later. Thus, the gage length was constant for a given sample over the course of its entire series of treatments. The accuracy of the absolute resistivity values given is limited to about $\pm 4 \%$ by our knowledge of the sample geometry. Platinum wire contacts were spotwelded to the primary niobium contacts and copper leads were attached to the Pt by soldering. The resistance measurements were made by the potentiometer technique using a Rubicon Six Dial Microvolt Potentiometer. 'l'he sample was immersed in liquid helium inside a superconducting magnet capable of 20 kilogauss. The resistance values were picked of lis suptrunduclirit transition curve at fields ranging from 15 to $18 \mathrm{kilogauss,} \mathrm{as} \mathrm{required}$ to insure that each sample was fully normal.

\section{Pre-Irradiation Measurements}

Internal friction measurements on sample A are shown in Fig. 8.18. The difference between the first and second run data shown is due to the precipitation of carbon during the first run measurements. Internal friction measurements on samples $C$ and $E$ are shown in Fig. 8.19. In 
Table 8.3. Annealing Temperatures, Vacua, and Resulting Characteristics for Niobium Samples.

\begin{tabular}{|c|c|c|c|c|c|c|c|c|}
\hline Sample & $\begin{array}{c}\text { Annealing. } \\
\text { Temp. } \\
\left({ }^{\circ} \mathrm{C}\right)\end{array}$ & $\begin{array}{l}\text { Final Vacuum } \\
\text { Achieved } \\
\text { During } \\
\text { Annealing }\end{array}$ & $\begin{array}{c}\text { Re-Heating } \\
\text { Temp. } \\
\left({ }^{\circ} \mathrm{C}\right)\end{array}$ & $\begin{array}{c}\text { Re-Heating } \\
\text { atm }\end{array}$ & \begin{tabular}{|} 
Resistivity \\
$(\mu, \mathrm{cm})$ \\
at \\
$4.2^{\circ} \mathrm{K}$
\end{tabular} & $\frac{R_{\text {Room Temp. }}}{R_{4.2^{\circ} \mathrm{K}}}$ & \begin{tabular}{|l} 
Interstitial \\
Impurities \\
Weight ppm
\end{tabular} & $\begin{array}{c}\text { Metallic } \\
\text { Impurities }\end{array}$ \\
\hline A & 1800 & $\begin{array}{l}5 \times 10^{-6} \\
\text { torr }\end{array}$ & -- & -- & -- & -- & $\begin{array}{l}40(0) \\
60(\mathrm{C}) \\
7.7(\mathrm{~N})\end{array}$ & $\begin{array}{l}367 \mathrm{Ta} \\
227 \mathrm{~W}\end{array}$ \\
\hline E & 1700 & $5 \times 10^{-6}$ & -- & -- & -- & -- & $\begin{array}{l}70(0) \\
60(\mathrm{C}) \\
12(\mathrm{~N})\end{array}$ & $\begin{array}{l}367 \mathrm{Ta} \\
229 \mathrm{~W}\end{array}$ \\
\hline $\mathrm{C}$ & 2100 & $1 \times 10^{-7}$ & $--?$ & -- & 0.069 & 208 & $\begin{array}{r}33(0) \\
3(\mathrm{C}) \\
10(\mathrm{~N})\end{array}$ & $\begin{array}{l}367 \mathrm{Ta} \\
227 . \mathrm{W}\end{array}$ \\
\hline J & 2100 & $\begin{array}{l}1 \times 10^{-7} \\
\therefore\end{array}$ & 1700 & $\begin{array}{l}5 \times 10^{-8} \\
\text { torr } \\
\left(\mathrm{O}_{2}\right)\end{array}$ & 0.27 & 57 & $\begin{array}{l}3(0) \\
30(\mathrm{C}) \\
10(\mathrm{~N}):\end{array}$ & $\begin{array}{l}367 \mathrm{Ta} \\
227 \mathrm{~W}\end{array}$ \\
\hline$\Xi$ & 2200 & $3 \times 10^{-9}$ & -- & -- & 0.017 & 870 & $\left\{\begin{array}{l}4(0) \\
4(\mathrm{C}) \\
4(\mathrm{~N})\end{array}\right.$ & $\begin{array}{l}367 \mathrm{Ta} \\
227 \mathrm{~W}\end{array}$ \\
\hline$F$ & 2200 & $5 \times 10^{-9}$ & $\Xi 100$ & $5 \times 10^{-6}$ & 1.0 & 16 & $260(0)$ & $\begin{array}{l}296 \mathrm{Ta} \\
73 \mathrm{~W}\end{array}$ \\
\hline
\end{tabular}




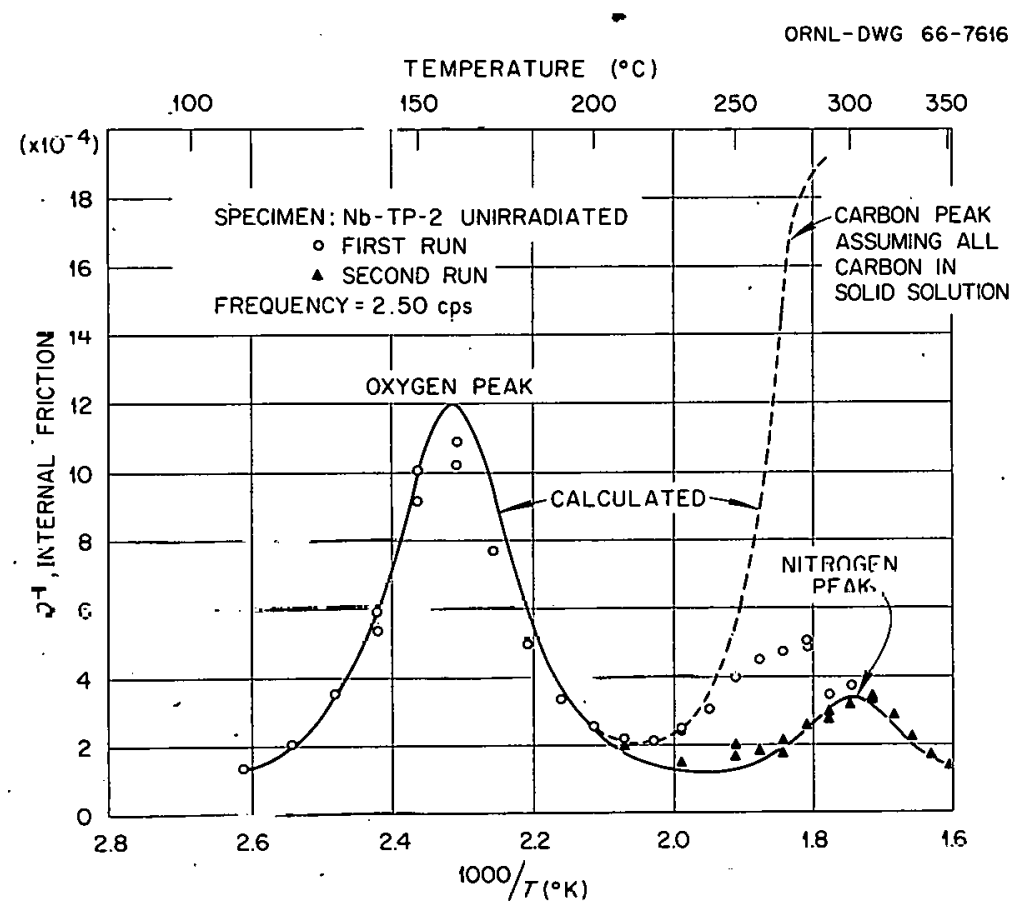

Fig. 8.18. Pre-Irradiation Internal Friction Measurements on Sample A.

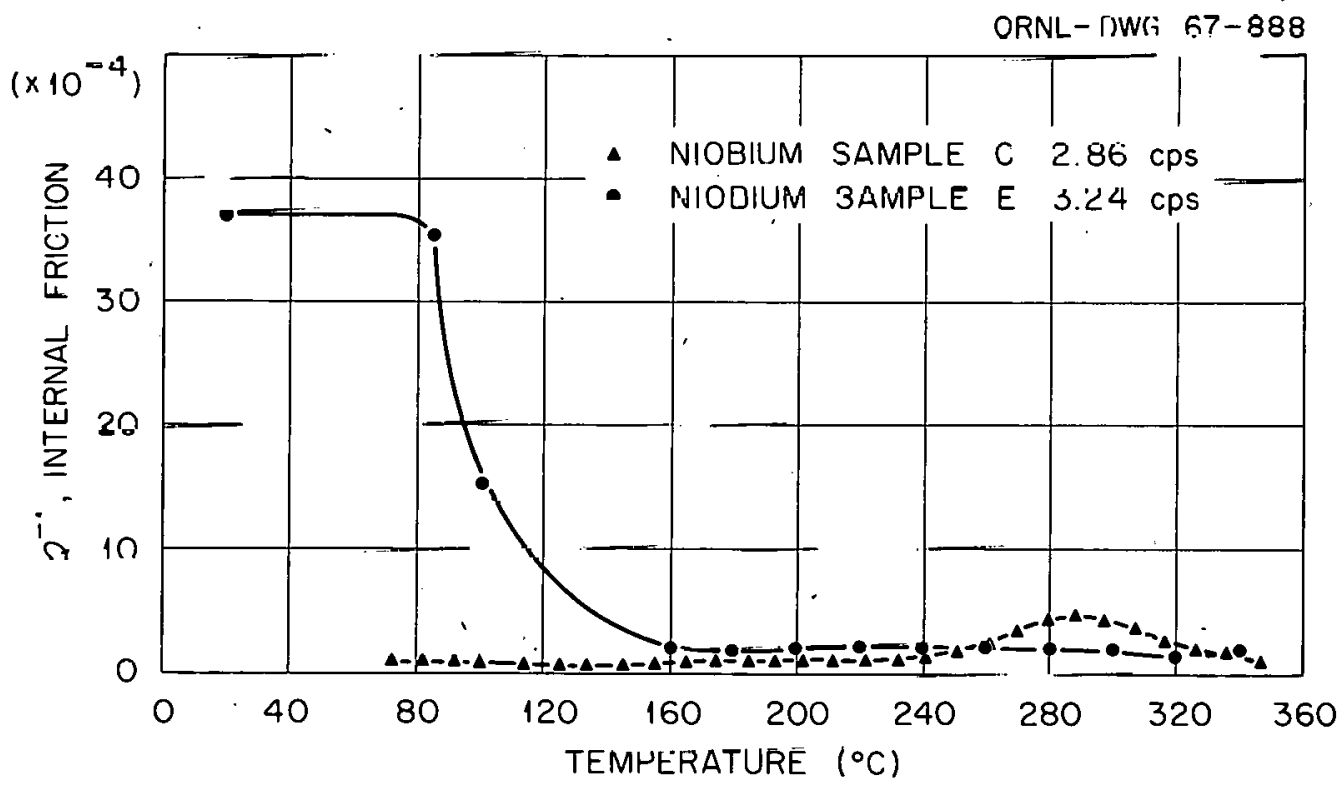

Fig. 8.19: Pre-Irradiation Internal Friction Measurements on Samples C and E. 
both of these specimens the oxygen peak seems to be buried in the background damping and is certainly less than $1 \times 10^{-4}$. This value of internal friction corresponds to about $3 \mathrm{ppm}$ by weight of oxygen.' The resistivity of sample $\mathrm{E}(0.017 \mu \Omega-\mathrm{cm})$ would correspond to about $4 \mathrm{ppm}$ oxygen if the total resistivity were attributable to oxygen. However, the large metallic impurity concentration probably accounts for much of this resistivity, so that the oxygen content should be much less. Nitrogen and carbon remain in sample $\mathrm{C}$ in sufficient quantities to produce the small peaks shown in Fig. 8.19 and the observed resistivity of $0.069 \mu \Omega-\mathrm{cm}$. Both specimens show decreases in the background damping. at temperatures where the oxygen atoms become mobile. This effect is especially pronounced in sample E.

The internal friction measurements on sample $F$ are shown in Fig. 8.20. The oxygen peak height of $75 \times 10^{-4}$ corresponds to $260 \mathrm{ppm}$ of oxygen. The resistivity of $1.0 \mu \Omega-\mathrm{cm}$ corresponds to $\sim 255 \mathrm{ppm}$.

Irradiation and Anneali,ing Procedures

Internal friction specimens from samples $A$ and $B$ were irradiated to doses of $8 \times 10^{17}$ and $1.6 \times 10^{18}(\mathrm{E}>1.0 \mathrm{Mev})$, respectively, in position P-5 of the Bulk Shielding Reactor. The irradiation temperature was $50^{\circ} \mathrm{C}$.

Resistivity and internal friction specimens from samples C, D, E, / and $\mathrm{F}$ were irradiated in position C-4I of the LITR. Samples C and D were irradiated together to a dose of approximately $1 \times 10^{18}$ neutrons $/ \mathrm{cm}^{2}$ $(E>1.0 \mathrm{Mev})$ and $E$ and $F$ were irradiated simultaneously to a dose of $2 \times 10^{18}$ Hétruns $/ \mathrm{cm}^{2}$ ( $\left.E>1.0 \mathrm{Mev}\right)$. The irradiation temperature was $\sim 50^{\circ} \mathrm{C}$ for both irradiations.

Post irradiation annealing of the internal friction specimens was done in conjunction with the internal friction measurements. The resistivity specimens were isochronally annealed for periods of $\mathrm{I}$ hr at $25^{\circ} \mathrm{C}$ temperature intervals starting with $75^{\circ} \mathrm{C}$. The annealing was done with the samples In a quartz tubc attached to a INTV pumping s.ystem. A tube furnace was preheated to the desired annealing temperature and placed around the tube. The pressure in the vacuum system during these anneals never exceeded $1 \times 10^{-7}$ torr. 


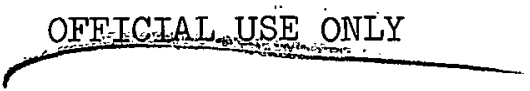

106

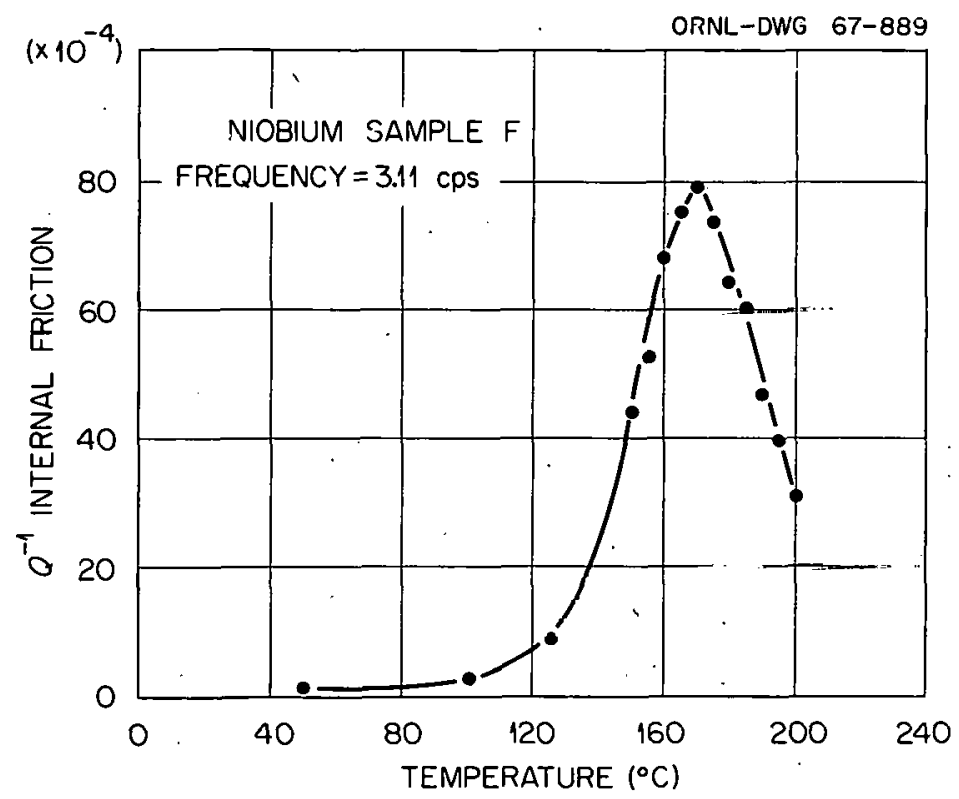

Fig. 8.20. Pre-Irradiation Internal Friction Measurements over the Oxygen Peak Region in Sample. F.

\section{Internal Friction Results}

$1 \mathrm{y} .38$ Internal friction measurements on sperimen $B$ were made as a function

of time at the oxygen peak temperature in order to determine the decrease of the peak with time. The results are shown in Fig. 8.2l. Interral friclion measurements on specimens from irradiater somples C, D, $\mathbb{E}$, and F showed no changes firom the pre-irradiated measurements.

Resistivity Results

Figure 8.22 shows the post irradiation isuchronal annealing data for samples.C and D. The change in resistivity io taken wilh respect to the pre-irradiation value. Thus, we see that sample $D$, the more impure cample, increased about twice as much as sample fo for thil dose. The annealing results on sample $\mathrm{C}$ appear somewhat erratic but no marked annealing stages appear up to $325^{\circ} \mathrm{C}$. At $325^{\circ} \mathrm{C}$ the sample appears to be approaching ito pre-irradiation value. It is planned to extend these anneals to $400^{\circ} \mathrm{C}$.

Sample $D$ exhibits a sharp decrease in resistivity setting in above $200^{\circ} \mathrm{C}$. The resistivity goes well below the pre-irradiation value. As was previously mentioned, carbon precipitation occurs in this temperature 


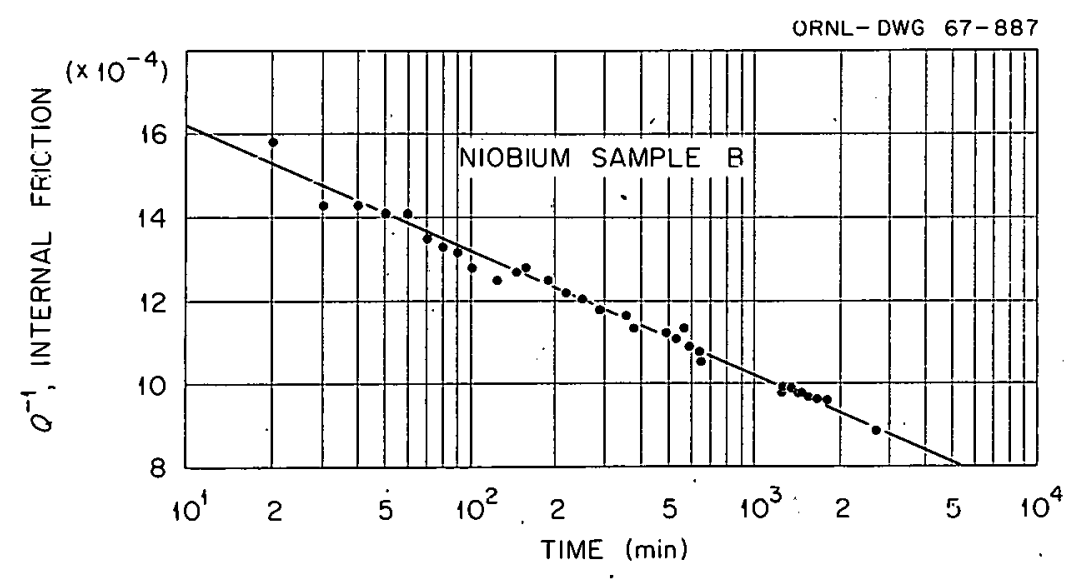

Fig. 8.21. Decrease in Oxygen Peak Height Versus Time at the Peak Temperature $\left(150^{\circ} \mathrm{C}\right)$ for Sample B Irradiated to. $1.6 \times 10^{18}$ neutrons $/ \mathrm{cm}^{2}$ $(\mathrm{E}>1.0 \mathrm{Mev})$. Frequency $=0.854 \mathrm{cps}: \mathrm{Q}^{-1}(t=0)=19.5 \times 10^{-4}$.

region, even in unirradiated samples. 38 We therefore feel that this annealing stage is probably not related to radiation effects. In order to test this contention, annealing of control (unirradiated) specimens of both $\mathrm{C}$ and $\mathrm{D}$ has been undertaken, but this annealing has not yet progressed beyond $200^{\circ} \mathrm{C}$.

Significantly, neither sample exhibits an annealing stage in the vicinity of $125^{\circ} \mathrm{C}$. The annealing stage obtained by Peacock and Johnson 37 for their dose of $\sim 1 \times 10^{19}$ ( $\mathrm{E}>$ thermal) is also shown in Fig. 8.22. This dose should be comparable to our dose of $\sim 1 \times 10^{18}$. ( $\mathrm{E}>1.0 \mathrm{Mev}$ ). The curve of Peacock and Johnson ${ }^{37}$ is arbitrarily placed along the ordinate so that their post-irradiation change in resistivity corresponds ito that of sample D. Pparnnk and Johnson estimate their impurity concen-

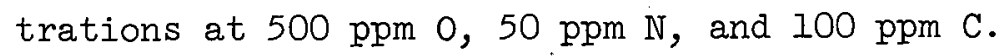

Figure 8.23 shows the annealing results obtained thus far on sample $E$ and $F$. Again the irradiation produced a smaller resistivity increase in the purer sample $(E)$ than in the contaminated sample $(F)$. However, neither of these samples exhibited as large an increase as did either of the two previous samplec ( $C$ and $D$ ) even through they were irradiated to a slightly larger dose. Sample F (260 ppm 0) shows an annealing stage in the proper. place for stage III. Indeed, the resistivity goes below the pre-irradiation value. Little effect is observed in sample $\mathrm{E}$ or the two control specimens. 


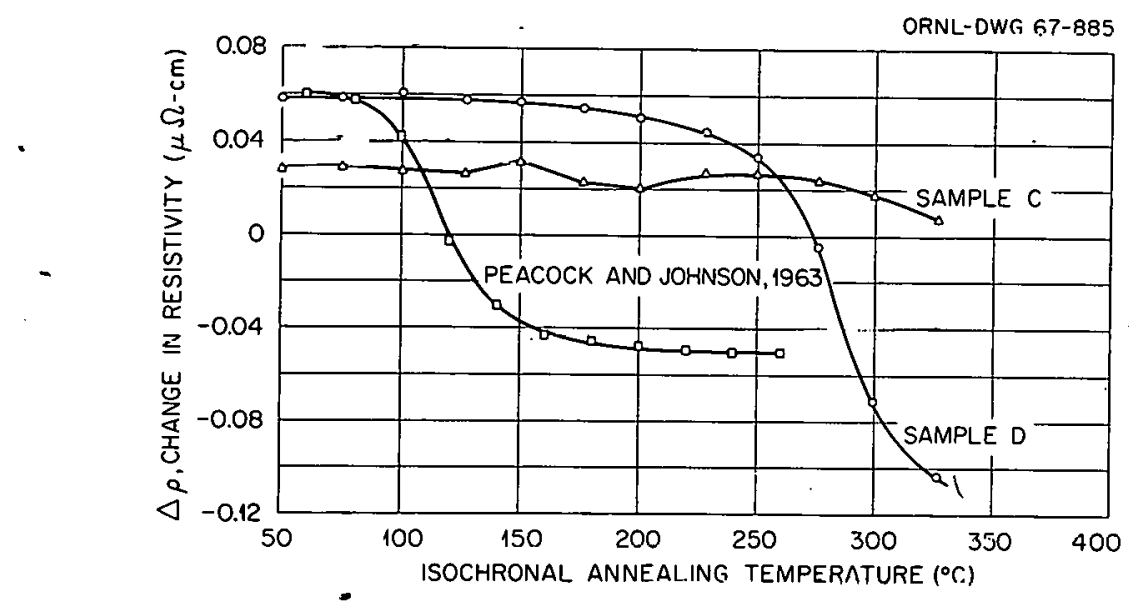

Fig. R.22. Thange in Resistivity Versus Isuchropla Anrealing Temperature for Samples $C$ and $D$ after Irradiation to $1 \times 10^{18}$ neutrons $/ \mathrm{cm}^{2}$ $(E>1.0 \mathrm{Mev}$ ) and for Commercial Niobium ( 500 ppm oxygen) after Irradiation to $1 \times 10^{19}$ neutrons $/ \mathrm{cm}^{2}$ (epithermal). 3

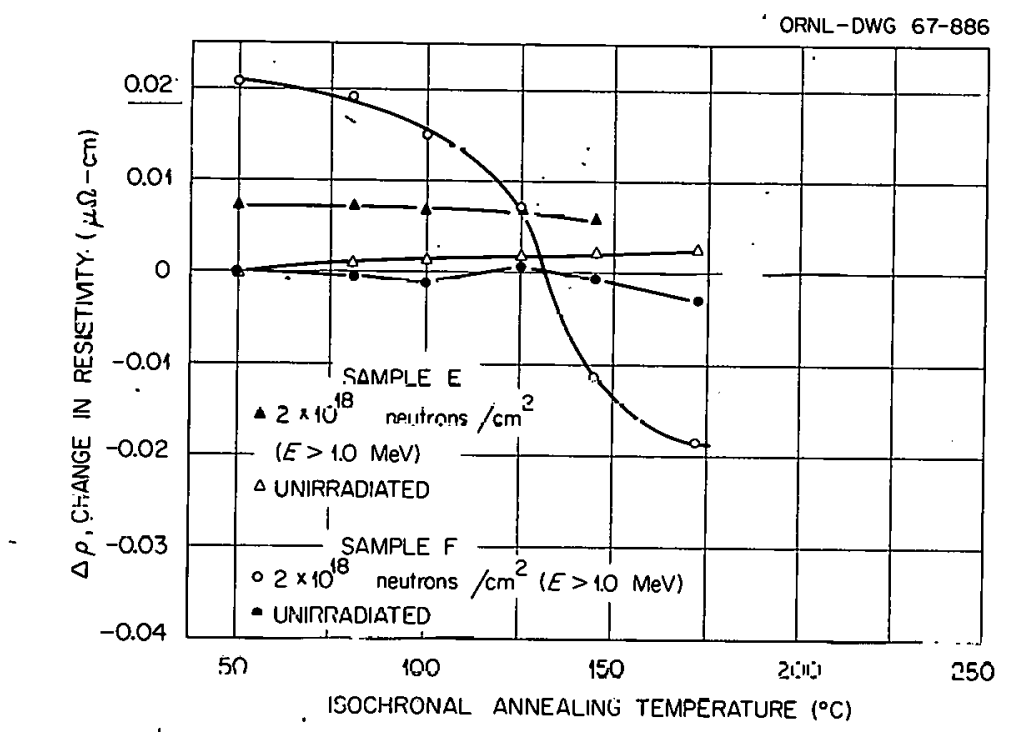

Fig. 8.23. Isochronal Annealing of. Irradiated and Unirradiated Niobium Samples.

\section{Discussion}

This work has shown the following results: (1.) In the temperature range of stage III annealing in niobium no resistivity decreare of irradiated specimens is observed in the absence of interstitial-impurity atoms. (2) If oxygen is present in irradiated niobium a resistivity decrease is observed upon annealing in the temperature interval from $75^{\circ} \mathrm{C}$. 
to $200^{\circ} \mathrm{C}$. (3) If carbon is present in niobium a resistivity decrease is observed in the temperature interval 200 to $320^{\circ} \mathrm{C}$. (4). The oxygen internal friction peak decreases after irradiation and annealing in the temperature interval near $150^{\circ} \mathrm{C}$. From these facts we conclude that the resistivity decrease observed by Peacock and Johnson and the yield stress increase observed by Makin and Minter in this temperature range were caused by migration of oxygen atoms to irradiation produced defects.

We alsso observed that the initial purity and/or crystal perfection influences the amount of damage produced by the irradiation at $50^{\circ} \mathrm{C}$ and also the amount of annealing in Stage III. This suggests that the oxygen atoms migrate to a defect structure that was formed by migration of an elementary defect at some lower temperature and that the clusters of these elementary defects were nucleated by impurity atoms.

Stage III annealing has also been reported in other b.c.c. metals, and we are interested in speculating about the possibility that interstiti.al impurity atoms are responsible for the annealing stage III in these other metals. Tungsten is particularly interesting since Kuhlmam and Schultz recently reported that neutron irradiated tungsten that had been degassed in high vacuum so as to remove interstitial impurities still showed Stage III annealing. 43 The estimate of interstitial content in their sample was based on resistivity at $4.5^{\circ} \mathrm{K}$ after rapid cooling from $1600^{\circ} \mathrm{C}$. However, the solubility of interstitial impurities in tungsten is known to be very low at low temperature and at $1600^{\circ} \mathrm{C}$ most of the interstitial impurities are probably already precipitated as oxides and carbides. 44 we have previously shown evidence that carbon that has precipitated from solution in niobium can be put back into solution by neutron irradiation. 38 We suggest that this effect could account for the above mentioned observations in tungsten.

H. H. Kuhlmann and H. Schultz, "Erholungsstufe III in Entkohltem Wolfram nach Neutronenbestrahlung bei $4.5^{\circ} \mathrm{K}$, Acta Met. I'l, 798 (1966). ${ }^{44}$. H. Schnitzel, "Internal Friction of Tungsten Single Crystals," Trans. AIME 233 , 186 (1965). 
Previous reports in this series are:

$\begin{array}{ll}\text { ORNL-TM-920 } & \text { Period Ending June 30, 1964 } \\ \text { ORNL-TM-960 } & \text { Period Ending September 30, 1964 } \\ \text { ORNL-TM-1000 } & \text { Period Ending December 31, 1964 } \\ \text { ORNL-TM-1100 } & \text { Period Dndilis March 31, 1965 } \\ \text { ORNL-TM-1200 } & \text { Period Ending June 30, 1965 } \\ \text { ORNL-TM-1270 } & \text { Period Ending September 30, } 1965 \\ \text { ORNL-TM-1400 } & \text { Period Ending December 31, 1965 } \\ \text { ORNL-TM-1500 } & \text { Period Ending March 31, 1966 } \\ \text { ORNL-TM-1570 } & \text { Period Ending Junc 30, 1966. } \\ \text { ORNL-TM-1700 } & \text { Period Fnding September 30, 1966 } \\ \text { ORNL-TM-1720 } & \text { Period Ending December 31, 1966 }\end{array}$




\section{INTERNAL DISTRIBUTION}

1-3. Central Research Library

4-5. ORNL - Y-12 Technical Library Document Reference Section

6-15. Laboratory Records Department

16. Laboratory Records, ORNL R.C.

17. ORNL Patent Office

18. G. M. Adamson, Jr.

19. J. H. Barrett

20. S. E. Beall

2l. R. J. Beaver

22. M. Bender

23. R. G. Berggren

24. J. 0. Betterton, Jr.

25. D. S. Billington

26. A. I. Boch

27. B. S. Borie

28. G. E. Boyd

29. W. H. Bridges

30. R. B. Briggs

31. W. E. Brundage

32. D. A. Canonico

33. R. M.' Carroll

34. J. V. Cathcart

35. G. W. Clark

36. K. V. Cook

37. G. I. Copeland

38. J. H. Crawford

39. F. L. Culler

40. J. E. Cunningham

41. J. H. DeVan

42. C. V. Dodd

43. K. Farrell

44. J. I. Federer

45. B. E. Foster

46. A. P. Fraas

47. E. A. Franco-Ferreira

48. J. H Frye, Jr.

49. R. J. Gray

50. W. R. Grimes

5i.. H. D. Guberman

52. J. P. Hammond

53. D. G. Harman

54. W. O. Harms

55-56.: M. R. Hill

57. N. E. Hinkle

58. D. O. Hobson
59. H. W. Hoffman

60. W. R. Huntley

61. H. Inouye

62. T. N. Jones

63. G. W. Keilholtz

64. B. C. Kelley

65. J. A. Lane

66. C. F. Leitten, Jr:

67. A. P. Litman

68. A. L. Lotts

69. R. N. Lyon

70. H. G. MacPherson

71. R. E. MacPherson

72. M. M. Martin

73. W. R. Martin

74. R. W. McClung

75. H. E. McCoy, Jr.

76. H. C. McCurdy

77. R. E. MeDonald

78. J. L. McElroy

79. C. J. McHargue

80. F. R. McQuilkin

81. A. J. Miller

82. E. C. Miller

83. J.० G. Morgan

84. F. H. Neill

85. T. A. Nolan (K-25)

86. S. M. Ohr

87. P. Patriarca.

88. A. M. Perry

89. S. Peterson

9u. K. E. Reed

91. P. L. Rittenhouse

92. W. C. Robinson

93. M. W. Rosenthal

94. G. Samuels

95. A. W. Savolainen

96. J. L. Scott

97. 0. Sisman

98. G. M. Slaughter

99. N. K. Sinith

100. S. D. Snyder

101. I. Spiewak

102. J. T. Stanley

103. W. J. Stelzman

104. J. 0. Stiegler 
105. D. B. Trauger

106. "R. P. Tucker

107. J. T. Venard

108. G. M. Watson

109. A. M. Weinberg

110. J. R. Weir, Jr.

1II. W. J. Werner
112. H. L. Whaley

113. G. D. Whitman

114. J. M. Williams

115. R. O. Williams

Il6. J. C. Wilson

117. F. W. Young, Jr.

118. C. S. Yust

\section{EXTERNAL DISTRIBUTION}

119-122. F. W. Albaugh, Battelle, PNL

123-125. R. T. Allio, Westinghouse Atomic Power Division

126. R. D. Baker, Los Alamos Scientific Laboratory

127. C. Baroch, Bubcock and Wilcox

128. L. Brewer, University of California, Berkeley

129. V. P. Calkins, GE, NMPO

130. W. Cashin, Knolls Atomic Power Laboratory

131. S. Christopher, Combustion Engineering, Inc.

132. D. B. Coburn, General Atomic

133. D. F. Cope, RDT, SSR, AEC, Oak Ridge National Laboratory

134. G. K. Dicker, Division of Reactor Development and Technology, $\mathrm{AEC}$, Washington

135. D. E. Erb, Division of Reactor Development and Technology, $A E C$, Washington

136. E. A. Evans, GE, Vallecitos

137. W. C. Francis, Idaho Nuclear Corporation

138. A. J. Goodjohn, General Atomic

139. R. G. Grove, Mound Laboratory

140. D. H. Gurinsky, BNL

141. A. N. Hoil_en, GE, APED

142-144. J. S. Kane, Lawrence Radiation Laboratory, Livermore

145. H. Kato, U.S. Department of the Interior, Bureau of Mines

146. E. A. Kintner, Fuel Fabrication Branch, AEC, Washington

147. J. H. Kittel, ANL

148. E. T. Kreih, Westinghouse, Bettis Atomic Fower Laboratory

149. W. J. Larkin, AEC, Oak Ridge Operations

150. W. I. Larsen, Iowa state University, Ames Laboratory

151. J. J. Lombardn, NASA, Lewis Roocarch Cente1

152. J. H. MacMillan, Babcock and Wilcox Company

153. R. Mayfield, ANI

154. M. McGurty, GE, NMPO

155. M. Nevitt, ANL

156. R. E. Pahler, Division of Reactor Development and Technology, AEC, Washington

157. S. Paprocki, BMI

158. D. Ragone, General Atomic

159. B. Rubin, Lawrence Radiation Laboratory, Livermore

160. F. C. Schwenk, Division of Reactor Development and Technology, AEC, Washington 
161-163. J. M. Simmons, Division of Reactor Development and Technology, AEC, Washington

164. L. E. Steele, Naval Research Laboratory

165. R. H. Steele, Division of Reactor Development and Technology, AEC, Washington

166. W. F. Sheely, Division of Research, AEC, Washington

167. A. Strasser, United Nuclear Corporation

168. A. Taboada, Division of Reactor Development and Technology, AEC, Washington

169. A. Van Echo, Division of Reactor Development and Technology, AEC, Washington

170. R. Van Tyne, Illinois Institute of Technology Research Institute

171. C. E. Weber, Atomics International

172. J. F. Weissenberger, RDT, OSR, GE', INMPO

173. G. W. Wensch, Division of Reactor Development and Technology, $A E C$, Washington

174. E. A. Wright, AEC, Washington

175. Division of Research and Development, AEC, Oak Ridge Operations

176-190. Division of Technical Information Extension 
OFFICIAL USE ONLY

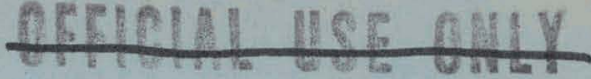

$$
\begin{aligned}
& \begin{array}{c}
\text { Central } \\
\text { Research Ibrary } \\
\text { noount Collectios }
\end{array} \\
& \text { MAY } 181967
\end{aligned}
$$

